UNIVERSIDADE DE SÃO PAULO

INSTITUTO DE QUÍMICA DE SÃO CARLOS

\title{
CARACTERIZAÇÃO PARCIAL DAS REAÇÕES DE FOTOOXIDAÇÃO E ELETROOXIDAÇÃO DO DIPIRIDAMOL E DAS SUBUNIDADES DE HEMOGLOBINA EXTRACELULAR
}

MARILENE SILVA OLIVEIRA

Tese apresentada ao Instituto de Química de São Carlos, da Universidade de São Paulo para obtenção do título de Doutor em Ciências Área de concentração: Química Analítica.

ORIENTADOR: PROF. DR. MARCEL TABAK

São Carlos 
Dedico este trabalho a Deus e a minha mãezinha do céu, Maria, por ter me dado forças para concluir este trabalho,

aos meus pais Elson Umbelino e Maria das Dores, que sempre me deram força, presença e apoio,

ao meu irmão Solemar e a minha amiga Viviane que sempre estiveram presentes quando eu mais precisei. 


\section{Agradecimentos}

Quero agradecer a todos que de uma maneira direta ou indireta contribuíram para que este trabalho fosse possível.

Agradeço primeiramente a Deus, pela minha vida, e por fazer isso possível.

Ao Prof. Dr. Marcel Tabak pela orientação, confiança, paciência e pelos ensinamentos que foram necessários para o desenvolvimento do trabalho e da minha formação profissional.

Ao Prof. Dr. Paolo Di Mascio pelo amplo apoio durante estes anos abrangendo discussões teóricas e experimentos, disponibilizando a infraestrutura do seu laboratório e por sua amizade.

Ao Prof. Dr. Maurício da Silva Baptista pela infra-estrutura disponibilizada e pelas valiosas discussões, contribuindo com parte importante do trabalho.

Ao Prof. Dr. Luiz Henrique Mazo por ter disponibilizado seu laboratório para as análises eletroquímicas.

Á Dr. Andrea Renata Malagutti pela colaboração nas análises eletroquímicas.

Á Fernanda M. Prado pelas análises de espectrometria de massas, pela paciência, interesse, discussões, incentivo e amizade. Ao pessoal do laboratório de Lesões em Biomoléculas, pela ajuda e amizade, sempre foi bom estar com vocês e dar várias gargalhadas.

Ao aluno de pós-doc Divinomar Severino pela colaboração no desenvolvimento deste trabalho, o qual se mostrou acessivo e prestativo. $E$ aos alunos do laboratório de Cinética Rápida e Fototermia do Departamento de Bioquímica da USP-SP.

À Izaura N. Toma do laboratório de Lesões em biomoléculas pelas análises de MALDI-TOF-MS.

Ao pessoal da central analítica da Universidade de São Paulo, Miriam, Luzia, Nanci e Alessandra, pelo trabalho prestado. 
Ao Prof. Daniel Rodrigues Cardoso pelos experimentos de EPR, pela paciência e pelas várias discussões que tiveram uma contribuição significativa no meu conhecimento e no desenvolvimento do trabalho.

À Dr. Carla Cristina Schimitt Cavalheiro, pelo interesse e ajuda.

Ao pessoal do CAQUI, principalmente a Silvana e o Paulo. Às secretarias Claúdia e Vanessa, sempre prestativas e alegres, vocês são ótimas pessoas.

À Bel e Andressa, técnicas do laboratório de biofísica do Departamento de Física de São Carlos, pela amizade, pelos diversos favores e por me deixar usar e abusar da sua disponibilidade e infra-estrutura.

À minha irmãzona Viviane, meu anjo, nos momentos que mais precisei você sempre esteve lá, passamos ótimos momentos juntas, sempre me ajudando a ser forte, a crescer e a ser quem eu sou, obrigado por você existir.

À Michelle (bola de fogo), pelos momentos que passamos juntas, ninguém melhor que você sabe o que passamos para desenvolver esse trabalho. Mas tivemos excelentes momentos que nunca vou esquecer, os vários bafões e risadas, obrigado pelo apoio e incentivo no decorrer e no final do meu doutorado. Quebramos a cabeça juntas e nos divertimos, obrigado por me ajudor a crescer e dar valor na pessoa que sou.

A minha amiga Patrícia, pelos momentos, risadas, amizade e sempre me ajudando a dar um "jeitinho" quando precisei. Pelo apoio e por estar presente, partilhando comigo todos os momentos do dia a dia.

Aos meus amigos, que de uma maneira ou de outra sempre estiveram presentes, Julio, Alessandra, Claúdia, Aline, Shirley, Angel, Érica, Franciane, Rommel, Adriano (Chico), Marco (Herry), Priscila (Kely Kei), Diogenes, Emerson, Luis Eduardo, Janiciara, Marilza e desculpe se esqueci o nome de alguém.

Ao Ezer, pela amizade e por sempre dar um jeitinho em me ajudar na realização dos experimentos.

Ao Leonardo (boca nervosa) pela contribuição cientifica, você foi um ótimo colaborador, pela amizade e pelas gargalhadas.

Ao laboratório de Biofísica molecular. 
Ao Luiz Humberto por cuidar dos meus peixinhos, quando precisei ir pra São Paulo.

Ao Thiago (da Patrícia), por me ensinar a melhorar o designer gráfico dos artigos.

Ao meu irmão Solemar e ao meu pai que me deram o primeiro impurrão para estar aqui hoje.

A minha família que sempre me apoiou, me dando forças para a conclusão deste trabalho.

A FAPESP e CAPES pelo apoio financeiro. 


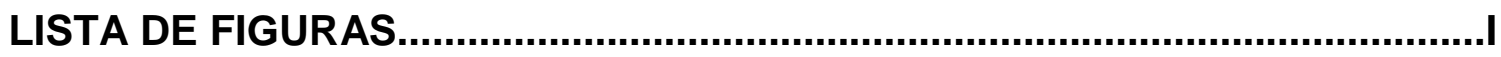

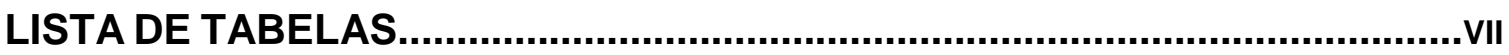

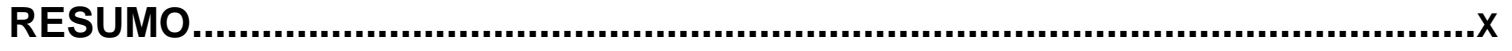

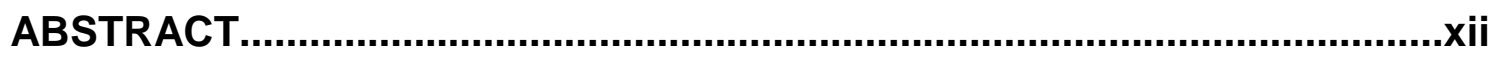

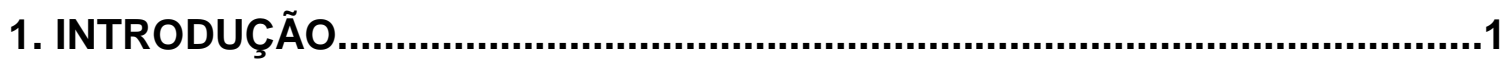

1.1. ANTIOXIDANTES E ESPÉCIES REATIVAS DE OXIGÊNIO (ERO)..............1

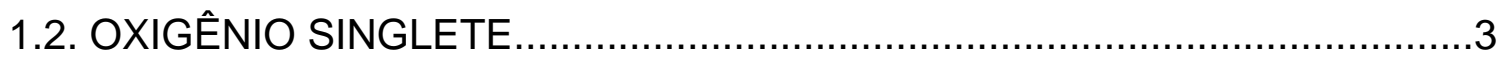

1.2.1. DESATIVAÇÃO DO OXIGÊNIO SINGLETE........................................

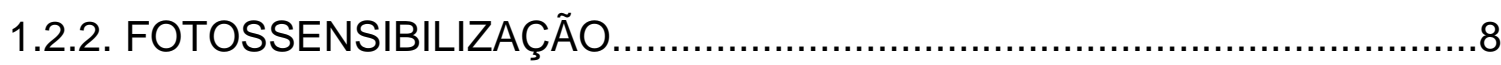

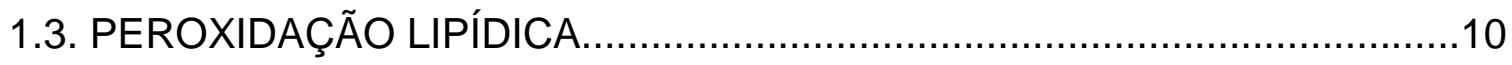

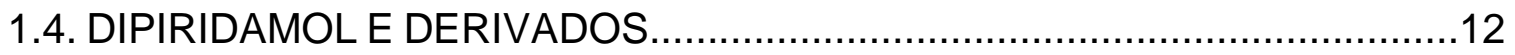

1.5. HEMOGLOBINA DE GLOSSOSCOLEX PAULISTUS .............................18

1.6. DESSORÇÃO/IONIZAÇÃO POR LASER AUXILIADA POR MATRIZ

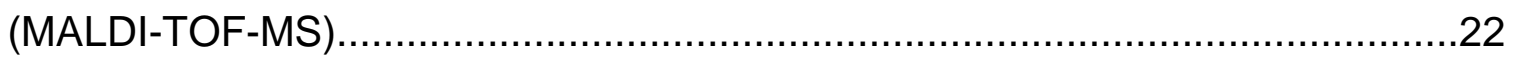

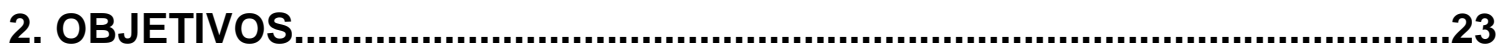

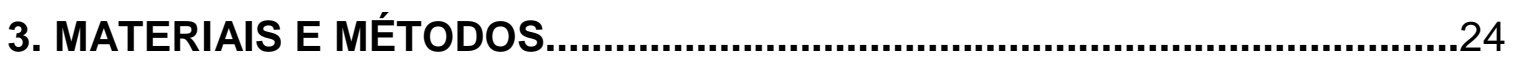

3.1- ANÁLISES DE SUPRESSÃO DE OXIGÊNIO SINGLETE.........................24

3.2. CÁLCULO DA CONSTANTE DE SUPRESSÃO QUÍMICA $\left(\mathrm{k}_{\mathrm{R}}\right) \ldots \ldots \ldots \ldots \ldots \ldots . . . . . . . .26$

3.3. ANÁLISES POR RESSONÂNCIA PARAMAGNÉTICA ELETRÔNICA

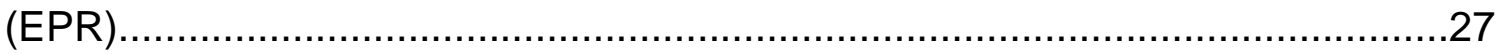

3.4. FOTOOXIDAÇÃO DO DIP NA PRESENÇA DE OXIGÊNIO-18..................28

3.5. OXIDAÇÃO DO DIP NA PRESENÇA DE DHPNO

3.6. FOTOOXIDAÇÃO DO DIPIRIDAMOL EM ACETONITRILA E MEIO AQUOSO ÁCIDO

3.7. CROMATOGRAFIA LÍQUIDA E ESPECTROMETRIA DE MASSAS (LC-

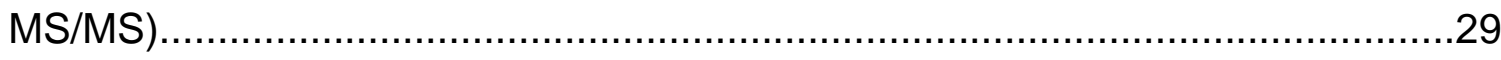


3.8. OBTENÇÃO E PURIFICAÇÃO DA HEMOGLOBINA DE GLOSSOSCOLEX

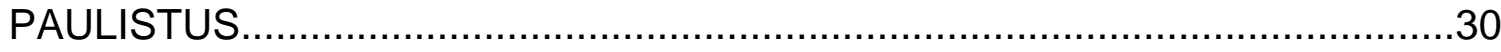

4. RESULTADOS E DISCUSSÕES

4.1. SUPRESSÃO DE OXIGÊNIO SINGLETE PELO DIP E DERIVADOS..........31

4.2. CÁLCULO DA CONSTANTE DE SUPRESSÃO QUÍMICA $\left(\mathrm{k}_{\mathrm{R}}\right) \ldots \ldots \ldots \ldots \ldots . . . . . . .37$

4.3. MECANISMO DE TRANSFERÊNCIA DE ELÉTORNS.............................40

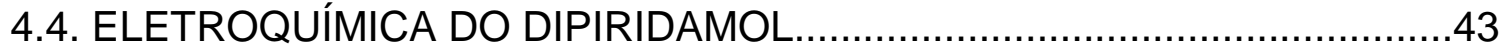

4.5. OXIDAÇÃO DO DIPIRIDAMOL USANDO UMA FONTE QUÍMICA DE $\mathrm{O}_{2}\left({ }^{1} \Delta_{\mathrm{G}}\right)$,

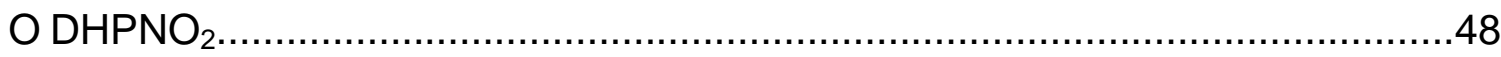

4.6. COMPORTAMENTO FOTOQUÍMICO DO DIP EM ACETONITRILA E MEIO

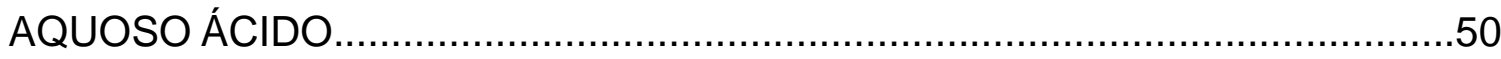

4.6.1. FOTOOXIDAÇÃO DO DIPIRIDAMOL EM ACETONITRILA......................50

4.6.2. FOTOOXIDAÇÃO DO DIP NA AUSÊNCIA DE OXIGÊNIO.....................60

4.7. FOTODEGRADAÇÃO DO DIPIRIDAMOL EM MEIO AQUOSO ÁCIDO......65

4.8. CARACTERIZAÇÃO PARCIAL DA HEMOGLOBINA GIGANTE DE GLOSSOSCOLEX PAULISTUS POR MALDI-TOF-MS .................................74

4.9. INTERAÇÃO DA HEMOGLOBINA EXTRACELULAR GIGANTE DE GLOSSOSCOLEX PAULISTUS COM SUFACTANTES IÔNICOS.....................84

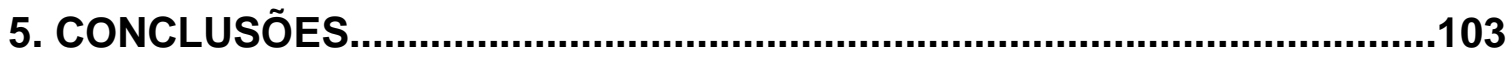

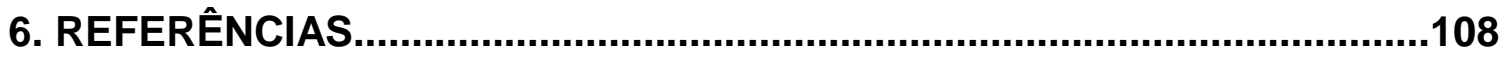




\section{Lista de figuras}

Figura 1: Distribuição eletrônica nos orbitais moleculares $\left(\pi^{*}\right)$ do oxigênio no estado excitado singlete $\left({ }^{1} \Sigma_{g}{ }^{+},{ }^{1} \Delta_{g}\right)$ e no estado fundamental triplete $\left({ }^{3} \Sigma_{g}{ }^{-}\right)[10] \ldots 4$

Figura 2: Diagrama de Jablonski ilustrando a absorção de luz pelo fotossensibilizador, a formação do estado tripleto excitado e posterior desativação por transferência de energia para o oxigênio triplete gerando o oxigênio singlete excitado [22].

Figura 3: Esquema de fotossensibilização mostrando os mecanismos do tipo I e II. $(S=$ substrato, ISC = cruzamento intersistemas, sens $=$ sensibilizador $)$ [23]....... 10

Figura 4: Esquema das etapas de iniciação, propagação e terminação da peroxidação lípidica e da catálise mediada por metais de transição [11]. .11

Figura 5: Estrutura Molecular do DIP, RA47, RA25 e Azul de Metileno (AM)....13 Figura 6: Representação esquemática da estrutura da hemoglobina de Lumbricus terrestris observada por microscopia eletrônica: (A) Bicamada hexagonal; (B) Uma das subunidades da hemoglobina íntegra corresponde a 1/12 da molécula. Essa subunidade 1/12 constitui-se por três estruturas tetrâmericas $(\mathrm{abcd})$, um dodecâmero e três cadeias linkers L; (C) tetrâmero (abcd), indicando as ligações disulfeto do trímero abc, (D) estrutura da cadeia monomérica d da HbLt obtida por modelagem molecular..................................20

Figura 7: Estrutura molecular dos surfactantes iônicos SDS e CTAC................22 Figura 8: Esquema do procedimento realizado na supressão de oxigênio singlete........ .24

Figura 9: Esquema do procedimento realizado no calculo da constante de supressão química de oxigênio singlete. 26

Figura 10: Espectros de absorção óptica em acetonitrila do (A) DIP, RA 47, RA25 e (B) Azul de Metileno (AM). 32

Figura 11: Curvas de emissão de $\mathrm{O}_{2}\left({ }^{1} \Delta_{\mathrm{g}}\right)$ produzido pelo fotossensibilizador $A M$ em algumas concentrações de DIP em ACN. 34 
Figura 12: Curvas de Stern-Volmer para a supressão de $\mathrm{O}_{2}\left({ }^{1} \Delta_{\mathrm{g}}\right)$ pelo DIP, RA47 e RA25 em (A) acetonitrila e (B) meio aquoso ácido deuterado.

Figura 13: Espectro de absorção óptica em função do tempo de irradiação contínua, em acetonitrila (A) DPBF e (B) DIP, usando AM como fotossensibilizador, utilizando um laser no comprimento de onda de $650 \mathrm{~nm}$.....38 Figure 14: Curvas cinéticas de primeira-ordem para a fotooxidação do DIP, RA47, RA25 e do composto de referência (DPBF) determinadas a partir do espectro de absorção óptica, em acetonitrila usando AM como fotossensibilizador 39

Figure 15: Curvas de emissão de $\mathrm{O}_{2}\left({ }^{1} \Delta_{g}\right)$ produzido pelo DIP (a) e fenalenona (b) em ACN (A) e clorofórmio (B). O Inserto (C) mostra as curvas de decaimento para o DIP em clorofórmio (b) e ACN (a). Inserto (D) mostra o espectro de emissão de oxigênio singlete produzido pelo DIP em clorofórmio. 41

Figura 16: Proposta de estrutura para o produto da eletrooxidação (fração aquosa), m/z 472, em acetonitrila [38]. .45

Figura 17: Proposta de mecanismo para a formação do produto da eletrooxidação com $\mathrm{m} / \mathrm{z} 269$ (fração metanólica) na primeira e segunda ondas em acetonitrila.

Figura 18: Proposta de estrutura molecular para o produto da eletrooxidação, $\mathrm{m} / z 519$ (fração metanólica) na primeira e segunda ondas em acetonitrila

Figura 19: Espectro de massas da fotooxidação do DIP utilizando uma fonte química de $\mathrm{O}_{2}\left({ }^{1} \Delta_{\mathrm{g}}\right)$ em meio aquoso deuterado. 49

Figura 20: Esquema proposto para o mecanismo de fotodegradação do dipiridamol em meio aquoso ácido $\mathrm{pH}=3,0$. 49

Figura 21: Espectros de absorção ótica da reação de fotooxidação do DIP 0,5 $\mathrm{mM}$ em acetonitrila

Figura 22: Cromatograma da fotooxidação do DIP em acetonitrila submetido a irradiação. Método de eluição: gradiente; tampão acetato $40 \mathrm{mM}, \mathrm{pH}$ 4,0/MeOH; 20 min 5-95\% de $\mathrm{MeOH}, 95-5 \%$ de $\mathrm{MeOH}$, stop em 35 min, utilizando uma coluna C18 Luna ( 250 x 4,6 mm, $5 \mu \mathrm{m}$ - Phenomenex) como fase estacionária. Volume de injeção: $20 \mu \mathrm{L}$ com fluxo de $1 \mathrm{~mL} / \mathrm{min}$. .52 
Figura 23: Cromatograma do DIP (A) e da reação de fotooxidação do DIP (B) em acetonitrila. Método de eluição: gradiente; solução de ácido fórmico 0,1\%/ACN, $5-70 \%$ de ACN em 10 min, $70-5 \%$ de ACN de $10-15$ min e stop em 20 min, utilizando uma coluna C18 Luna $(250 \times 4,6 \mathrm{~mm}, 5 \mu \mathrm{m}-$ Phenomenex) como fase estacionária. Volume de injeção: $20 \mu \mathrm{L}$ com fluxo de $1 \mathrm{~mL} / \mathrm{min}$. .53

Figura 24: Porcentagens de reagentes e produtos na reação de fotooxidação do DIP em função do tempo em acetonitrila, obtidas a partir de cromatogramas similares ao apresentado na Figura 23B. Nota-se o consumo do DIP (a) e formação majoritária do produto correspondente ao pico $1(\bullet)$. .54

Figura 25: Espectros de massas dos produtos da fotooxidação em acetonitrila com tempos de retenção de 3,87 e 6,01 min. (A e C) ESI/EM no modo positivo, voltagem do cone $40 \mathrm{~V}$, voltagem do capilar $3,6 \mathrm{kV}$. (B e D) Respectivos íons fragmentos do $\mathrm{m} / \mathrm{z} 269$, energia de colisão de $30 \mathrm{eV}$. .55

Figura 26: Espectros de massas do produto da fotooxidação em acetonitrila com tempo de retenção de 7,24 min. (A) ESI/EM no modo positivo, voltagem do cone $40 \mathrm{~V}$, voltagem do capilar $3,6 \mathrm{kV}$. (B) Respectivos íons fragmentos do $\mathrm{m} / \mathrm{z} 519$, energia de colisão de $70 \mathrm{eV}$. .56

Figura 27: Proposta estrutural para o produto da fotooxidação em acetonitrila com tempo de retenção de 7,24 min. .57

Figura 28: Espectros de massas do DIP não fotooxidado em acetonitrila com tempo de retenção de 9,75 min. ESI/EM no modo positivo, voltagem do cone 40 $\mathrm{V}$, voltagem do capilar $3,6 \mathrm{kV}$. 58

Figura 29: Espectro de massas do produto da fotooxidação em acetonitrila após $4 \mathrm{~h}$ de irradiação na presença de oxigênio-18. ESI/EM no modo positivo, voltage do cone $40 \mathrm{~V}$, voltagem do capilar $3,6 \mathrm{kV}$. 59

Figura 30: Cromatograma dos produtos da fotooxidação do DIP em acetonitrila, obtidos após a coleta dos picos 1 e 2 do cromatograma da figura 23B e reinjeção no HPLC. Método de eluição: gradiente; solução de ácido fórmico 0,1\%/ACN, 5 - 70\% de ACN em 10 min, 70 - 5\% de ACN de 10 - 15 min e stop em 20 min, 
utilizando uma coluna C18 Luna ( $250 \times 4,6 \mathrm{~mm}, 5 \mu \mathrm{m}$ - Phenomenex) como fase estacionária. Volume de injeção: $20 \mu \mathrm{L}$ com fluxo de $1 \mathrm{~mL} / \mathrm{min}$.........................60

Figura 31: Cromatograma da fotooxidação do DIP $0,25 \mathrm{mM}$ na ausência de oxigênio em acetonitrila obtido após a irradiação por seis horas seguido de repouso por 24 horas em temperatura ambiente. Método de eluição: tampão acetato $40 \mathrm{mM} \mathrm{pH}=4,0 / \mathrm{MeOH}, 5-95 \%$ de $\mathrm{MeOH}$ em $20 \mathrm{~min}$, de $20-35 \mathrm{~min}$ $95 \%$ de $\mathrm{MeOH}$, de $35-45 \min 95-5 \%$ de $\mathrm{MeOH}$, utilizando uma coluna $\mathrm{C} 18$ Luna ( $250 \times$ 4,6 mm, $5 \mu \mathrm{m}$ - Phenomenex) como fase estacionária. Volume de injeção: $20 \mu \mathrm{L}$ com fluxo de $1 \mathrm{~mL} / \mathrm{min}$. 62

Figura 32: Espectros de EPR obtidos para uma solução de DIP $(0,6 \mathrm{mM})$ na presença do radical nitroxido TEMPO $(0,6 \mathrm{mM})$ em acetonitrila, e saturado com argônio, antes e após irradiação de 5 e 10 min, utilizando um laser de Nd:YAG ajustado para $440 \mathrm{~nm}$ irradiando direto na cavidade do EPR. 63

Figura 33: Esquema proposto para o mecanismo de fotodegradação do dipiridamol em acetonitrila. 64

Figura 34: Espectros de absorção óptica da fotooxidação do DIP $0,5 \mathrm{mM}$ em meio ácido $\mathrm{pH}=3,0$, na ausência $(A)$ e na presença $(B)$ de azul de metileno......67 Figura 35: Cromatograma do DIP em meio ácido $\mathrm{pH}=3,0 \mathrm{com}$ azul de metileno (A) e após seis horas de irradiação na presença (B) e na ausência (C) de azul de metileno (AM). Método de eluição: gradiente; ácido fórmico 0,1\%/ACN, $5-70 \%$ de $A C N$ em $10 \mathrm{~min}, 70-5 \%$ de $A C N$ de 10 - 15 min e stop em $20 \mathrm{~min}$, utilizando uma coluna C18 Luna ( $250 \times 4,6 \mathrm{~mm}, 5 \mu \mathrm{m}$ - Phenomenex) como fase estacionária. Volume de injeção: $20 \mu \mathrm{L}$ com fluxo de $1 \mathrm{~mL} / \mathrm{min}$. 68

Figura 36: Porcentagens das áreas dos picos obtidos na reação de fotooxidação do DIP (Fig. 35C) em função do tempo de irradiação. Os picos 1, 2 e 3 correspondem aos tempos de retenção 3,3, 5,5 e 6,3 min da Figura 35C.

Figura 37: Espectros de massas dos produtos da fotooxidação em meio aquoso ácido $\mathrm{pH}=3.0$ após $6 \mathrm{~h}$ de irradiação, com tempos de retenção de 3,3 e 5,5 min (Fig. 35C). (A e C) ESI/EM no modo positivo, voltagem do cone $40 \mathrm{~V}$, voltagem do capilar 3,6 kV. (B e D) Respectivos íons fragmentos do produto de $\mathrm{m} / \mathrm{z} 472$, energia de colisão de $30 \mathrm{eV}$ 
Figura 38: Espectros de massas do produto da fotooxidação em meio aquoso ácido $\mathrm{pH}=3,0$ após $6 \mathrm{~h}$ de irradiação, com tempo de retenção de 6,3 min. (A) ESI/EM no modo positivo, voltagem do cone $40 \mathrm{~V}$, voltagem do capilar 3,6 kV. (B) Respectivos íons fragmentos do produto de $\mathrm{m} / z 269$, energia de colisão de $30 \mathrm{eV}$. .71

Figura 39: Espectro de massas do produto da fotooxidação em meio aquoso ácido $\mathrm{pH}=3,0$ após $6 \mathrm{~h}$ de irradiação na presença de oxigênio-18. ESI/EM no modo positivo, voltagem do cone $40 \mathrm{~V}$, voltagem do capilar 3,6 $\mathrm{kV}$. .72

Figura 40: Esquema proposto para o mecanismo de fotodegradação do dipiridamol em meio aquoso ácido $\mathrm{pH}=3,0$. .73 Figura 41: (A) Espectro de massas da HbGp íntegra na forma Oxy em pH 7,0. O inserto mostra a região ampliada, enfatizando os picos de menor intensidade; (B) região expandida de 15.600 a $18.800 \mathrm{Da}$, correspondente ao monômero protonado $\mathrm{d}^{+}$. (C) região expandida de 8.050 a $8.600 \mathrm{Da}$, correspondente ao monômero duplamente protonado $\mathrm{d}^{2+}$ .76

Figura 42: (A) Espectro de massas do monômero d obtido na filtração em gel em pH 9.0. O inserto mostra a região do espectro ampliada, enfatizando os picos de menor intensidade; (B) região expandida de 16.000 a $17.600 \mathrm{Da}$, correspondente ao monômero protonado $\mathrm{d}^{+}$. (C) região expandida de 8.100 a 8.600 Da, correspondente ao monômero duplamente protonado $\mathrm{d}^{2+}$ 81 Figura 43: (A) Espectro de massas da HbGp íntegra na forma Oxy em pH 7,0 submetida a reação com 2-mercaptoetanol. $O$ inserto mostra a região do espectro ampliada enfatizando aos picos de menor intensidade; (B) região expandida de 16.000 a $18.800 \mathrm{Da}$, correspondente ao monômero protonado $\mathrm{d}^{+}$. (C) região expandida de 8.000 a $9.400 \mathrm{Da}$, correspondente ao monômero duplamente protonado. .83

Figura 44: (A) Espectro de massas do monômero d com 0,2 mM de CTAC. (B) região expandida de 15.000 a $20.000 \mathrm{Da}$, correspondente ao monômero protonado $\mathrm{d}^{+}$com incremento de $\mathrm{n}$ moléculas de CTAC. (C) região expandida de 
8.000 a $8.500 \mathrm{Da}$, correspondente ao monômero duplamente protonado, $\mathrm{d}^{2+}$

Figura 45: (A) Espectro de massas do monômero d com 0,2 mM de CTAC. (B) região expandida de 15.000 a $20.000 \mathrm{Da}$, correspondente ao monômero protonado $\mathrm{d}^{+}$com incremento de $\mathrm{n}$ moléculas de CTAC. (C) região expandida de 8.000 a $8.600 \mathrm{Da}$, correspondente ao monômero duplamente protonado..........92

Figura 46: (A) Espectro de massas da HbGp íntegra com 1,0 mM de CTAC. (B) região expandida de 15.600 a $18.800 \mathrm{Da}$, correspondente ao monômero protonado $\mathbf{d}^{+}$com incremento de $n$ moléculas de CTAC. (C) região expandida de 8.050 a $8.600 \mathrm{Da}$, correspondente ao monômero duplamente protonado...........96

Figura 47: (A) Espectro de massas do monômero d com 0,2 mM de SDS. (B) região expandida de 16.000 a $17.600 \mathrm{Da}$, correspondente ao monômero protonado $\mathrm{d}^{+}$. (C) região expandida de 8.000 a $8.500 \mathrm{Da}$, correspondente ao monômero duplamente protonado.

Figura 48: (A) Espectro de massas da HbGp íntegra com 1,0 mM de SDS. (B) região expandida de 16.000 a $17.600 \mathrm{Da}$, correspondente ao monômero protonado $\mathrm{d}^{+}$. (C) região expandida de 8.000 a $8.500 \mathrm{Da}$, correspondente ao monômero duplamente protonado. 101 


\section{Lista de tabelas}

Tabela 1: Valores das constantes de velocidade de supressão física, potencial de meia onda e energia livre para $O$ DIP e derivados nos solventes usados. 37

Tabela 2: Valores obtidos das constantes de supressão química $\left(\mathrm{k}_{\mathrm{r}}\right)$ de $\mathrm{O}_{2}\left({ }^{1} \Delta_{\mathrm{g}}\right)$ e rendimento quântico de oxidação para o DIP e derivados RA47 e RA25 em acetonitrila

Tabela 3. Massas obtidas por MALDI-TOF-MS em Da para as cadeias e subunidades das hemoglobinas extracelulares de Glossoscolex paulistus (HbGp) e Lumbricus terrestris ( $\mathrm{HbLt})$. .77

Table 4. Massas obtidas por MALDI-TOF-MS para as isoformas do monômero d, $\mathbf{d}_{1}$ and $\mathbf{d}_{2}$, da hemoglobina extracelular Glossoscolex paulistus ( $\mathrm{HbGp}$ ). A coluna com os incrementos de massa corresponde as diferenças de massas dos picos das Figuras 41-43. .88 


\section{Lista de Símbolos}

ERO - Espécies Reativas de Oxigênio

$\mathrm{O}_{2}{ }^{\circ-}$ - ânion radical superóxido

$\cdot \mathrm{OOH}$ - radical perhidroxila

$\cdot \mathrm{OH}$ - radical hidroxila

$\mathrm{RO}^{\circ}$ - radical alcoxila

$\mathrm{ROO}^{\circ}$ - radical peroxila

$\mathrm{CO}_{3}{ }^{\circ-}$ - radical ânion carbonato

$\mathrm{H}_{2} \mathrm{O}_{2}$ - peróxido de hidrogênio

$\mathrm{HOCl}$ - ácido hipocloroso

$\mathrm{ROOH}$ - hidroperóxidos orgânicos

$\mathrm{O}_{2}\left({ }^{1} \Delta_{\mathrm{g}}\right)$ - oxigênio molecular singlete

$\mathrm{O}_{3}$ - ozônio

ACN - acetonitrila

$\mathrm{k}_{\mathrm{t}}$ - constante bimolecular de supressão

$\mathrm{k}_{\mathrm{q}}$ - constante de supressão física

$\mathrm{k}_{\mathrm{r}}$ - constante de supressão química

SCE - eletrodo saturado de calomelano

HPLC-MS/MS - Cromatografia líquida de alta eficiência acoplada espectrometria de massas

LFP -fotólise por pulso de laser

EPR - Ressonância paramagnética eletrônica

$\mathrm{DHPNO}_{2}$ - N,N'-di(2,3-dihidroxipropil)-1,4 naftalenodipropanamida

MALDI-TOF-MS - espectrometria de massas por dessorção/ionização por laser auxiliada por matriz, com analisador por tempo de vôo.

SDS - dodecilsulfato de sódio

CTAC - catiônico cloreto de cetiltrimetilamonio

${ }^{3} \mathrm{O}_{2}$ - oxigênio molecular

LH - lipídios

$L^{\bullet}-$ radical alquila 
$\mathrm{LOO}^{\circ}$ - radical peroxila

$\mathrm{LOOH}$ - hidroperóxido de lipídios

BSA - albumina de soro bovino

RMN ${ }^{1} \mathrm{H}$ - Ressonância magnética nuclear de hidrogênio

RMN ${ }^{13} \mathrm{C}$ - Ressonância magnética nuclear de carbono

$\mathrm{AM}$ - azul de metileno

DPBF - 1,3-difenillisobenzofurano

$\phi_{\text {ox }}$ - rendimento quântico de oxidação

$\mathrm{MeOH}$ - metanol

ESI - ionização por electrospray

$\tau_{0}$ - tempo de vida do $\mathrm{O}_{2}\left({ }^{1} \Delta_{\mathrm{g}}\right)$ na ausência de supressor

$\tau$ - tempo de vida do $\mathrm{O}_{2}\left({ }^{1} \Delta_{\mathrm{g}}\right)$ na presença de supressor

$\mathrm{K}_{\mathrm{sv}}$ - constante de supressão de Stern-Volmer

$\Delta G_{\text {et }}$ - energia livre de transferência de elétrons

$E_{1 / 2}{ }^{0 x}$ - potencial de oxidação de meia onda

$\mathrm{E}_{1 / 2}{ }^{\text {red }}$ - potencial de redução de meia onda

ISC - cruzamento intersistemas

$m / z$ - razão massa/carga

TEMPO - 2,2,6,6-tetrametilpiperidino-1-N-oxil

HbGp - Hemoglobina de Glossoscolex paulistus

HbLt - Hemoglibina de Lumbricus terrestris 


\section{Resumo}

O dipiridamol (DIP), 2,6-bis(dietanolamina)-4,8-dipiperidinapirimida-[5,4-d] pirimidina), é conhecido por seu efeito vasodilatador coronariano e antiagregante plaquetário, exibindo também um potente efeito antioxidante fortemente inibidor da peroxidação lipídica. No presente trabalho, a supressão de $\mathrm{O}_{2}\left({ }^{1} \Delta_{\mathrm{g}}\right)$, pelo DIP e derivados foi analisada em acetonitrila ( $A C N$ ) e em meio aquoso ácido. As constantes bimoleculares de supressão obtidas em ACN são consistentes com uma eficiente supressão física, apresentando valores próximos do limite difusional $\left(k_{t}=3,4-6,8 \times 10^{8} \mathrm{M}^{-1} \mathrm{~s}^{-1}\right)$. $\mathrm{O}$ processo de supressão ocorre via 0 mecanismo reversível de transferência de cargas com a formação do exciplex. Cálculos de $\Delta G_{e t}$ associado à supressão de $\mathrm{O}_{2}\left({ }^{1} \Delta_{\mathrm{g}}\right)$ corroboram com uma transferência de elétrons incompleta. Em soluções aquosas ácidas $(\mathrm{pH}=3,0)$ os valores de $k_{t}$ obtidos para o DIP e derivados são 20 vezes menores quando comparados com os valores em ACN. Os dados de supressão de $\mathrm{O}_{2}\left({ }^{1} \Delta_{\mathrm{g}}\right)$ são consistentes com os dados eletroquímicos. As propriedades eletroquímicas do DIP em ACN são caracterizadas por dois processos consecutivos de um elétron cada, com potenciais de meia onda de $0,30 \mathrm{~V}$ e $0,67 \mathrm{~V}$ vs SCE. No entanto, em meio aquoso ácido uma única onda de oxidação é observada envolvendo um processo com à perda de dois elétrons $(0,80 \mathrm{~V}$ vs $\mathrm{SCE})$. A eletrooxidação do DIP leva a formação de produtos não-fluorescentes e uma considerável mudança no espectro de absorção. Os espectros de massas dos produtos da eletrooxidação apresentaram picos com $\mathrm{m} / \mathrm{z}$ de 472, 269 e 519. Neste trabalho, a fotólise do DIP em ACN e meio aquoso ácido em $\mathrm{pH}=3,0$ foi estudada. Em meio aquoso ácido DIP foi oxidado pela fotosensibilização com AM e pela reação com uma fonte química de $\mathrm{O}_{2}\left({ }^{1} \Delta_{g}\right), \quad N, N^{\prime}$-di(2,3-dihidroxipropil)-1,4 naftalenodipropanamida $\left(\mathrm{DHPNO}_{2}\right)$. A fotooxidação ocorre predominantemente pelo mecansimo do tipo II, onde o DIP é oxidado pelo $\mathrm{O}_{2}\left({ }^{1} \Delta_{\mathrm{g}}\right)$, mas alguns produtos com baixa intensidade e $\mathrm{m} / \mathrm{z}$ de 472 foram observados em meio ácido, o que está de acordo com a eletrooxidação. Por outro lado, em ACN, DIP é fotodegradado pelo mecansimo do tipo I, via geração de radicais ou por 
espécies excitadas no estado triplete, como observado através de EPR. Contudo, a oxidação produz a mesma espécie nos dois solventes. O dioxetano pode ser formado como um intermediário da reação de fotooxidação. O produto formado com m/z de 269 pode corresponder a metade da molécula do DIP ligado a um átomo de oxigênio ou a molécula do DIP com dois átomos de oxigênio duplamente protonada. A conclusão é que o DIP é fotooxidado envolvendo $\mathrm{O}_{2}\left({ }^{1} \Delta_{g}\right)$ em soluções aquosas ou oxigênio molecular em ACN.

Outro trabalho envolvendo a hemoglobina extracelular gigante de Glossoscolex paulistus ( $\mathrm{HbGp}$ ) foi desenvolvido. Análises de MALDI-TOF-MS foram realizadas para obter informações sobre a massa molecular das diferentes subunidades da HbGp na forma oxi. Os resultados são comparados com a hemoglobina homóloga de Lumbricus terrestris ( $\mathrm{HbLt}$ ) e algumas tentativas de atribuição de massas são feitas para algumas subunidades. Para o monômero d duas isoformas majoritárias de idênticas proporções com massas de 16.355 \pm 25 e 16.428 $\pm 24 \mathrm{Da}$ foram observadas. A redução das pontes disulfeto produz a dissociação do trímero e novos picos correspondentes aos monômeros a, b e c são observados, apresentando massas moleculares de 18.258 $\pm 30 \mathrm{Da}$, 16.492 $\pm 24 \mathrm{Da}$ e $17.363 \pm 17 \mathrm{Da}$, respectivamente. Duas cadeias linkers para HbGp foram também observadas em $25.817 \pm 50$ e $26.761 \pm 16 \mathrm{Da}$. Finalmente, os trímeros (abc) foram observados em 51-52 kDa. Esta caracterização parcial representa um passo importante na caracterização das subunidades desta hemoglobina gigante. $O$ efeito dos surfactantes aniônico dodecilsulfato de sódio (SDS) e catiônico cloreto de cetiltrimetilamonio (CTAC) na estrutura oligomérica de HbGp também foi estudado por MALDI-TOF-MS. Uma efetiva interação do surfactante catiônico CTAC com as duas isoformas de monômero $d, d_{1}$ e $d_{2}$, na proteína íntegra bem como no monômero puro d foi observada. Até 10 moléculas de CTAC são ligadas a cada isoforma do monômero. Diferentemente, o espectro de massas obtido para o sistema SDS-HbGp mostrou que a interação SDS-HbGp é significativamente menos efetiva quando comparada ao sistema CTAC-HbGp. 


\begin{abstract}
Dipyridamole (DIP), 2,6-bis(dietanolamina)-4,8-dipiperidinapirimida-[5,4-d] pirimidina) is known for its vasodilating and antiplatelet aggregation activity, exhibiting also a potent antioxidant effect, strongly inhibiting lipid peroxidation. In the present work, the quenching of singlet molecular oxygen, $\mathrm{O}_{2}\left({ }^{1} \Delta_{\mathrm{g}}\right)$, by dipyridamole, RA47 and RA25 was analyzed in acetonitrile and aqueous acid solutions. Bimolecular quenching constants in acetonitrile (ACN) are consistent with an efficient physical quenching, presenting values slightly lower than the diffusion limit $\left(k_{t}=3,4-6,8 \times 10^{8} \mathrm{M}^{-1} \mathrm{~s}^{-1}\right)$. The quenching process occurs probably, via reversible charge transfer with the formation of an exciplex. Calculation of $\Delta G_{\text {et }}$ associated to $\mathrm{O}_{2}\left({ }^{1} \Delta_{\mathrm{g}}\right)$ quenching corroborates with uncomplete electron transfer. In aqueous acid solutions $(\mathrm{pH}=3,0)$ the $\mathrm{k}_{\mathrm{t}}$ values for DIP and derivatives are 20-fold smaller as compared to ACN. The electrochemical properties of DIP in ACN are characterized by two consecutive one-electron processes with halfwave oxidation potentials of $0,30 \mathrm{~V}$ and $0,67 \mathrm{~V}$ vs SCE. However, in aqueous acid medium a single oxidation wave is observed involving a two-electron process $\left(0,80 \mathrm{~V}\right.$ vs SCE). Therefore, $\mathrm{O}_{2}\left({ }^{1} \Delta_{g}\right)$ quenching is consistent with electrochemical data. The eletrooxidation of DIP leads to nonfluorescent products and a considerable change in the absorption spectra occurs. The mass spectrum of eletrooxidation products of DIP showed peaks with $\mathrm{m} / z$ 472, 269 and 519. In this work the photolysis of DIP in acetronitrile (ACN) and aqueous solutions at $\mathrm{pH} 3,0$ was examined. In aqueous acid solutions DIP was oxidized by photosensitization with methylene blue and by a reaction with a clean chemical source of $\mathrm{O}_{2}\left({ }^{1} \Delta_{\mathrm{g}}\right)$, N,N'-di(2,3-dihydroxypropyl)-1,4 naphtalenedipropanamide $\left(\mathrm{DHPNO}_{2}\right)$. Photooxidation occurs predominantly by type II mechanism, where DIP is oxidized by $\mathrm{O}_{2}\left({ }^{1} \Delta_{\mathrm{g}}\right)$. Some products with low intensity and $\mathrm{m} / \mathrm{z}$ of 472 were observed, in agreement with eletrooxidation. On the other hand, in ACN, DIP is photooxidated by type I mechanism via radicals generation or by excited triplet state species, as observed by EPR. However, the oxidation produces the same species in both solvents. A dioxetane can be formed as an intermediate of the reaction of the
\end{abstract}


photo-oxidation. The observed product, with $\mathrm{m} / \mathrm{z} 269$, can correspond to half of the DIP molecule with an attached oxygen atom or the DIP molecule with two oxygen atom with two protons. The conclusion at this stage is that DIP is photooxidated involving either $\mathrm{O}_{2}\left({ }^{1} \Delta_{\mathrm{g}}\right)$ in aqueous solution or molecular oxygen in ACN.

Another work involving the giant extracelular hemoglobin of Glossoscolex paulistus ( $\mathrm{HbGp}$ ) was performed. MALDI-TOF-MS analysis of the different subunits from the HbGp in the oxy-form was made. The results are compared to those reported for the homologous hemoglobin of Lumbricus terrestris ( $\mathrm{HbLt})$ and some tentative assignments are made for the observed polypeptides. The monomer $\mathbf{d}$ is found to exist in, at least, two major forms of identical proportions with masses of $16.355 \pm 25$ and $16.428 \pm 24 \mathrm{Da}$, respectively. Two minor forms were also observed around $16 \mathrm{kDa}$ for the monomers. Upon disulfide bonds reduction the peak associated to the trimer is absent in the mass spectrum, and new peaks assigned tentatively to the monomers $\mathbf{a}, \mathbf{b}$ and $\mathbf{c}$ are observed. Their molecular masses were 18.258 $\pm 30 \mathrm{Da}, 16.492 \pm 24 \mathrm{Da}$ and 17.363 $\pm 17 \mathrm{Da}$, respectively. Two Linker chains for HbGp were also observed at $25.817 \pm 50$ and $26.761 \pm 16 \mathrm{Da}$. Finally, trimers (abc) were observed at 51-52 kDa. This partial characterization, performed for the first time, is an important step in the characterization of subunits of this giant hemoglobin. The effects of anionic sodium dodecyl sulfate (SDS) and cationic cethyltrimethylammonium chloride (CTAC) on the oligomeric structure of HbGp were also studied by MALDI-TOFMS. The data obtained with this technique show an effective interaction of cationic surfactant CTAC with the two isoforms of monomer $\mathbf{d}, \mathbf{d}_{1}$ and $\mathbf{d}_{2}$, both in the whole protein as well as in the pure isolated monomer. The results show that up to 10 molecules of CTAC are bound to each isoform of the monomer. Differently, the mass spectra obtained for SDS-HbGp system showed that the interaction is, probably, significantly less effective as compared to CTAC-HbGp one. The acid pl of the protein around 5,5 is, probably, responsible for this behavior. 


\section{Introdução}

\subsection{Antioxidantes e Espécies Reativas de Oxigênio (ERO).}

Antioxidantes é qualquer substância que, presente em baixas concentrações quando comparado ao do substrato oxidável, suprime, retarda ou inibe a oxidação deste substrato de maneira eficaz [1].

Diversos estudos têm demonstrado que o consumo de substâncias antioxidantes na dieta diária pode produzir uma ação protetora efetiva contra os processos oxidativos que naturalmente ocorrem no organismo. Foi descoberto que uma série de doenças entre as quais câncer, aterosclerose, diabetes, artrite, malária, AIDS, doenças do coração, podem estar ligadas aos danos causados por formas de oxigênio extremamente reativas denominadas de "Espécies Reativas de Oxigênio" ou simplesmente ERO. Estas substâncias também estão ligadas com processos responsáveis pelo envelhecimento do corpo [2].

Essas espécies (ERO) não são necessariamente radicais e podem ser formadas através de reações de transferência de energia ou de elétrons para o oxigênio molecular no estado fundamental. As espécies reativas de oxigênio incluem espécies radicalares tais como o ânion radical superóxido $\left(\mathrm{O}_{2}{ }^{*}\right)$, 0 radical hidroxila $\left({ }^{\circ} \mathrm{OH}\right)$, o radical alcoxila $\left(\mathrm{RO}^{\circ}\right)$, o radical peroxila $\left(\mathrm{ROO}^{\circ}\right)$, o radical ânion carbonato $\left(\mathrm{CO}_{3}{ }^{\circ}\right)$ e espécies não radicalares tais como o peróxido de hidrogênio $\left(\mathrm{H}_{2} \mathrm{O}_{2}\right)$, o ácido hipocloroso $(\mathrm{HOCl})$, os hidroperóxidos orgânicos $(\mathrm{ROOH})$, o oxigênio molecular singlete $\left({ }^{1} \mathrm{O}_{2}\right)$ e o ozônio $\left(\mathrm{O}_{3}\right)$.

Estando a célula exposta a tantos agressores sua sobrevivência depende de uma linha de defesa antioxidante eficiente. Exemplos dessa defesa são as enzimas superóxido dismutase, glutationa peroxidase e catalase e alguns compostos orgânicos tais como carotenóides, tióis e vitaminas E e C.

Quando ocorre um desequilíbrio e a geração dessas espécies reativas (ERO) se sobrepõe às defesas antioxidantes, ocorre um fenômeno conhecido como estresse oxidativo [3].

As vitaminas $\mathrm{C}, \mathrm{E}$ e $\circ \beta$-caroteno são considerados excelentes antioxidantes, capazes de seqüestrar os radicais livres com grande eficiência. A 
vitamina $E$ encontra-se em grande quantidade nos lipídeos, e evidências recentes sugerem que essa vitamina impede ou minimiza os danos provocados pelos radicais associados com doenças degenerativas e o envelhecimento [4]. Possui também a capacidade de impedir a propagação das reações em cadeia induzidas pelos radicais livres nas membranas biológicas [4]. Os danos oxidativos podem ser inibidos pela ação antioxidante dessa vitamina, juntamente com a glutationa, a vitamina $\mathrm{C}$ e os carotenóides, constituindo um dos principais mecanismos da defesa endógena do organismo [4].

Os antioxidantes podem atuar como captadores de radicais através da sua habilidade de doar átomo de hidrogênio, como por exemplo, a Vitamina E, conforme ilustrado na reação abaixo:<smiles>Cc1c(C)c2c(c(C)c1O)CCC(C)([18F])O2</smiles>

Também podem reagir através do mecanismo de transferência de elétrons (ET), como ilustrado pelo esquema de reação:

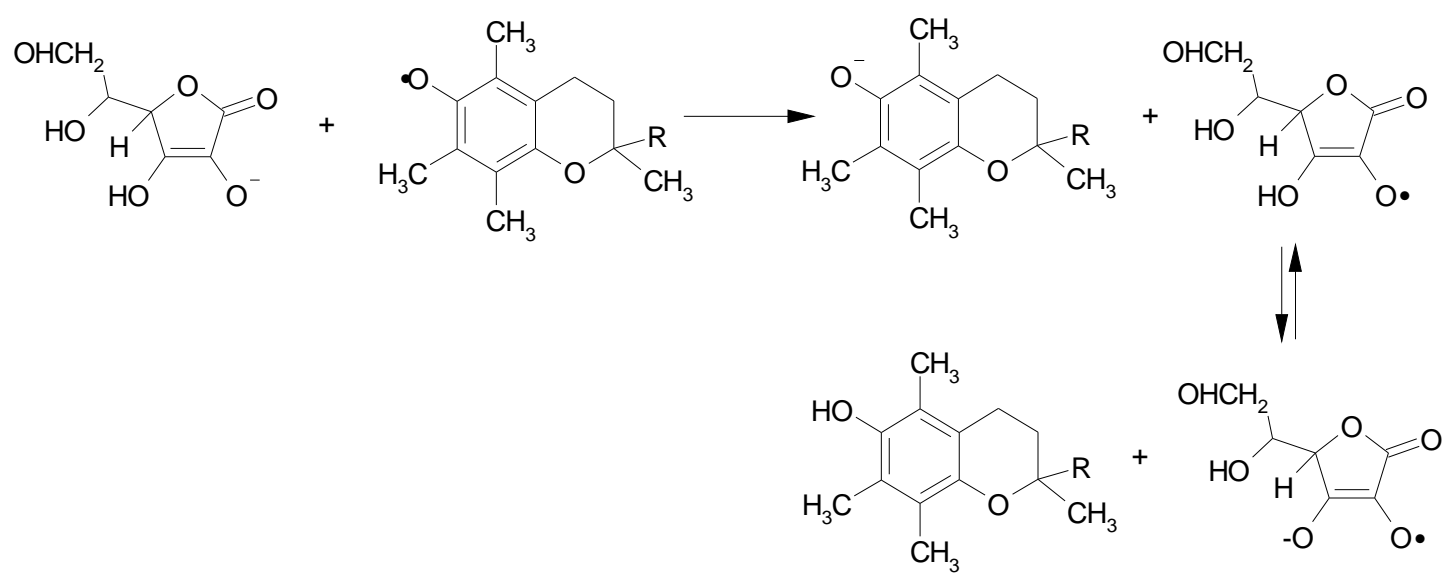

No esquema acima é esperado uma boa correlação entre a velocidade de captação do radical pelo antioxidante com o seu potencial redox, como pode ser exemplificado pela teoria de Marcus [5]. 
Metais de transição participam ativamente no processo oxidativo pela decomposição de hidroperóxidos formados nas reações e também pela sua presença ativa na reação de Fenton. Os compostos fenólicos podem apresentar atividade antioxidante por complexação com íons metálicos alterando o potencial redox do centro metálico de forma a torná-lo menos susceptível a determinados processos redox.

Compostos antioxidantes podem também agir como supressores/captadores do oxigênio singlete através de reação de transferência de energia do estado excitado do oxigênio para o estado fundamental do supressor excitando-o a um estado de mais alta energia. $O$ retorno ao estado fundamental pode ocorrer através de decaimento térmico ou radiativo sem promover reações adicionais. Um exemplo de uma classe de compostos capazes de agir como antioxidante frente ao oxigênio singlete através de sua desativação física, $\mathrm{k}_{\mathrm{q}} \sim 10^{9} \mathrm{M}^{-1} \mathrm{~s}^{-1}$, são os carotenóides (reação 3 e 4) [6].

$$
\begin{aligned}
& \mathrm{O}_{2}\left({ }^{1} \Delta_{\mathrm{g}}\right) .+ \text { caroteno } \rightarrow{ }^{3} \mathrm{O}_{2}+{ }^{3} \text { caroteno } \\
& { }^{3} \text { caroteno } \\
& { }^{*}{ }^{1} \text { caroteno }+ \text { calor }
\end{aligned}
$$

Nas últimas décadas vários estudos têm sido desenvolvidos para entender melhor os mecanismos de ação e prevenção e a origem de substâncias que apresentam efeitos antioxidantes. Métodos tais como: eletroquímicos, onde o potencial redox é conhecido, análises por fotólise por pulso de laser onde intermediários com tempos de vida curtos são detectados, espectroscopia de EPR e processos fotoquímicos têm sido extensivamente utilizados para entender melhor o mecanismo de ação antioxidante de muitos compostos [7-9].

\subsection{Oxigênio singlete}

O oxigênio molecular, no estado fundamental, apresenta seu nível eletrônico de mais alta energia constituído por dois orbitais degenerados $\pi^{*}$ (orbitais diferentes com a mesma energia) ocupados por dois elétrons, sendo 
que cada elétron fica em um orbital $\pi^{*}$ com spins paralelos, constituindo um estado triplete $\left({ }^{3} \Sigma_{g}{ }^{-}\right)$(Figura 1). Esta característica conferiria ao oxigênio uma alta reatividade, entretanto, sua redução direta por dois elétrons com spins antiparalelos é proibida pela regra de conservação de spin, tornando-o relativamente inerte.

O oxigênio eletronicamente excitado pode apresentar-se em dois estados distintos, o ${ }^{1} \Delta_{\mathrm{g}}$ e $\circ{ }^{1} \Sigma_{\mathrm{g}}{ }^{+}$, com energias de 22 e $37,5 \mathrm{kcal} / \mathrm{mol}$ acima do estado fundamental, respectivamente. A vida-média para o primeiro estado é alta, cerca de 2 a $4 \mu \mathrm{s}$ em $\mathrm{H}_{2} \mathrm{O}$, e para o segundo é muito menor, decaindo rapidamente para o estado ${ }^{1} \Delta_{\mathrm{g}}$ (Figura 1). Considerando estas características, a única forma de oxigênio singlete que apresenta interesse em sistemas biológicos é a forma ${ }^{1} \Delta_{\mathrm{g}}$, que será denotado por $\mathrm{O}_{2}\left({ }^{1} \Delta_{\mathrm{g}}\right)$.

\begin{tabular}{|c|c|c|}
\hline Estado & Orbitais $\pi^{*}$ & Energia (kcal/mol) \\
\hline${ }^{1} \Sigma_{g}^{+}$ & $\downarrow$ & 37,5 \\
\hline${ }^{1} \Delta_{g}$ & $\uparrow \downarrow$ & 22,5 \\
\hline${ }^{3} \Sigma_{g}^{-}$ & 个 & \\
\hline
\end{tabular}

Figura 1: Distribuição eletrônica nos orbitais moleculares $\left(\pi^{*}\right)$ do oxigênio no estado excitado singlete $\left({ }^{1} \Sigma_{g}{ }^{+},{ }^{1} \Delta_{g}\right)$ e no estado fundamental triplete $\left({ }^{3} \Sigma_{g}{ }^{-}\right)[10]$.

Sendo $0 \mathrm{O}_{2}\left({ }^{1} \Delta_{\mathrm{g}}\right)$ uma molécula no estado eletrônico excitado, o decaimento para o estado fundamental pode ser acompanhado de emissão de luz. Essa luminescência é extremamente fraca e o rendimento quântico de luminescência, ou seja, a fração de moléculas de $\mathrm{O}_{2}\left({ }^{1} \Delta_{g}\right)$ que decai emitindo luz em vez de decair por outras vias não radiativas (por exemplo, desativação por solvente), varia em torno de $10^{-6}$ a $10^{-3} \mathrm{M}^{-1} \mathrm{~s}^{-1}[10]$. 
$\mathrm{O}_{2}\left({ }^{1} \Delta_{\mathrm{g}}\right)$ pode decair para o estado fundamental de duas formas, conhecidas como decaimento bimolecular e monomolecular. O decaimento bimolecular, como o próprio nome diz, ocorre por meio da transição simultânea de duas moléculas de $\mathrm{O}_{2}\left({ }^{1} \Delta_{g}\right)$ para o estado fundamental. Esse decaimento é acompanhado por uma emissão de luz no visível centradas em 634 nm e 703 nm (reação 5) [10]. O decaimento monomolecular envolve apenas uma molécula de oxigênio, e é acompanhada por uma emissão de luz no infravermelho centrada em $1270 \mathrm{~nm}$ (reação 6) [11].

$$
\begin{aligned}
& 2 \mathrm{O}_{2}\left({ }^{1} \Delta_{\mathrm{g}}\right) \longrightarrow 2 \mathrm{O}_{2}\left({ }^{3} \Sigma_{\mathrm{g}}{ }^{-}\right)+\mathrm{hv} \quad(\lambda=634 \text { e } 703 \mathrm{~nm}) \\
& \mathrm{O}_{2}\left({ }^{1} \Delta_{\mathrm{g}}\right) \longrightarrow \mathrm{O}_{2}\left({ }^{3} \Sigma_{\mathrm{g}}{ }^{-}\right)+\mathrm{hv} \quad(\lambda=1270 \mathrm{~nm})
\end{aligned}
$$

O tempo de vida do $\mathrm{O}_{2}\left({ }^{1} \Delta_{\mathrm{g}}\right)$ em solução é fortemente dependente da natureza do solvente, sendo maior em meio deuterado [12].

$\mathrm{O} \mathrm{O}_{2}\left({ }^{1} \Delta_{\mathrm{g}}\right)$ é altamente eletrofílico atacando compostos com insaturações e átomos com alta densidade eletrônica. As reações de $\mathrm{O}_{2}\left({ }^{1} \Delta_{\mathrm{g}}\right)$ com compostos contendo insaturações podem ser divididas em basicamente três tipos de reações, descritas a seguir:

\section{Reação do tipo ene e formação de hidroperóxidos alílicos}

A reação do tipo "ene" ocorre com olefinas contendo hidrogênio alílico e leva à formação de hidroperóxidos. Nessa reação, o $\mathrm{O}_{2}\left({ }^{1} \Delta_{\mathrm{g}}\right)$ adiciona-se ao $\mathrm{C} 1$ promovendo a movimentação da dupla ligação para uma posição adjacente e a formação de um hidroperóxido alílico (reação 7)

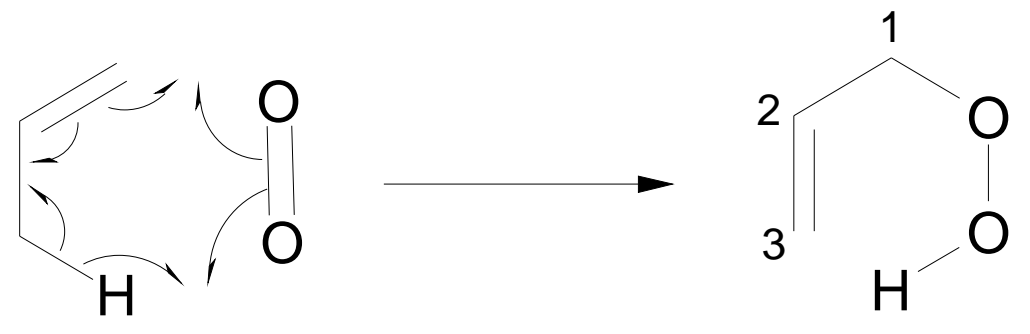




\section{Cicloadição [2+2] e formação de 1,2-dioxetanos}

A cicloadição de $\mathrm{O}_{2}\left({ }^{1} \Delta_{g}\right)$ às insaturações presentes em algumas olefinas e enaminas produz 1,2-dioxetanos. Esses peróxidos cíclicos são moderadamente estáveis e podem sofrer decomposição gerando 2 carbonilas, uma delas no estado excitado. Normalmente a carbonila excitada produzida é formada predominantemente no estado triplete, exceto em dioxetano com substituintes ricos em elétrons onde a carbonila no estado singlete prevalece.

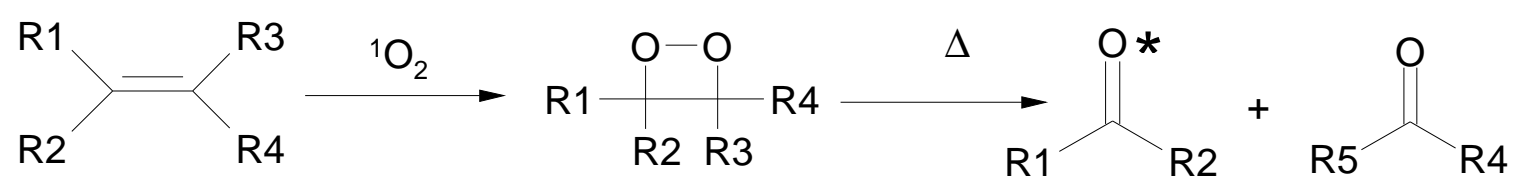

\section{$>$ Cicloadição [4+2] e formação de endoperóxidos}

$\mathrm{Na}$ cicloadição do tipo Diels-Alder [4+2] o $\mathrm{O}_{2}\left({ }^{1} \Delta_{g}\right)$ comporta-se como um poderoso dienófilo. Neste tipo de reação $0^{\circ} \mathrm{O}_{2}\left({ }^{1} \Delta_{\mathrm{g}}\right)$ adiciona-se a um dieno produzindo endoperóxidos (reação 9). A estabilidade desses produtos é bem variada e depende da estrutura do substrato.

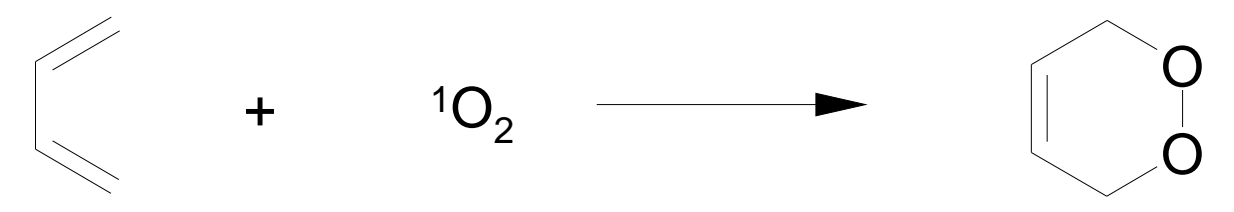

\subsubsection{Desativação do oxigênio singlete}

$\mathrm{O}_{2}\left({ }^{1} \Delta_{g}\right)$ é desativado por uma variedade de compostos, sendo que esta desativação pode ser colisional (supressão física), com regeneração do estado fundamental triplete do oxigênio $\mathrm{O}_{2}\left({ }^{3} \Sigma_{\mathrm{g}}^{-}\right)$de acordo com a reação 10 , ou a 
interação pode resultar em uma reação química (supressão química), onde os compostos são oxidados de acordo com a reação 11 [13-15].

$$
\begin{aligned}
& \mathrm{O}_{2}\left({ }^{1} \Delta_{\mathrm{g}}\right)+\mathrm{Q} \stackrel{\mathrm{k}_{\mathrm{q}}}{\longrightarrow} \mathrm{O}_{2}\left({ }^{3} \Sigma_{\mathrm{g}}^{-}\right)+\mathrm{Q} \\
& \mathrm{O}_{2}\left({ }^{1} \Delta_{\mathrm{g}}\right)+\mathrm{Q} \stackrel{\mathrm{k}_{\mathrm{r}}}{\longrightarrow} \text { Produtos }
\end{aligned}
$$

$Q$ é o supressor, $k_{q}$ é a constante de supressão física e $k_{r}$ é a constante de supressão química. A constante de supressão bimolecular $\left(k_{t}\right)$ é dada como a somatória dos dois processos de supressão: $k_{t}=k_{q}+k_{r}$.

Existem dois mecanismos principais para a desativação física: transferência de energia e transferência de carga.

O mecanismo de transferência de energia pode ser exemplificado pela ação de carotenos. O $\beta$-caroteno, em solventes apolares, interage com o $\mathrm{O}_{2}\left({ }^{1} \Delta_{\mathrm{g}}\right)$ e é promovido ao estado triplete excitado. A eficiência desse processo de transferência se deve ao fato da energia de excitação do $\beta$-caroteno ficar abaixo da energia do $\mathrm{O}_{2}\left({ }^{1} \Delta_{\mathrm{g}}\right)$.

O mecanismo de supressão física para certos sistemas ricos em elétrons é conhecido como transferência de carga. Numerosos estudos envolvendo aminas alifáticas e aromáticas, hidrazinas, fenóis, metoxibenzenos, e diversos compostos biológicos incluindo vitamina $\mathrm{E}$, porfirinas, ascorbato e amino ácidos como supressores de $\mathrm{O}_{2}\left({ }^{1} \Delta_{g}\right)$ tem sido desenvolvidos, levando a propor que a supressão física por transferência de carga representa o caminho principal para a desativação do oxigênio singlete. Neste caminho ocorre a formação de um exciplex ${ }^{1}\left(\right.$ Supressor $\left.^{\delta+} \ldots \mathrm{O}_{2}{ }^{\delta}\right)$, através do qual os compostos decaem para o estado fundamental desativando $0 \mathrm{O}_{2}\left({ }^{1} \Delta_{\mathrm{g}}\right)$ sem que ocorra a formação de produtos [16-20].

$\mathrm{Na}$ via de supressão química há consumo de oxigênio e formação de produtos (reação 11). Em geral, as reações químicas do $\mathrm{O}_{2}\left({ }^{1} \Delta_{g}\right)$ com compostos insaturados levam à formação de hidroperóxidos alílicos, dioxetanos e endoperóxidos (reações 7-9). 
Vários estudos têm mostrado que a constante de supressão de $\mathrm{O}_{2}\left({ }^{1} \Delta_{g}\right)$ está relacionada com o potencial de oxidação. Moléculas com baixo potencial de oxidação são eficientes supressores de $\mathrm{O}_{2}\left({ }^{1} \Delta_{\mathrm{g}}\right)$ [16].

\subsubsection{Fotossensibilização}

O oxigênio singlete $\mathrm{O}_{2}\left({ }^{1} \Delta_{g}\right)$ é produzido pela reação de fotossensitização do tipo II [21], envolvendo a energia de transferência do sensibilizador no estado triplete excitado para o estado fundamental $\mathrm{O}_{2}\left({ }^{3} \Sigma_{\mathrm{g}}{ }^{-}\right)$.

Geralmente, a absorção ocorre a partir do estado singlete fundamental para o estado singlete excitado $\left(S_{0} \rightarrow S_{1}\right)$. Algumas moléculas geralmente denominadas de fotossensibilizador são capazes de transferir com eficiência a excitação para o estado triplete excitado $\left(T_{1}\right)$ que por ter um tempo de vida longo, permanecendo durante $10^{-6}-10^{-3} \mathrm{~s}$ em solução, como apresentado na figura 2, é capaz de participar de vários tipos de reação inclusive as reações do tipo II em que ocorre produção de oxigênio singlete ${ }^{1} \mathrm{O}_{2}$, espécie muito reativa e capaz de produzir reações de oxidação. Este tipo de reação é especialmente eficiente em presença do oxigênio molecular ${ }^{3} \mathrm{O}_{2}$, que participa da reação. 


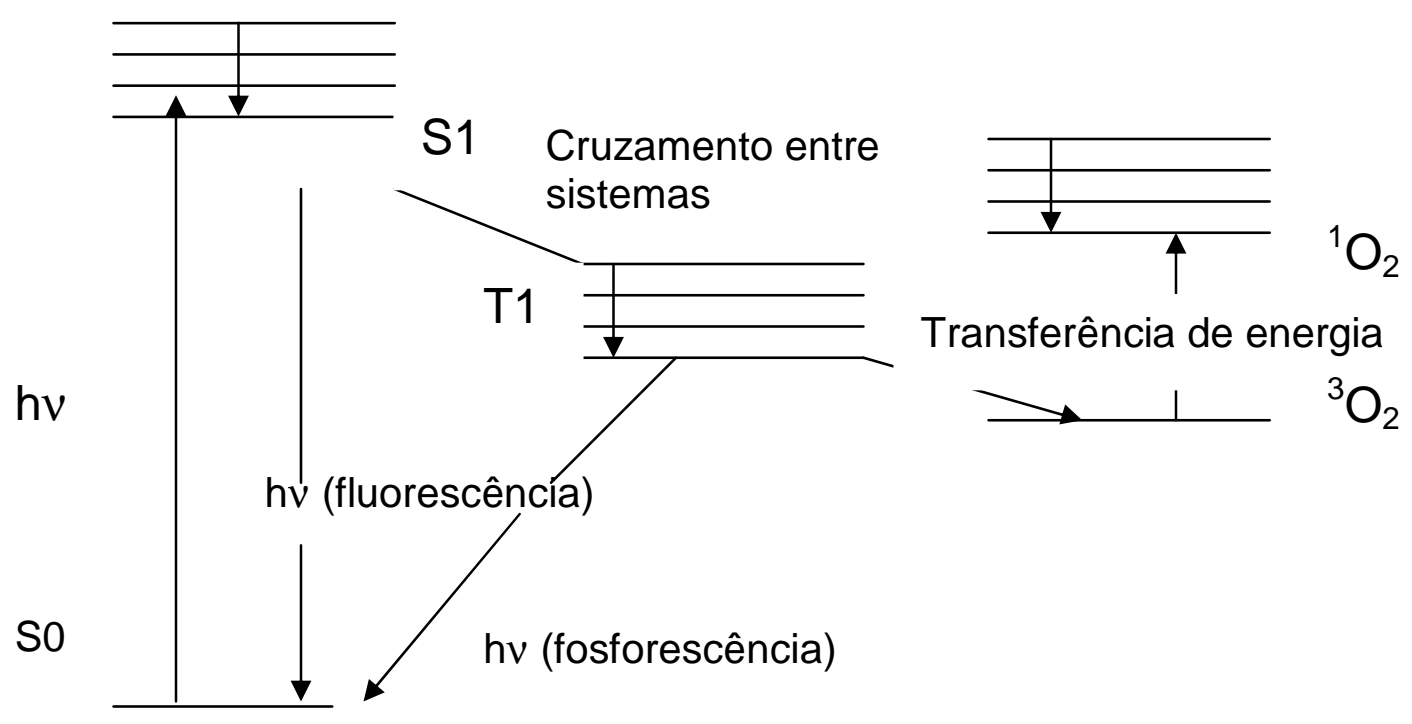

Figura 2: Diagrama de Jablonski ilustrando a absorção de luz pelo fotossensibilizador, a formação do estado tripleto excitado e posterior desativação por transferência de energia para o oxigênio triplete gerando 0 oxigênio singlete excitado [22].

Existem dois possíveis caminhos para a dexecitação ${ }^{3}$ sens ${ }^{*}$ (sensibilizador no estado excitado triplete). No mecanismo tipo I há transferência de elétron entre $0{ }^{3}$ sens $^{*}$ e componentes do sistema. Esse processo gera íons radicais que podem reagir com $\mathrm{O}_{2}\left({ }^{3} \Sigma_{g}\right)$ resultando em produtos oxidados (Fig. 3). No mecanismo tipo II ocorre transferência de energia do ${ }^{3}$ sens $^{*}$ para $\circ \mathrm{O}_{2}$ $\left({ }^{3} \Sigma_{\mathrm{g}}\right.$ ), gerando ${ }^{1} \mathrm{O}_{2}$ (Fig. 3). Esses mecanismos podem ocorrer simultaneamente e a razão entre eles é altamente influenciada pelo tipo de sensibilizador, natureza do substrato e concentração de oxigênio em solução [21-23]. 


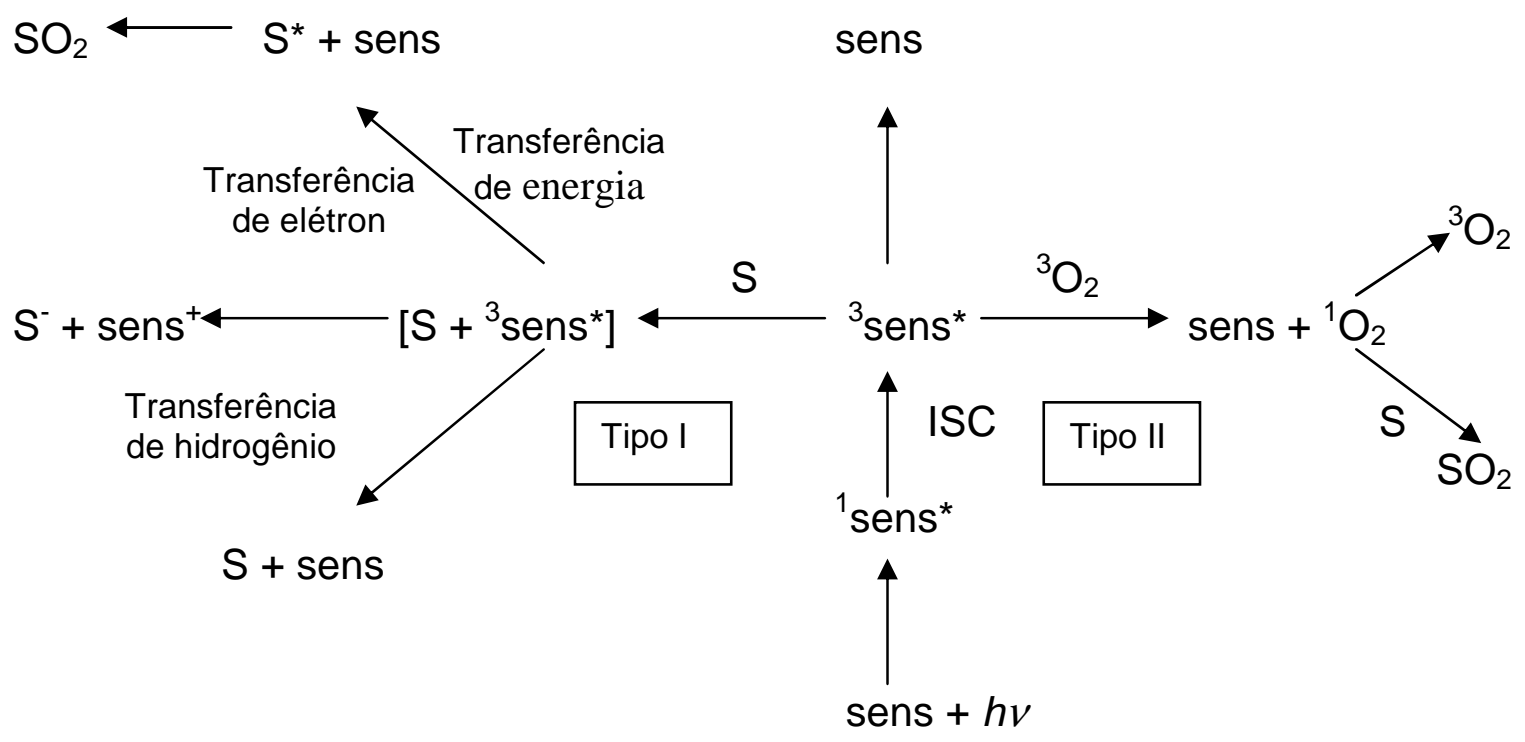

Figura 3: Esquema de fotossensibilização mostrando os mecanismos tipo I e II. ( $\mathrm{S}=$ substrato, ISC $=$ cruzamento intersistemas, sens $=$ sensibilizador $)$ [23].

Muitas substâncias são utilizadas como fotossensibilizadores tais como porfirinas (usadas em terapia fotodinâmica), riboflavina (como iniciador de processos oxidativos no leite e derivados), antioxidantes e azul de metileno.

No entanto, $\mathrm{O}_{2}\left({ }^{1} \Delta_{\mathrm{g}}\right)$ pode também ser gerado por outros processos químicos e bioquímicos e está envolvido em reações do peróxido de hidrogênio com hipoclorito ou peroxinitrito, processos enzimáticos de peroxidases e oxidases e na decomposição de dioxietanos e endoperóxidos. Biomoléculas com densidade eletrônica significativa, incluindo DNA, ribossomos, mitocôndrias e membranas celulares são os principais alvos de ataque de reações de oxidação por $\mathrm{O}_{2}\left({ }^{1} \Delta_{\mathrm{g}}\right)$ [24].

\subsection{Peroxidação Lípidica}

Todos os componentes celulares são suscetíveis à ação das ERO, porém a membrana é um dos mais atingidos em decorrência da peroxidação lipídica, que acarreta alterações na estrutura e na permeabilidade das membranas celulares. 
A peroxidação lipídica é composta basicamente de três etapas: iniciação, propagação e terminação (Fig. 4). A peroxidação lipídica se inicia pelo ataque à bicamada lipídica por qualquer espécie suficientemente reativa para abstrair um átomo de hidrogênio bis-alílico de um ácido graxo insaturado (LH), formando um radical lipídico centrado no carbono $\left(\mathrm{L}^{\circ}\right)$, que é estabilizado por um rearranjo molecular, adquirindo a estrutura de um dieno conjugado. Após iniciado, o processo se torna autocatalítico, a adição extremamente rápida de uma molécula de oxigênio ao radical lipídico leva à formação de um radical peroxila (LOO*). Este é capaz de reagir com outro ácido graxo insaturado, iniciando assim uma nova cadeia de oxidação a partir da formação de outro radical lipidíco $\left(\mathrm{L}^{\circ}\right)$. E por fim o radical $\mathrm{LOO}^{\circ}$ se combina com o átomo de hidrogênio abstraído e forma um hidroperóxido lipídico ( $\mathrm{LOOH})$.

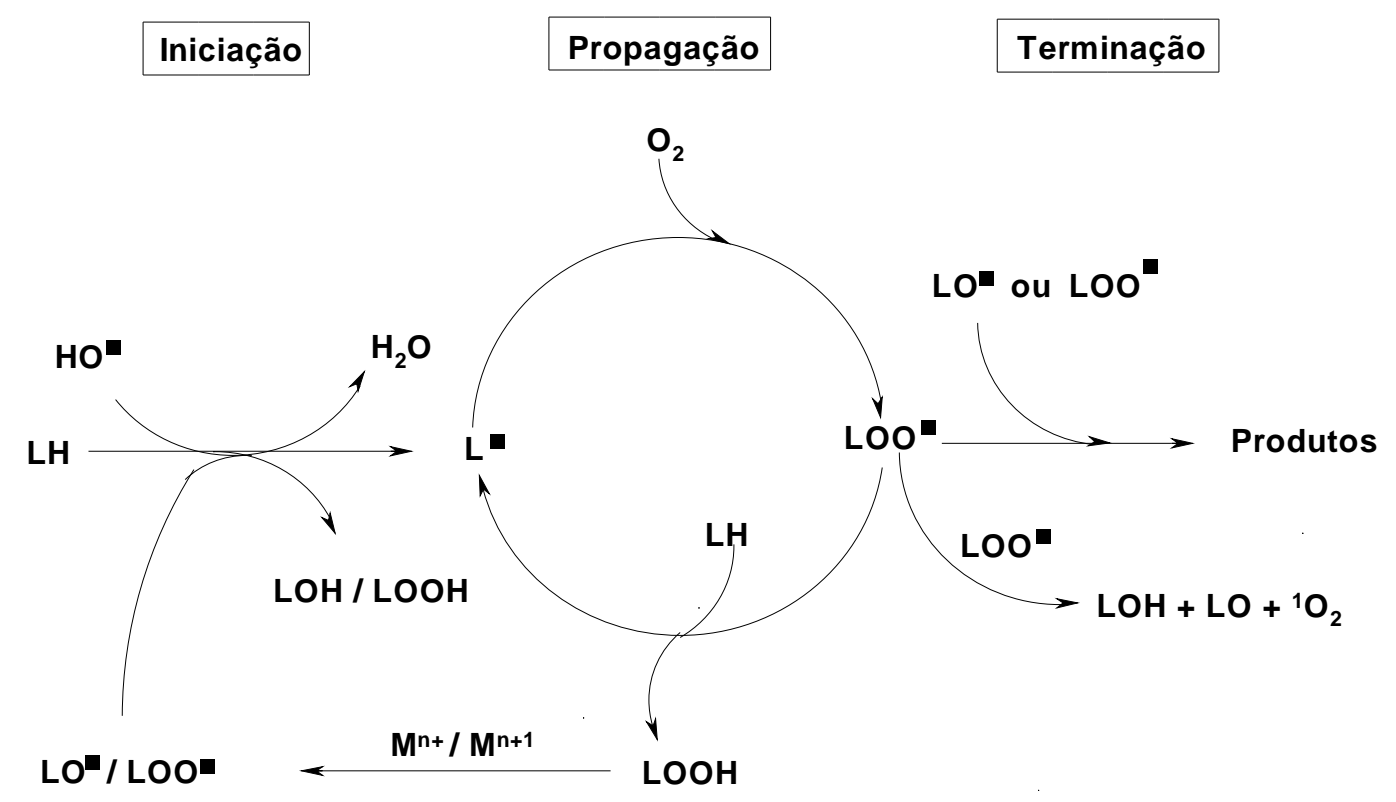

Figura 4: Esquema das etapas de iniciação, propagação e terminação da peroxidação lípidica e da catálise mediada por metais de transição [11]. 


\subsection{Dipiridamol e derivados}

O dipiridamol (DIP), 2,6-bis-(bis-(2-hidroxietil)-amino)-4,8dipiperidinopirimido-[5,4-d] pirimidina), cuja estrutura está apresentada na

Figura 5, era uma droga bastante utilizada clinicamente no tratamento de doenças cardiovasculares por apresentar efeito vasodilatador, sendo utilizado no tratamento e profilaxia da angina do peito, no tratamento e profilaxia do reinfarto do miocárdio $[25,26]$.

A estimulação dos receptores $A_{2 a}$ da adenosina sobre as células musculares lisas produz relaxamento vascular, com vasodilatação arteriolar máxima (redução máxima da resistência coronariana), fazendo com que o fluxo sanguíneo coronariano aumente a níveis máximos [27,28]. O Dipiridamol bloqueia o retransporte intracelular de adenosina e inibe a adenosinadeaminase, responsável pela degradação intracelular da adenosina. Portanto, o Dipiridamol age como um vasodilatador coronariano indireto, aumentando as concentrações intracelulares e intersticiais de adenosina [27-28]. As propriedades biológicas do Dipiridamol levam a inibição da formação de trombos e eleva os níveis de adenosina no plasma [29]

Atualmente é uma das drogas mais utilizadas em Cardiologia Nuclear em diferentes técnicas aplicadas na aquisição e processamento de imagens (cintilografia miocárdica de perfusão, cintilografia de necrose miocárdica, ressonância magnética do coração, ventriculografia e angiocardiografia radioisotópica) onde, é de particular interesse, a realização de exames em pacientes com limitações físicas, na vigência de drogas que impeçam a elevação adequada da freqüência cardíaca ou em pacientes diabéticos com doença vascular periférica, com ampla margem de segurança ao mesmo [30].

Além de seu efeito vasodilatador, o emprego do dipiridamol na prática clínica baseia-se na diminuição da agregação plaquetária, com mecanismo de ação que inclui a inibição da fosfodiesterase, elevação nos níveis de adenosina e potencialização dos efeitos da Aspirina ${ }^{\circledR}[30]$. 
O aumento do fluxo nas artérias coronárias normais após Dipiridamol é de três a cinco vezes maior que os valores obtidos em repouso, em artérias sem obstrução significativa. Em regiões supridas por artérias coronárias com lesões obstrutivas, verifica-se menor variação de fluxo durante a vasodilatação (até o limite de dobrar-se o valor em repouso) [30].

Administrado por via intravenosa, na dose convencional de $0,56 \mathrm{mg} / \mathrm{kg}$ no tempo de 4 minutos, é distribuído em 15 minutos, apresentando meia-vida biológica variável (45 a 136 minutos). Administrado por via oral requer uma dose de $200 \mathrm{mg} /$ dia. O Dipiridamol é encontrado nos níveis plasmáticos com uma concentração em torno de $4,0 \mu \mathrm{M}$ onde ocorre os vários mecanismos de ação desta droga [30].

O DIP além das importantes aplicações já estabelecidas em medicina apresenta uma ação antioxidante em sistemas biológicos bastante acentuada, associada à neutralização de radicais peroxilas, responsáveis pela peroxidação lipídica.

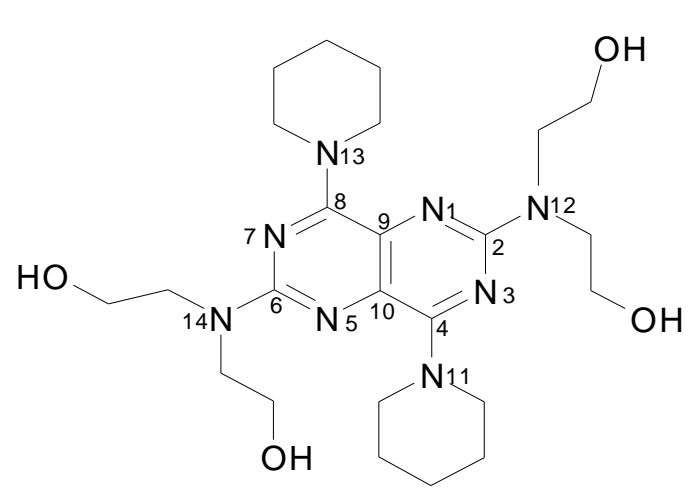

Dipiridamol

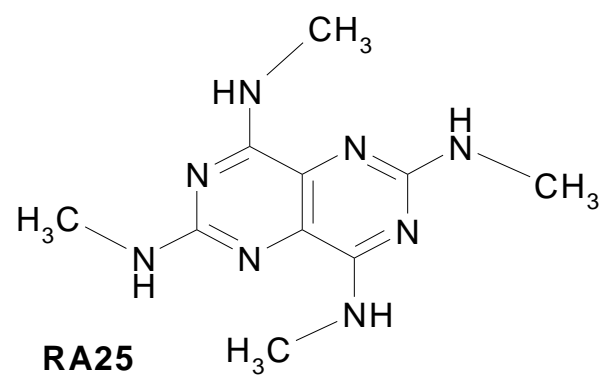

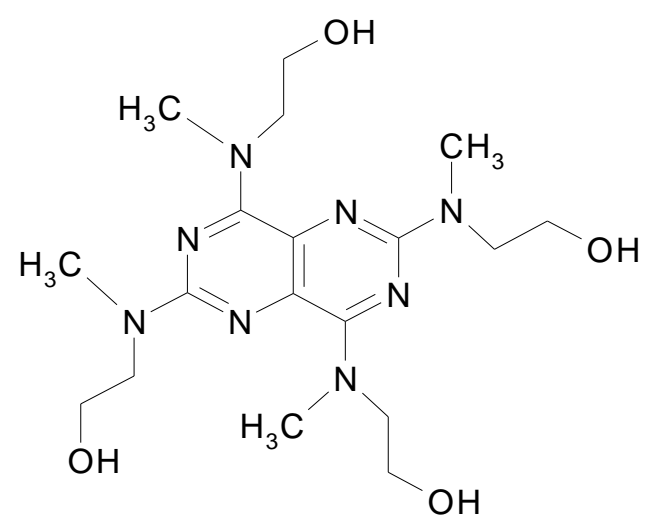

RA47

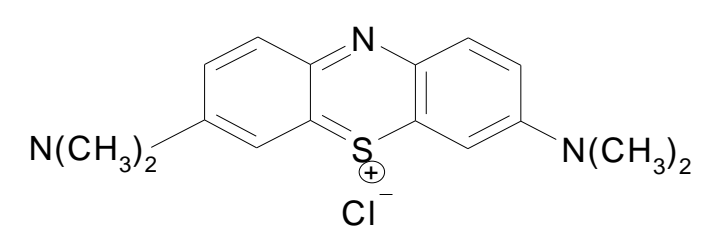

Azul de metileno

Figura 5: Estrutura Molecular do DIP, RA47, RA25, Azul de Metileno (AM). 
Seu mecanismo de ação antioxidante foi comparado com o que ocorre em compostos antioxidantes do tipo fenólicos, como por exemplo, a vitamina $E$, e que envolve a transferência de um átomo de hidrogênio para radicais peroxilas, conforme demonstrada no estudo de luliano e colaboradores [31]; dos resultados relatados, o DIP mostrou ser mais efetivo e mais ativo que a vitamina E em ambas as fases aquosa e lipídica, sendo que a vitamina $E$ apresenta a sua ação restrita ao ambiente da membrana. Entretanto, Pedulli e colaboradores [32] relatam que a ação antioxidante do DIP resulta da reação de transferência direta de um elétron para radicais peroxilas.

No entanto, analisando a molécula do DIP é difícil dizer qual dos hidrogênios poderia ser facilmente retirado por radicais peroxila, de forma similar com o que aparentemente ocorre com compostos fenólicos. Diante deste fato, um estudo do Dipiridamol abordando métodos eletroquímicos e espectroscópicos vem sendo desenvolvido em nosso Laboratório há vários anos. Tal estudo inclui a oxidação eletroquímica em acetonitrila e etanol [33], foi verificado que o mecanismo de oxidação ocorre via duas etapas referentes a perda consecutiva reversível de um elétron por etapa, com a formação do radical cátion DIP $^{{ }^{+}}$no primeiro processo e um dicátion no segundo processo (reações 12 e 13) [34], e um trabalho em meio aquoso ácido, onde a protonação da droga altera o mecanismo de oxidação para um processo único de 2 elétrons (reação 14) [35], onde $A^{2+}$ é o produto resultante da reação eletroquímica.

$$
\begin{array}{ll}
\mathrm{DIP} \leftrightarrow \mathrm{DIP}^{+\bullet}+1 \mathrm{e}^{-} & (\mathrm{E}=350 \mathrm{mV}) \\
\mathrm{DIP}^{++} \leftrightarrow \mathrm{DIP}^{2+}+1 \mathrm{e}^{-} & (\mathrm{E}=680 \mathrm{mV}) \\
\mathrm{DIPH}^{+} \rightarrow \mathrm{A}^{2+}+\mathrm{H}^{+}+2 \mathrm{e}^{-} & (\mathrm{E}=850 \mathrm{mV})
\end{array}
$$

De acordo com o trabalho de Pedulli e colaboradores [32] a atividade antioxidante do DIP deve estar relacionada com um mecanismo via transferência de um elétron. Como o DIP apresenta efeito inibidor da peroxidação lipídica [31], seu mecanismo de ação poderia ser exemplificado da seguinte maneira: 


$$
\mathrm{LOO}^{\bullet}+\mathrm{DIP} \leftrightarrow \mathrm{LOO}^{-}+\mathrm{DIP}^{\bullet+}
$$

No trabalho de Marilza Castilho [36] $\circ \Delta \mathrm{G}^{0}$ para a transferência de elétron, sendo o dipiridamol o doador, e o radical peroxila lipídio o aceptor, foi calculado usando a teoria de Marcus [37]. Os valores obtidos no intervalo de $-3,03$ a 3,88 $\mathrm{Kcal} \mathrm{mol}^{-1}$ mostraram que são suficientemente altos para justificar 0 comportamento antioxidante do DIP em meio aquoso, para este sistema.

Estudos iniciais que fizeram parte da tese de doutorado de Adaíla M. P. Almeida [38] mostraram que os produtos da oxidação eletroquímica possuem características espectroscópicas diferentes, quando comparados ao DIP, como o desaparecimento da fluorescência característica e da banda de absorção em torno de $400 \mathrm{~nm}$. Uma parcial caracterização também foi desenvolvida no mestrado de Michelle Lima, sugerindo que os produtos de eletooxidação podem ser gerados por modificações nos substituintes do anel pirimido-pirimidino, visto que cálculos teóricos mostram que o elétron pode ser retirado dos nitrogênios da etanolaminas [39].

O DIP e seus derivados, cujas estruturas estão apresentadas na Fig. 1, apresentam sistemas de alta densidade eletrônica (elétrons $\pi$ delocalizados) presentes nos nitrogênios, e como resultado desta propriedade estes compostos são geralmente bons doadores e/ou aceptores de elétrons. Esta propriedade permite que estas moléculas sejam estudadas por técnicas eletroquímicas e os processos químicos acoplados podem ser investigados.

O DIP caracteriza-se espectroscopicamente por duas bandas largas de absorção na região de 400 nm e 290 nm e uma intensa emissão de fluorescência centrada em torno de 500 nm (excitação em 400nm), sendo sensível à polaridade do solvente, bem como à protonação dos nitrogênios [40]. É ligeiramente solúvel em água, pouco solúvel em ACN e muito solúvel em etanol, metanol, clorofórmio e DMSO.

Com o aumento da concentração de íons $\mathrm{H}^{+}$em solução, ocorre um deslocamento das bandas de absorção para o azul e uma diminuição da intensidade de Fluorescência, sem a modificação do espectro, o que pode ser 
devido a supressão de fluorescência pela protonação do DIP. Estudos espectroscópicos do DIP e derivados em solução aquosa foram realizados em função do pH. Foram relatados valores de pKa para o DIP de 5,8 e 12,5, sendo que o valor do pKa de 5,8 foi associado à protonação dos nitrogênios dos substituintes do anel (bis-etanolamina e piperidino), e o valor de 12.5, não está bem definido [40]. Cálculos teóricos realizados recentemente [39] sugerem que o sítio mais suscetível de protonação é o nitrogênio na posição 1 (5) no anel pirimido-pirimidino (Fig. 5). Os anéis aromáticos são responsáveis pelas propriedades de fluorescência, as quais variam com o estado de protonação da droga e com o meio no qual se encontra.

O DIP e seus derivados (Fig. 5) exibem seu efeito antioxidante em mitocôndrias de acordo com a sua ordem de hidrofobicidade DIP $\geq R A 14>R A 47>R A 25$, a qual está relacionada aos valores das constantes de associação para estes compostos em sistemas modelo de membranas (micelas), sendo que esta ordem de também está de acordo com o potencial eletroquímico [41,42].

Estudos sobre interação do DIP com modelos de membranas foram desenvolvidos, mostrando a importância da interação do composto com a membrana celular. Neste sentido, trabalhos na literatura $[43,44]$ demonstraram através de medidas de fluorescência o equilíbrio de protonação do DIP, sendo determinada a constante de ionização ácida em água e na presença de diferentes tipos de micelas. Em um outro trabalho foram obtidas as constantes de associação do DIP em vesículas de fosfolípideos, utilizando a técnica de fluorescência [45].

Estudos sobre a fragmentação do DIP e alguns de seus derivados, com o objetivo de obter mais informações sobre suas propriedades químicas, também foram realizados utilizando a técnica de Espectrometria de massas, resultando em trabalho publicado recentemente. Este trabalho demonstra que a fragmentação do DIP por ionização electrospray, no modo positivo e no modo negativo, ocorre nas etanolaminas [46]. 
O DIP exibe também um importante papel como antioxidante na proteção de células frente ao ataque de radicais livres e espécies reativas de oxigênio, tais como oxigênio singlete $\left(\mathrm{O}_{2}\left({ }^{1} \Delta \mathrm{g}\right)\right)$. O DIP e seus derivados podem reagir fotoquimicamente com $\mathrm{O}_{2}\left({ }^{1} \Delta_{\mathrm{g}}\right)$ pelo mecanismo de transferência de carga, desativando-o.

A possibilidade do DIP ser usado na proteção de células vermelhas do sangue (RBCs) no tratamento fotodinâmico contra vírus foi investigado [47]. DIP pode proteger vários substratos (histidina, triptofano, metionina, tirosina e guanosina), os quais podem ser oxidados por $\mathrm{O}_{2}\left({ }^{1} \Delta_{\mathrm{g}}\right)$.

Outro fato que deve ser melhor estudado e que ainda não é bem conhecido está relacionado ao mecanismo de fotooxidação do Dipiridamol. Um estudo desenvolvido por Franklin Vargas e colaboradores examina em várias condições do meio (PBS-solução salina de fosfato tamponada, metanol e na presença de albumina de soro humano-HSA) a fotólise do Dipridamol. Como resultado deste estudo os autores apresentam apenas uma estrutura, como produto da fotooxidação [48], correspondente a uma pequena mudança em um dos 4 substituintes nas posições 2,6 e 4,8.

Um outro estudo das características cinéticas de fotodecomposição do DIP em função da solução e na presença de sistemas modelos tais como L-PC (liso fosfotidilcolina) e BSA (albumina de soro bovino) foi realizado [49], demonstrando ser uma ferramenta importante para entender melhor a ligação desta droga com proteínas e membranas.

A análise dos produtos de oxidação via remoção de um e dois elétrons e dos produtos de fotooxidação onde é observado um intermediário radicalar, em meio de alta polaridade, fornecerá dados adicionais para entender melhor este mecanismo de transferência de elétrons. 


\subsection{Hemoglobina de Glossoscolex paulistus}

As hemoglobinas extracelulares gigantes, também chamadas eritrocruorinas, são hemoproteínas interessantes devido à massa molecular elevada e à estrutura oligomérica, que envolve um grande número de subunidades.

Elas possuem alta cooperatividade na ligação com o oxigênio molecular [50-52] e apresentam um ponto isoelétrico em torno de 5,5. Suas cadeias linkers, que são subunidades com função estrutural e sem grupamento prostético heme, possuem um ponto isoelétrico entre 4,7 e 5,6 [53].

Segundo Vinogradov [54], as hemoglobinas extracelulares gigantes representam o ápice de complexidade das hemoproteínas que ligam oxigênio. Estas hemoglobinas são sistemas supramoleculares muito intrigantes, inclusive, sob o aspecto da seleção natural, uma vez que demonstram propriedades de adaptação não triviais em meios ricos em sulfeto $[55,56]$. Entretanto, comparado com as hemoglobinas, muito pouco é conhecido sobre as relações entre suas funções fisiológicas e estruturas moleculares [57].

A hemoglobina de Lumbricus terrestris ( $\mathrm{HbLt}$ ) é a hemoglobina mais estudada desta classe e utilizada como modelo em pesquisas de sangue artificial [58]. Strand e colaboradores [59] afirmam que as eritrocuorinas têm sido sugeridas como sistemas modelos de substitutos terapêuticos do sangue devido à sua natureza extracelular, grande tamanho e resistência à oxidação. Realmente, essa hemoglobina extracelular, quando em seu estado íntegro, apresenta estabilidades estrutural e redox [50,60] significativamente maiores do que as hemoglobinas intracelulares, como por exemplo, a hemoglobina humana, o que não deixa de tornar a avaliação dos fatores que controlam esse comportamento altamente relevante não só para o estudo desta hemoglobina gigante, como igualmente, para proporcionar um melhor entendimento das hemoglobinas em geral.

A HbLt consiste de mais ou menos 180 cadeias polipeptídicas organizadas em um arranjo de duas camadas hexagonais sobrepostas com 
cerca de 144 subunidades contendo grupos heme (monômero d e o trímero (abc) que contem ligações disulfeto) e 36 subunidades linkers que não possuem grupos heme com peso molecular na faixa de 24-32 kDa. Essa configuração espacial final, que consiste na estrutura quaternária da proteína, é chamada "modelo do bracelete", sendo que tal arquitetura é evidenciada por experimentos de microscopia eletrônica [51-61]. As cadeias da HbLt estão dispostas como dois discos hexagonais sobrepostos, apresentando as subunidade a, b, c e d, que contém grupos heme, nos vértices dos hexágonos e as subunidades "linkers" ou cadeias "L", que não apresentam grupamentos heme, na parte central do arranjo supramolecular [62]. As subunidades estão arranjadas como doze dodecâmeros, sendo que cada um deles é constituído por três tetrâmeros. Portanto, o dodecâmero consiste de três subunidades monoméricas e três subunidades trímero, $(\mathrm{abcd})_{3}$, com massa em torno de $200 \mathrm{kDa}$ (Figura 6). 


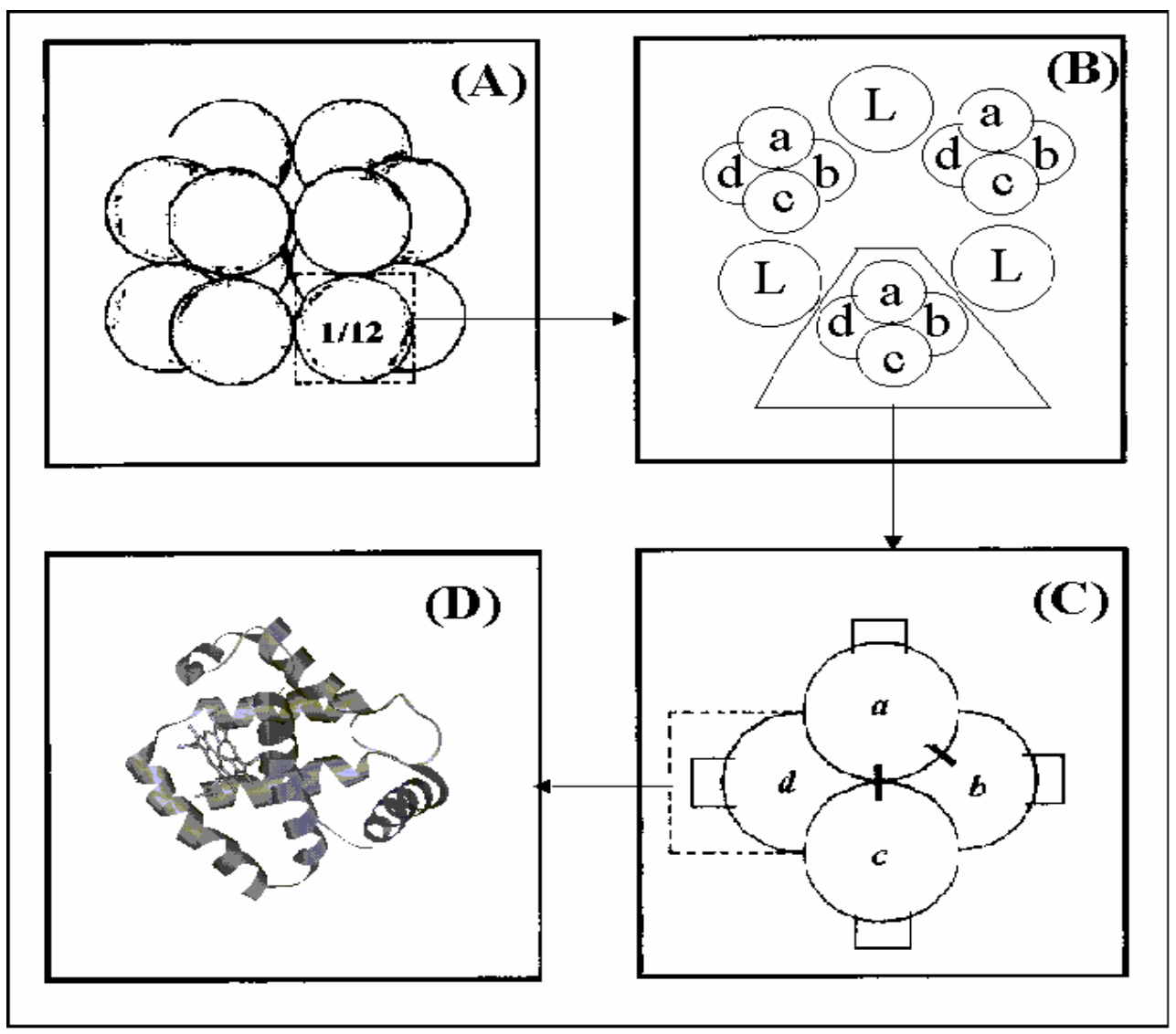

Figura 6: Representação esquemática da estrutura da hemoglobina de Lumbricus terrestris observada por microscopia eletrônica: (A) Bicamada hexagonal; (B) Uma das subunidades da hemoglobina íntegra corresponde a 1/12 da molécula. Essa subunidade 1/12 constitui-se por três estruturas tetrâmericas (abcd), um dodecâmero e três cadeias linkers L; (C) tetrâmero (abcd), indicando as ligações disulfeto do trímero abc, (D) estrutura da cadeia monomérica d da HbLt obtida por modelagem molecular.

O anelídeo Glossoscolex paulistus pertence ao filo Anelídae, à classe Oligochaeta e à família Glossoscolecidae [63, 64]. É uma minhoca de tamanho expressivo, conhecida popularmente como minhocoçu, encontrada em determinados sítios da cidade de Piracicaba, Araras e Rio Claro, no estado de São Paulo, Brasil. 
A hemoglobina extracelular gigante de Glossoscolex paulistus (HbGp) é uma hemoproteína oligomérica [65] que se apresenta como uma bicamada hexagonal, sua massa molecular foi determinada por ultracenttrifugação sendo estimada em torno de 3,1 MDa [66-67]. Esta hemoglobina apresenta alta similaridade com a hemoglobina de Lumbricus terrestris (HbLt).

A estrutura quaternária da HbGp apresenta 144 cadeias com grupo heme (globinas) e 36 cadeias sem grupo heme (linkers), demonstrando alta cooperatividade, grande estabilidade oligomérica e significativa capacidade de re-associação. Sendo constituída por várias subunidades contendo grupos heme com massa molecular na faixa de $16 \mathrm{kDa}$ formando o monômero $\mathrm{d}$, um trímero de massa em torno de $52 \mathrm{kDa}$ e por cadeias linkers, que não possuiem grupo heme, com massa na faixa de 24-32 kDa. Estes valores foram estimados por eletroforeses, que é uma técnica limitada devido a uma incerteza experimental, em torno de 1-5\% [68] na determinação da massa molecular. Além disso, pode apresentar algum erro se a mobilidade da proteína investigada é afetada por sua estrutura, diferindo da proteína padrão usada para calibração. Por esta razão, mais detalhes sobre a massa molecular da HbGp podem contribuir para um melhor entendimento da estrutura oligomérica e a correlação com arranjos polipeptídicos de outras hemoglobinas extracelulares gigantes [69].

A interação da $\mathrm{HbGp}$ com surfactantes iônicos apresenta uma abordagem interessante, e de grande relevância interdisciplinar, uma vez que os surfactantes são largamente empregados em bioquímica e biotecnologia para a solubilização proteíca, purificação, caracterização e determinação de estrutura de algumas proteínas.

Estudos em nosso grupo sobre a interação entre $\mathrm{HbGp}$ e surfactantes iônicos foram desenvolvidos para avaliar os sítios de contato iônico na superfície da proteína bem como o mecanismo de desnovelamento, a dissociação oligomérica e o conseqüente processo de autoxidação da HbGp [70,71]. Neste trabalho os surfactantes aniônico dodecilsulfato de sódio (SDS) e catônico cloreto de cetiltrimetilamonio (Fig. 7, CTAC) foram utilizados com o objetivo de entender melhor a relação estrutura/função da proteína. 


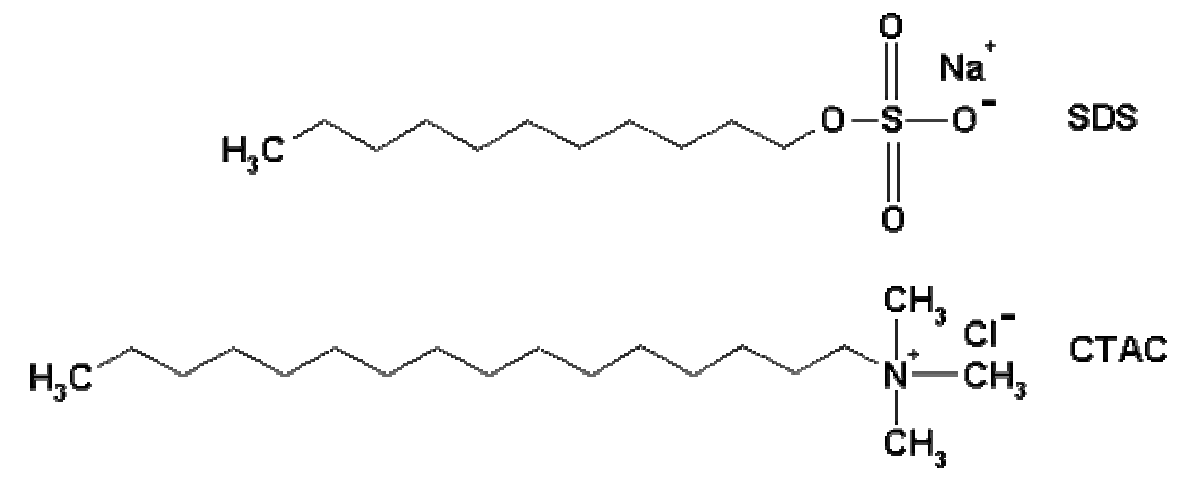

Figura 7: Estrutura molecular dos surfactantes iônicos SDS e CTAC.

Para saber mais sobre a estrutura oligomérica da HbGp e sua interação com surfactantes iônicos a técnica de MALDI-TOF-MS tem sido uma ferramenta interessante e muito útil [72-74].

\subsection{Dessorção/lonização por Laser Auxiliada por Matriz (MALDI-TOF-MS)}

A espectrometria de dessorção/ ionização por laser auxiliada por matriz (MALDI- matrix-assisted laser desorption/ionization) é um método de ionização que mostra grande potencial para obter massas moleculares exatas de biomoléculas [75]. Tem sido muito utilizada na caracterização de diferentes isoformas de algumas proteínas. É uma técnica de ionização branda e pode tolerar níveis relativamente altos de contaminantes que estão frequentemente presentes nas amostras, tais como sais e tampões, quando comparado com outras técnicas [76,77]

$\mathrm{Na}$ ionização do tipo MALDI, a amostra é misturada à uma solução supersaturada de matriz orgânica, a qual absorve fortemente a radiação eletromagnética em um determinado comprimento de onda. A solução resultante dessa mistura é então aplicada a uma placa metálica de MALDI (volumes da ordem de microlitros). Após alguns minutos o solvente evapora e ocorre a cristalização da amostra juntamente com o excesso de matriz. A placa é então transferida para dentro do espectrômetro e o cristal formado bombardeado por um feixe de laser de alta potência com comprimento de onda correspondente ao 
máximo de absorção da matriz. Essa energia é absorvida em grande parte pela matriz, a qual está em excesso na mistura com a amostra, e transferida de maneira branda para a amostra, de modo que ocorre a sublimação do analito e da matriz, resultando em íons na fase gasosa que seguirão para o analisador de massas.

Os analisadores do tipo TOF (Time-of-Flight) são os mais empregados em associação com MALDI e, em princípio, os mais simples. Eles baseiam-se na separação dos íons de diferentes razões $\mathrm{m} / \mathrm{z}$, porém, com a mesma energia cinética. Após desorvidos da matriz, os íons são acelerados em direção ao detector através de um tubo de vôo, mantido sob alto vácuo, por meio da aplicação de uma diferença de potencial alta (na faixa de 15-30 kV). Assim, o tempo necessário para atingir o detector é proporcional a tensão aplicada e a relação $\mathrm{m} / \mathrm{z}$ dos íons. Íons mais pesados irão se deslocar mais lentamente aparecendo no espectro de massas em tempos longos. 


\section{2 - Objetivos}

Estudar os produtos de fotooxidação do Dipiridamol com o intuito de tentar elucidar o mecanismo fotoquímico em acetonitrila e meio aquoso ácido, na presença e na ausência de um fotosensililizador ou uma fonte química geradora de oxigênio singlete. Investigar os intermediários e produtos da reação fotoquímica através de técnicas espectroscópicas, UV-Vis, emissão de fluorescência, HPLC e EM.

Avaliar o comportamento do antioxidante Dipiridamol como supressor de oxigênio singlete, utilizando a técnica de laser flash fotólise.

Relacionar os dados fotoquímicos com os eletroquímicos, visto que toda eletroquímica do dipiridamol já é bastante conhecida.

Cracterização das subunidades da hemoglobina extracelular gigante de Glossoscolex paulistus. 


\section{3-Materiais e Métodos}

\section{1- Análises de supressão de oxigênio singlete}

O azul de Metileno (AM) foi obtido da Merck Co. (Darmstadt, Germany). A solução foi preparada na concentração de $50 \mu \mathrm{M}$. Soluções estoque de DIP, RA47 e RA25 foram preparadas em acetonitrila $(40 \mu \mathrm{M}, 22 \mu \mathrm{M}$ e $39 \mu \mathrm{M}$, respectivamente) e em meio aquoso ácido deuterado $\mathrm{pH}=3,0(4 \mathrm{mM}, 4,9 \mathrm{mM}$ e $10,9 \mathrm{mM}$, respectivamente).

Os experimentos de supressão foram realizados pela adição de alíquotas (100-200 $\mu \mathrm{L})$ da solução estoque de DIP, RA47 e RA25 diretamente na cubeta contendo $2 \mathrm{~mL}$ de $\mathrm{AM}(50 \mu \mathrm{M})$ em acetonitrila e meio aquoso ácido deuterado. As concentrações do supressor foram na faixa de 0-40 $\mu \mathrm{M}$ em acetonitrila e 0$800 \mu \mathrm{M}$ em solução ácida deuterada. O esquema do experimento está apresentado na Figura 8.

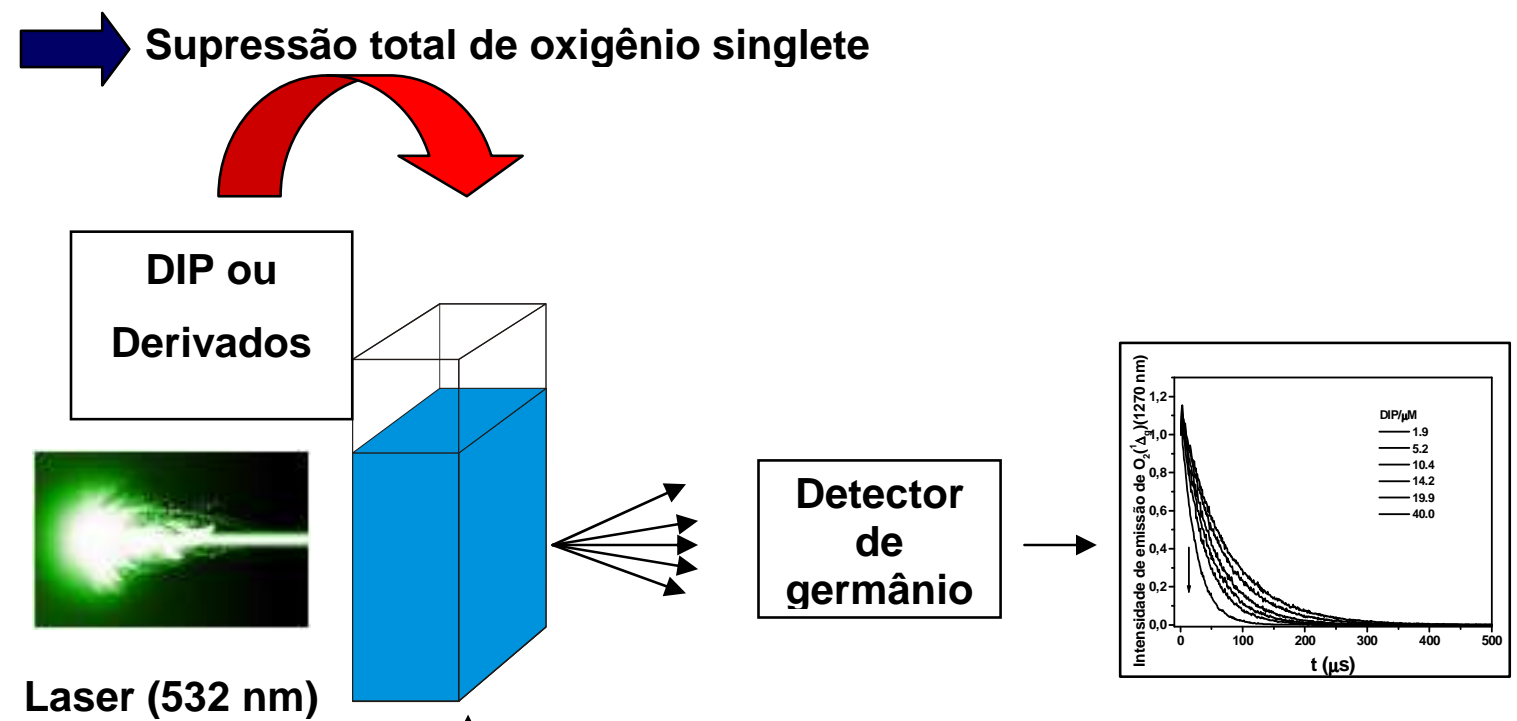

Laser (532 nm)

Azul de Metileno $(50 \mu \mathrm{M})$

$A C N$ ou $D_{2} \mathrm{O}$ ácido

$$
\begin{aligned}
& \mathrm{AM}+h v \longrightarrow{ }^{1} \mathrm{AM}^{*} \longrightarrow{ }^{3} \mathrm{AM}^{*} \\
& { }^{3} \mathrm{AM}^{*}+\mathrm{O}_{2}\left({ }^{3} \Sigma_{\mathrm{g}}{ }^{-}\right) \longrightarrow \mathrm{AM}+\mathrm{O}_{2}\left({ }^{1} \Delta_{\mathrm{g}}\right) \quad \mathrm{AM}-\phi_{\Delta} \sim 0.5
\end{aligned}
$$

Figura 8: Esquema do procedimento realizado na supressão de oxigênio singlete. 
A medida de emissão monomolecular requer instrumentos sensíveis à região do infravermelho próximo entre 800 a $1700 \mathrm{~nm}$. Os dados foram obtidos com um sistema desenvolvido em colaboração com a Edinburgh Instruments (Livingston, Reino Unido), composto de um laser Nd:YAG (Spectron Laser System, Warwickishire, UK) operando em 532 nm no caso do azul de metileno, emitindo pulsos com potência de $\sim 5 \mathrm{~mJ} /$ pulso e duração de $\sim 5 \mathrm{~ns}$. O sistema contem ainda um detector fotodiodo de germânio (Ge PIN, modelo EI-L, originalmente da empresa North Coast Scientific Co., Santa Rosa, CA) resfriado por nitrogênio líquido; uma fonte de tensão bias (modelo PS-1) que fornece uma tensão de $\pm 12 \mathrm{~V}$ d. c. para o detector; um filtro muon (modelo MF-1) e uma câmera escura. O sinal do detector de germânio foi processado por um amplificador (Lock-in Amplifier, Benthan) e os dados foram adquiridos pelo programa F-900 versão 6.22 (Edinburgh Analytical Instruments, Livingston, UK). Para realizar o experimento o detector de Ge é preenchido com $\mathrm{N}_{2}$ líquido, deixando-o equilibrar por 2 horas.

A fotomultiplicadora é composta por um tubo fotomultiplicador (R5509) adquirido da Hamamatsu Photoniks KK (Shizuoka, Japão) sensível à região do infravermelho (800-1400) a qual é refrigerada a $-80^{\circ} \mathrm{C}$ por meio de um sistema de refrigeração por nitrogênio líquido (S600 PHOTOCOOL ${ }^{\mathrm{TM}}$, PC176TSCE005 cooler, Products for Research Inc., MA). Este sistema está conectado a uma fonte de alta tensão (High Voltage DC Power Supply Model C3360, Hamamatsu Ohotoniks KK, Shizuoka, Japão) e um monocromador capaz de varrer as regiões do UV, visível e infravermelho (M300, Edinburgh Analytical Instruments, UK). A luz passa no monocromador por grades de difração que direcionam comprimentos de ondas específicos para a fotomultiplicadora. Este sistema permite realizar medidas de cinética de emissão em um determinado comprimento de onda, bem como a aquisição do espectro de emissão.

Estas análises foram realizadas em colaboração com o Prof. Dr. Maurício da Silva Baptista do Laboratório de cinética rápida e fototermia do Departamento de Bioquímica do Instituto de Química-USP, em São Paulo. 


\section{2- Cálculo da constante de supressão química $\left(\mathbf{k}_{\mathbf{r}}\right)$}

Para o cálculo da constante de supressão química $\mathrm{k}_{\mathrm{r}}$ foi utilizado como padrão o composto 1,3-difenillisobenzofurano (DPBF) que é bastante usado na literatura como aceptor de $\mathrm{O}_{2}\left({ }^{1} \Delta_{\mathrm{g}}\right)$ (supressor químico, $\phi_{\mathrm{ox}}=0,52$ ). DPBF é facilmente oxidado por $\mathrm{O}_{2}\left({ }^{1} \Delta_{\mathrm{g}}\right)$ em sistemas onde $\mathrm{O}_{2}\left({ }^{1} \Delta_{\mathrm{g}}\right)$ é produzido por reações fotossensibilizadas [15]. A constante de supressão de $\mathrm{O}_{2}\left({ }^{1} \Delta_{\mathrm{g}}\right)$ pelo DPBF é $\mathrm{k}_{\mathrm{rR}}=1 \times 10^{9} \mathrm{M}^{-1} \mathrm{~s}^{-1}$ [78]. Soluções de DPBF, DIP e derivados $100 \mu \mathrm{M}$ foram preparadas adicionando $10 \mu \mathrm{M}$ de azul de metileno como fotosensibilizador, sendo que a solução foi irradiada em $650 \mathrm{~nm}$, para excitação do fosensibilizador, com um diodo laser da LASERLine equipamentos, com 30 $\mathrm{mJ} / \mathrm{cm}^{2}$ de potência, diretamente na cubeta, e o desaparecimento do supressor foi monitorado através do decaimento da banda em $412 \mathrm{~nm}$ no espectro de absorção óptico, para o DIP , derivados e referência, como apresentado no esquema da figura 9.

\section{$\Longrightarrow$ Calculo da constante de reação química $\left(\mathrm{k}_{\mathrm{r}}\right)$}
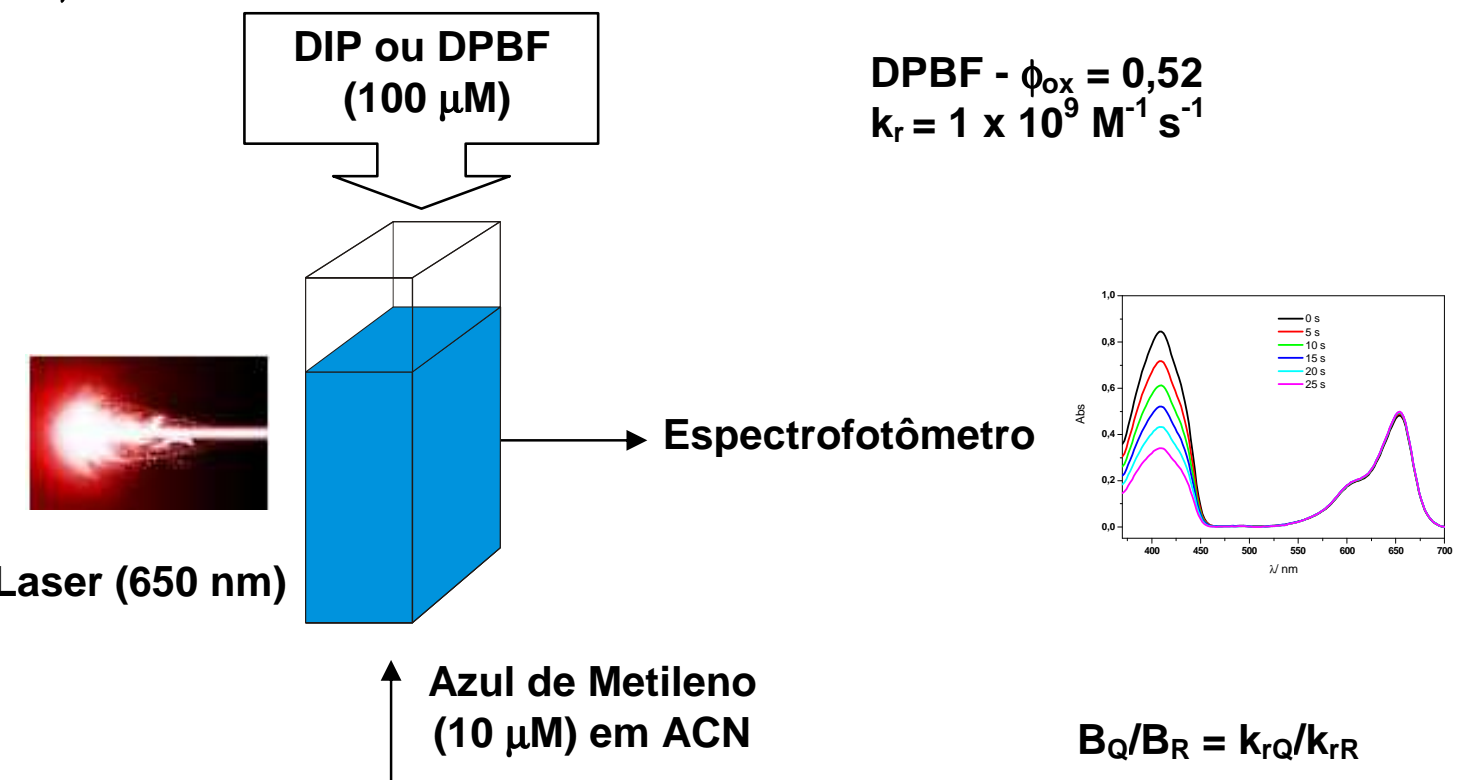

$$
B_{Q} / B_{R}=k_{r Q} / k_{r R}
$$

Figura 9: Esquema do procedimento realizado no cálculo da constante de supressão química de oxigênio singlete. 
A constante de supressão química foi determinada pelo método de Scully e Hoigné $[79,80]$, comparando as inclinações das curvas de cinética de primeiraordem, para o desaparecimento do supressor (Q, DIP e derivados, $100 \mu \mathrm{M}$ ) e referência $(R, D P B F)$ com o tempo. A razão dos coeficientes angulares do supressor $B_{Q}$ e da referência, $B_{R}$, define a relação das constantes de supressão (Eq. 1).

$$
\mathrm{B}_{\mathrm{Q}} / \mathrm{B}_{\mathrm{R}}=\mathrm{k}_{\mathrm{rQ}} / \mathrm{k}_{\mathrm{rR}}
$$

Os espectros de absorção foram obtidos, utilizando um espectrofotômetro Hitachi U-2000 e cubetas de quartzo de $1 \mathrm{~cm}$ de caminho óptico.

O rendimento quântico de oxidação do supressor (DIP e derivados) foi calculado seguindo a equação 2 :

$$
\phi_{\mathrm{Q}}=\phi_{\mathrm{R}} \times \mathrm{k}_{\mathrm{rQ}} / \mathrm{k}_{\mathrm{t}}
$$

onde $\phi_{Q}$ é o rendimento quântico de oxidação do supressor (DIP e derivados), $\phi_{R}$ é o rendimento quântico de oxidação da referência (DPBF), $k_{t}$ é a constante de supressão total obtida experimentalmente.

Estes experimentos foram realizados no Laboratório de Cinética Rápida e Fototermia em colaboração com o Prof. Dr. Maurício Baptista da Silva e com o pós-Doutorando Divinomar Severino.

\section{3 - Análises por Ressonância Paramagnética Eletrônica (EPR)}

Para as análises por EPR foram preparadas soluções de DIP e 2,2-6,6tetrametilpiperidino-1-N-oxil (TEMPO, obtido da Aldrich) 0,6 mM.

Foi utilizado um equipamento da Bruker ESP300e operando na Banda-X $(\sim 9,46 \mathrm{GHz})$, com cavidade ótica da Bruker (ER41040R) e Frequencímetro HP 53152A.

Para as fotólises foi utilizado um laser pulsado Nd:YAG, Continuum Surelite OPO II, com pulsos de $8 \mathrm{~ns}$ e potência $\sim 15 \mathrm{~mJ} / \mathrm{cm}^{2}$, operando em 440 $\mathrm{nm}$.

Experimentos realizados em colaboração com o Prof. Dr. Daniel R. Cardoso, do Instituto de Química de São Carlos, Universidade de São Paulo. 


\section{4- Fotooxidação do DIP na presença de oxigênio-18.}

Soluções de DIP 0,5 mM em acetonitrila e meio aquoso ácido foram preparadas, sendo que na solução ácida foi acrescentado $100 \mu \mathrm{m}$ de azul de metileno. Estas soluções foram colocadas em balões de fundo redondo com uma barra magnética para agitação, em seguida o balão foi resfriado com nitrogênio líquido e com uma bomba de sucção, o ar foi aspirado. Esse procedimento foi repetido 5 vezes. A reação foi resfriada com banho de gelo e irradiada com uma lâmpada de $500 \mathrm{~W}$ sob pressão de 1,4 bar de ${ }^{18} \mathrm{O}_{2}$ por 3 e $6 \mathrm{~h}$, respectivamente [24].

\section{5- Oxidação do DIP na presença de $\mathrm{DHPNO}_{2}$}

Uma solução de DIP $0,5 \mathrm{mM}$ em meio aquoso ácido deuterado foram incubadas com $\mathrm{DHPNO}_{2} 5 \mathrm{mM}$. O sistema foi aquecido em banho termostatizado a $37^{\circ} \mathrm{C}$ por duas horas.

\section{6- Fotooxidação do Dipiridamol em acetonitrila e meio aquoso ácido}

Soluções de DIP 0,5 mM (10 mL) em meio aquoso ácido $\mathrm{pH}=3,0$, com $100 \mu \mathrm{M}$ de azul de metileno como fotossensibilizador e em acetonitrila foram preparadas. Estas soluções foram irradiadas com uma lâmpada OSRAM HWL E40 de $500 \mathrm{~W}$ de potência, em banho de gelo, sendo que de hora em hora foram retiradas alíquotas de $400 \mu \mathrm{L}$, e analisadas por absorção óptica e HPLC, para acompanhar a cinética de decomposição. Para a retirada do azul de metileno foi utilizada uma resina de troca iônica, Cellex-CM (cátion exchange cellulose) da BIO-RAD (Richimond, Califórnia).

Soluções de DIP $0,25 \mathrm{mM}$ e $0,5 \mathrm{mM}$ em acetonitrila foram preparadas e desoxigenadas num ciclo de congelamento - vácuo - descongelamento, num sistema contendo um balão acoplado a uma cubeta de $1 \mathrm{~cm}$ de caminho ótico, utilizando-se nitrogênio líquido como congelante, para assegurar a eliminação do 
oxigênio, evitando a reação do DIP com o oxigênio. Uma bomba de vácuo Edwards de duplo estágio $\mathrm{N}^{\circ} 8$ foi utilizada para fazer o vácuo, o qual foi medido por um aparelho da Savant Instruments, INC. Model VG-5, mantendo a pressão do vácuo em $10^{-3}$ Torr. Esta solução foi irradiada por um período de $6 \mathrm{~h}$ em banho de gelo, para evitar o aquecimento proveniente da lâmpada OSRAM HWL E40 de 500 W de potência, que foi utilizada como fonte de luz. A solução de DIP $0,25 \mathrm{mM}$ em acetonitrila após irradiada por $6 \mathrm{~h}$, foi deixada em temperatura ambiente no sistema fechado e, depois de $24 \mathrm{~h}$, o espectro de absorção foi novamente medido, e em seguida esta solução foi analisada por HPLC.

Os espectros de absorção foram obtidos, utilizando um espectrofotômetro UV-1601PC Shimadzu, sendo monitorados na região do visível utilizando cubetas de quartzo com as quatro faces polidas de $1 \mathrm{~cm}$ de caminho óptico e cubetas de quartzo (acopladas ao sistema de congelamento) de $1 \mathrm{~mm}$ de caminho óptico.

Os compostos foram analisados por um Cromatógrafo Shimadzu com 2 bombas LC-10AD, detector SPD-M10A VP UV-Vís e sistema de comunicação detector/computador, controladas por Communications Bus Module-CBM-10A", utilizando uma coluna analítica C18 Luna ( $250 \times 4,6 \mathrm{~mm}, 5 \mu \mathrm{m}$ - Phenomenex), sendo utilizada como fase móvel ácido fórmico $0,1 \% / \mathrm{ACN}$ num gradiente de eluição de 5-70\% de acetonitrila em 10 e 30 min, respectivamente. $\mathrm{Na}$ análise da fotodegradação do DIP na ausência de oxigênio foi utilizado o seguinte gradiente de eluição: tampão acetato $40 \mathrm{mM} \mathrm{pH}=4,0 / \mathrm{MeOH}, 5-95 \%$ de $\mathrm{MeOH}$ em 20 $\min$, de $20-35 \min 95 \%$ de $\mathrm{MeOH}$, de $35-45 \min 95-5 \%$ de $\mathrm{MeOH}$.

\section{7- Cromatografia Líquida e Espectrometria de Massas (LC-EM/EM)}

As análises cromatográficas foram realizadas utilizando uma coluna C18 Luna (250 x 4,6 mm, $5 \mu \mathrm{m}$ - Phenomenex) como fase estacionária, e como fase móvel uma solução de ácido fórmico $0,1 \% / \mathrm{ACN}$, com gradiente de eluição de 5$70 \%$ de ACN em 30 min. Foi utilizado um HPLC da Shimadzu com fluxo de $1 \mathrm{~mL}$ /min. 
Dados também foram coletados no LC/ESI-EM/EM com um fluxo de $70 \mu \mathrm{l}$ $\min ^{-1}$, do cromatógrafo para dentro do espectrômetro. As análises de ionização por electrospray (ESI) e decomposição ativada por colisão (CAD) foram feitas em um triplo-quadrupolo Quattroll com uma fonte de ionização de Z-spray da Micromass. As temperaturas de dessolvatação e da fonte de ionização foram de 120 e $150^{\circ} \mathrm{C}$, respectivamente. $\mathrm{N}_{2}$ foi utilizado como gás de nebulização $\left(20 \mathrm{I} \mathrm{h}^{-1}\right)$ e gás de dessolvatação $\left(350 / \mathrm{h}^{-1}\right)$. As voltagens aplicadas foram de 3,6 $\mathrm{kV}$ para o capilar, 20 ou $40 \mathrm{~V}$ para o cone da amostra e $8 \mathrm{~V}$ para o cone extrator. Os experimentos de espectrometria de massas Tandem, foram realizados adicionando Ar na célula de colisão para produzir uma pressão de $2 \times 10^{-3} \mathrm{mbar}$ para o CAD. A energia de colisão usada para a decomposição dos íons gerados dos compostos $[\mathrm{M}+\mathrm{H}]^{+}$foi de 30 ou $70 \mathrm{eV}$ [46]. As análises por espectrometria de massas da reação de fotooxidação foram realizadas em colaboração com o Prof. Dr. Paolo Di Mascio e a doutoranda Fernanda M. Prado do Laboratório de Estudo de Lesões em Biomoléculas do Departamento de Bioquímica, Instituto de Química, USP, São Paulo.

\section{8- Obtenção e purificação da hemoglobina de Glossoscolex paulistus}

Os animais foram lavados em água corrente, anestesiados com éter e foi realizado um corte no dorso de cada espécime. A hemolinfa foi extraída com pipetas de Pasteur em presença de anti-coagulante (citrato de sódio $0,1 \mathrm{mM}$ ) e armazenada em tubos de eppendorf. A primeira etapa de purificação foi realizada pela centrifugação da hemolinfa a $2500 \mathrm{rpm}$ por 15 min para eliminar impurezas sólidas, o sobrenadante foi retirado para diálise contra tampão tris$\mathrm{HCl}$, pH 7,0 por uma noite a $4^{\circ} \mathrm{C}$. Após a diálise uma ultracentrifugação da proteína foi realizada, em uma ultracentrífuga SORVAL ULTRA PRO 80 a 25000 rpm por $3 \mathrm{~h}$ a $4^{\circ} \mathrm{C}$, sendo que o precipitado foi ressuspendido em tampão tris$\mathrm{HCl} 0,1 \mathrm{M}$. Esta solução foi purificada numa etapa final da cromatografia de exclusão em coluna de gel Sephadex G-200 (100 x 0,9 cm) equilibrada com tampão TRIS-HCl $100 \mathrm{mM}, \mathrm{pH} 7,0 \mathrm{com} \mathrm{0,1} \mathrm{mM} \mathrm{EDTA.} \mathrm{As} \mathrm{alíquotas} \mathrm{foram}$ 
coletadas por meio de um coletor regulado para um volume de 1,0 mL/tubo e a oxihemoglobina íntegra foi estocada a $4^{\circ} \mathrm{C}$.

A concentração final da proteína na solução estoque foi de $15-25 \mathrm{mg} / \mathrm{mL}$ em tampão TRIS-HCl 0,1M. Esta solução foi extensivamente dialisada para redução do sal do tampão para $5 \mathrm{mM}$ seguida pela diluição para obter uma concentração de proteína de $1-3 \mathrm{mg} / \mathrm{mL}$ para utilização nos experimentos de MALDI-TOF.

O monômero foi obtido através da filtração da solução estoque em coluna de Sephadex G-200 (100 x 0,9 cm) equilibrada Tris-HCl 0,1 M, em pH 9,0 com $0,1 \mathrm{mM}$ EDTA.

As concentrações foram determinadas utilizando um espectrofotômetro Hitachi U2000.

Para as análises por MALDI-TOF-MS foi utilizado como matriz o ácido 3,5-Dimetoxi-4-hidroxi-cinâmico (ácido sinápico), obtido da Aldrich. 2mercaptoetanol, citocromo $C$ (de coração bovino) e albumina de soro bovino (BSA) foram obtidos da Sigma, usados, respectivamente, como redutor de pontes disulfeto e como padrão para calibrar o equipamento.

A matriz solubilizada em $0,5 \%$ de ácido trifluoracético, 50\% acetonitrila:água foi adicionada as amostras da HbGp íntegra e monômero d nas proporções de 1:1 e 1:10 (v/v), respectivamente. Um microlitro destas misturas foram depositadas nos spots da placa do MALDI. Após a cristalização (secagem das amostras) a placa foi inserida no espectrômetro. As análises foram realizadas no modo positivo em um espectrômetro de massas da marca Etthan MALDI-TOF (Amersham Bioscience) usando uma voltagem de aceleração de 20 $\mathrm{kV}$. As amostras foram analisadas em duplicata e cada spot foi analisado também em duplicata. Os espectros foram acumulados com aproximadamente 200 disparos do laser sendo analisados pelo programa Ettan Evaluation (Amersham Bioscience). 


\section{4- Resultados e discussões}

\section{1- Supressão de oxigênio singlete pelo DIP e derivados}

O DIP e seus derivados (Fig. 10) são caracterizados por um anel aromático central o qual contêm um sistema de elétrons $\pi$ delocalizados, o que faz com que esta classe de compostos, de forma similar a vários outros compostos contendo nitrogênio, seja geralmente de bons doadores e/ou aceptores de elétrons. O DIP e seus derivados possuem transições $\pi \rightarrow \pi^{*}$ responsáveis pelas bandas de absorção em torno de 400 e 290 nm, apresentadas na figura 10A, e uma intensa emissão de fluorescência em torno de $500 \mathrm{~nm}$ em meio aquosos. A diferença entre eles está nos substiuintes das posições 2, 4, 6 e 8 do anel pirimido-pirimidino. Para o derivado RA 25 as bandas de absorção são deslocadas para menores comprimentos de onda, como mostra a figura $10 \mathrm{~A}$.

Esta classe de compostos apresenta uma baixa solubilidade em solução neutra $(\mathrm{pH} 7,0)$ e uma solubilidade acentuada em soluções ácidas. No entanto, estes compostos que possuem em seu núcleo central o anel pirimido-pirimidino apresentam uma diminuição na intensidade de fluorescência devido a protonação do anel heteroaromático [39].

A figura 10B apresenta o espectro de absorção do fotossensibilizador azul de metileno (AM), o qual é caracterizado por duas bandas em torno de $609 \mathrm{e}$ $654 \mathrm{~nm}$, relacionadas ao dímero e ao monômero, respectivamente, e também apresenta uma banda de absorção em torno de $290 \mathrm{~nm}$ [81]. O azul de metileno (AM, Fig. 5) é um fotossensibilizador muito conhecido e utilizado como fonte de oxigênio singlete $\left(\phi_{\Delta} \sim 0,5\right)$ [81], e foi escolhido para ser utilizado neste trabalho. 

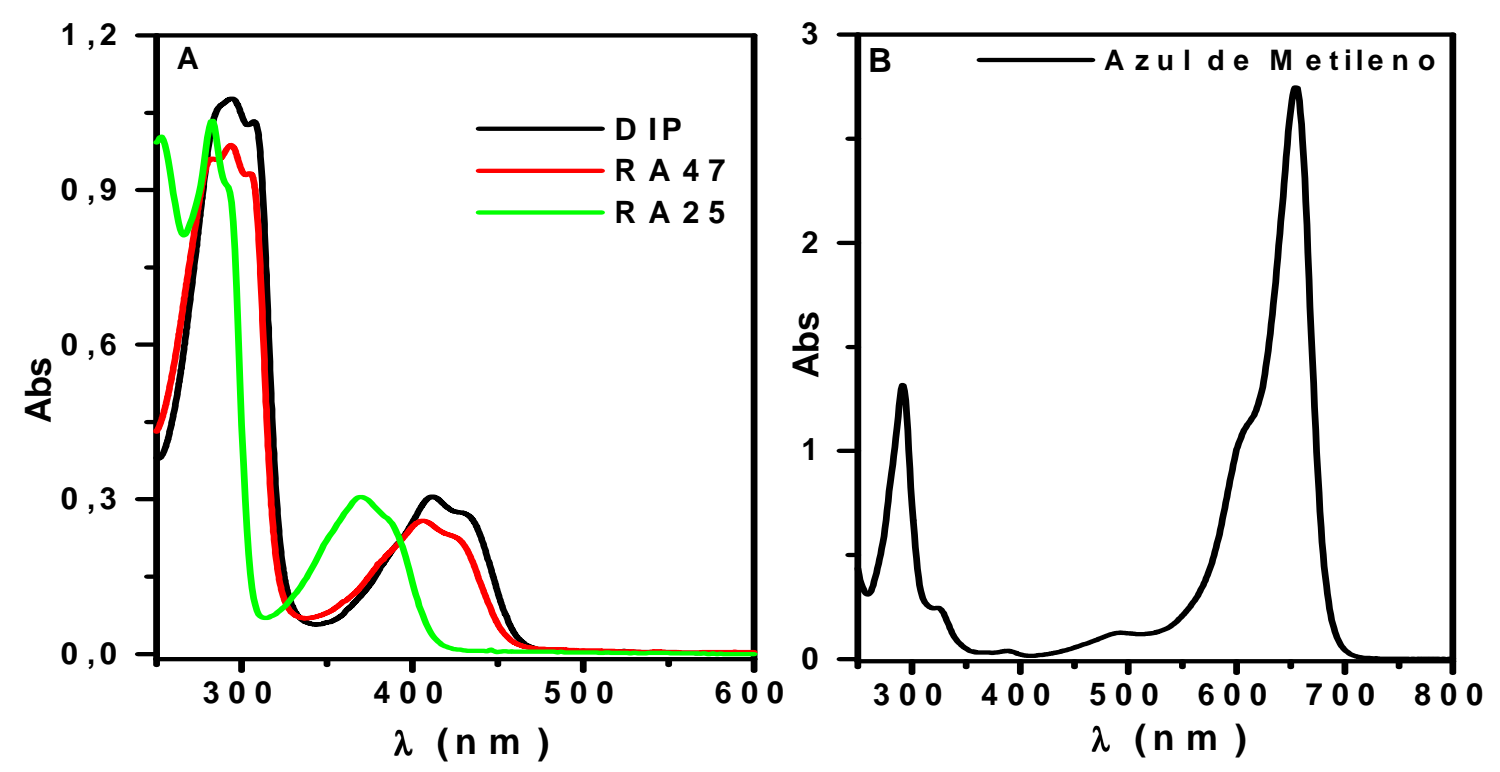

Figura 10: Espectros de absorção óptica em acetonitrila do (A) DIP, RA 47, RA25 e (B) azul de metileno (AM).

Estudos eletroquímicos do DIP em acetonitrila e meio aquoso ácido foram relatados previamente [34,35]. Em ACN a eletrooxidação do DIP é caracterizada por duas ondas voltamétricas reversíveis, correspondendo a dois processos consecutivos de um elétron. No primeiro processo ocorre a formação do radical cátion DIP*+ $\left(E_{1 / 2}=0,30 \mathrm{~V}\right.$ vs $\left.S C E\right)$, e no segundo processo um dicátion $\left(E_{1 / 2}=\right.$ 0,60V vs SCE) [34]. Em meio aquoso ácido, onde o DIP está protonado, somente uma onda de oxidação é observada envolvendo a transferência direta de dois elétrons $\left(E_{1 / 2}=0,80 \mathrm{~V}\right.$ vs SCE, Tabela 1$)$ [35]. Cálculos teóricos da estrutura do DIP mostraram que a protonação da molécula no nitrogênio N1 ou (N5) do anel central é energeticamente favorável, entretando a protonação simultânea nos dois sítios não ocorre devido a que a energia necessária para estabilizar a estrutura do DIP duplamente protonada é extremamente alta [39].

O radical cátion formado pela oxidação de um elétron está associado à remoção do elétron dos nitrogênios das etanolaminas substituintes do anel pirimido-pirimidino, sendo que o elétron é delocalizado para 0 anel 
hetoroaromático o qual é observado por análises de EPR [33]. A remoção do segundo elétron também parece estar associada à perda da densidade eletrônica destes mesmos nitrogênios, como já relatado anteriormente [39].

O radical cátion não é observado em meio aquoso ácido, provavelmente devido a uma maior dificuldade para remover o elétron do DIP protonado. O que está de acordo com um aumento significativo no potencial relacionado a oxidação por dois elétrons, quando comparado com meio orgânico acetonitrila.

O DIP e o derivado RA47 apresentam comportamento eletroquímico similar, no entanto, para o derivado RA25 a oxidação é um processo mais difícil. Isto pode ser atribuído a baixa estabilidade das espécies oxidadas, no caso do RA25, devido ao efeito dos substituintes. Em acetonitrila o DIP é mais fácil de ser oxidado quando comparado com o meio aquoso ácido, o que está de acordo com os dados de supressão de $\mathrm{O}_{2}\left({ }^{1} \Delta_{\mathrm{g}}\right)$. Para o RA 25 , os dados de supressão também estão de acordo com os dados eletroquímicos, visto que este derivado é mais difícil de ser oxidado.

A emissão monomolecular do $\mathrm{O}_{2}\left({ }^{1} \Delta_{\mathrm{g}}\right.$ ) em $1270 \mathrm{~nm}$ (reação 6) é uma evidência direta da geração de $\mathrm{O}_{2}\left({ }^{1} \Delta_{\mathrm{g}}\right)$ produzido pelo fotossensibilizador $\mathrm{AM}$, excitado em $532 \mathrm{~nm}$.

A supressão de oxigênio singlete produzido por AM foi monitorada em acetonitrila e meio aquoso ácido deuterado, utilizando DIP, RA47 e RA25 como supressores. A figura 11 apresenta as curvas de emissão de $\mathrm{O}_{2}\left({ }^{1} \Delta_{g}\right)$ obtidas na presença de diferentes concentrações de DIP em acetonitrila, sendo que os tempos de vida do $\mathrm{O}_{2}\left({ }^{1} \Delta_{\mathrm{g}}\right)$ foram obtidos pelo ajuste exponencial das curvas. 


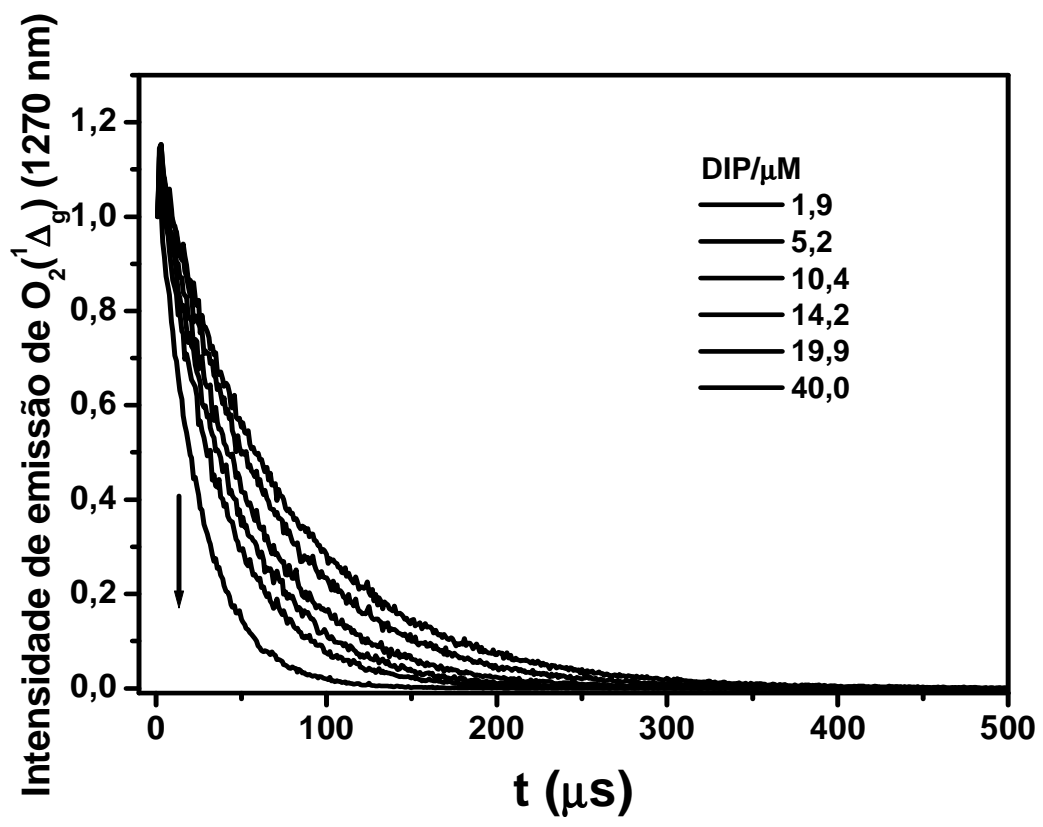

Figura 11: Curvas de emissão de $\mathrm{O}_{2}\left({ }^{1} \Delta_{\mathrm{g}}\right)$ produzido pelo fotossensibilizador AM em algumas concentrações de DIP em ACN.

Através do gráfico de Stern-Volmer obtém-se as constantes de desativação total $\left(\mathrm{k}_{\mathrm{t}}\right)$ do $\mathrm{O}_{2}\left({ }^{1} \Delta_{\mathrm{g}}\right)$. A figura 12 mostra os gráficos obtidos para o DIP, RA 25 e RA 47 em acetonitrila e meio aquoso ácido deuterado, respectivamente. Pelo ajuste linear dos pontos experimentais dos gráficos de $\tau_{0} /$ $\tau$ versus [Q], obtém-se a constante de supressão de Stern-Volmer, $\mathrm{K}_{\mathrm{sv}}$ (Eq. 3), a qual é igual ao produto da constante de supressão bimolecular $\mathrm{k}_{\mathrm{q}}$ e $\tau_{0}$ (Eq. 4).

$$
\begin{gathered}
\tau_{0} / \tau=1+\mathrm{K}_{\mathrm{sv}}[\mathrm{Q}] \\
\mathrm{K}_{\mathrm{sv}}=\mathrm{k}_{\mathrm{q}} \tau_{0}
\end{gathered}
$$

Onde, $\tau_{0}$ e $\tau$ são os tempos de vida do $\mathrm{O}_{2}\left({ }^{1} \Delta_{g}\right)$ na ausência e na presença do supressor, e [Q] é a concentração do supressor. 

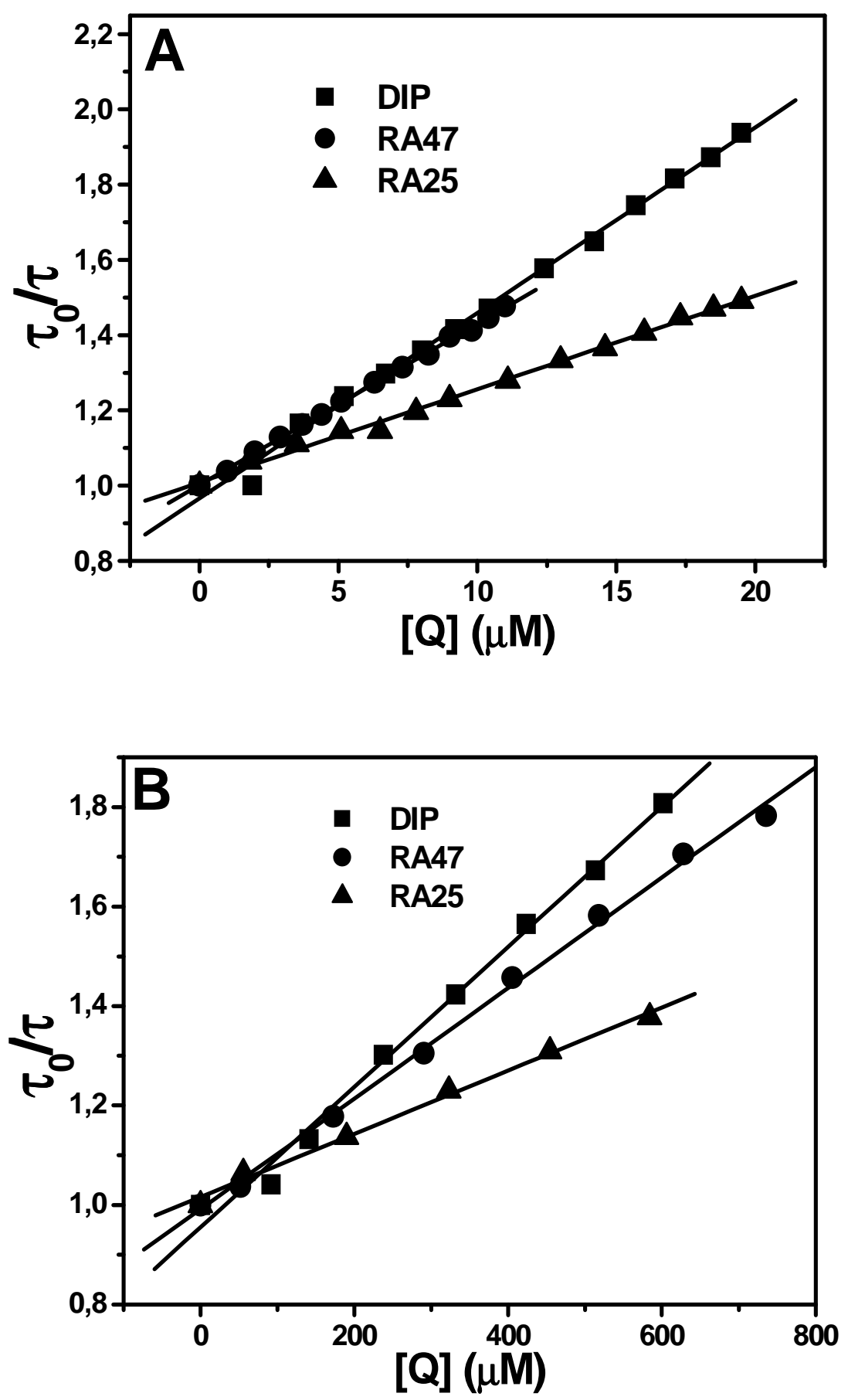

Figura 12: Curvas de Stern-Volmer para a supressão de $\mathrm{O}_{2}\left({ }^{1} \Delta_{g}\right)$ pelo DIP, RA47 e RA25 em (A) acetonitrila e (B) meio aquoso ácido deuterado.

O tempo de vida do $\mathrm{O}_{2}\left({ }^{1} \Delta_{\mathrm{g}}\right)$ em solução é fortemente dependente da natureza do solvente, sendo maior em meio deuterado [12]. O tempo de vida 
para o $\mathrm{O}_{2}\left({ }^{1} \Delta_{\mathrm{g}}\right)$ em $\mathrm{H}_{2} \mathrm{O}$ é $3,8 \mu$ s enquanto que em $\mathrm{D}_{2} \mathrm{O}$ aumenta para $62 \mu \mathrm{s}$. Em acetonitrila o tempo de vida do $\mathrm{O}_{2}\left({ }^{1} \Delta_{\mathrm{g}}\right)$ é de $62 \mu \mathrm{s}$, aumentando em acetonitrila deuterado nove vezes [82]. No entanto, a utilização deste solvente é limitada devido ao seu alto custo.

As constantes bimoleculares de supressão estimadas são apresentadas na Tabela 1. Sabendo que o limite difusional é de $1 \times 10^{10} \mathrm{~s}^{-1} \mathrm{M}^{-1}$, os valores das constantes encontrados em acetonitrila são um pouco abaixo do limite difusional, os quais são consistentes com um eficiente supressor de $\mathrm{O}_{2}\left({ }^{1} \Delta_{\mathrm{g}}\right)$.

Em meio aquoso ácido deuterado a constante de supressão bimolecular para o DIP e seus derivados possui valores $\sim 30$ vezes menores do que em ACN. Esta diferença está certamente relacionada ao fato de que a protonação do DIP e derivados envolve a ligação do próton com os nitrogênios do anel aromático. Para o RA25, uma molécula mais simples com substituintes menores (os grupos metilenoamina) e que não possui os grupos hidrofílicos hidroxilas, os valores das constantes de supressão são menores que as encontradas para o DIP e o RA47. Estes valores estão de acordo com os dados eletroquímicos, onde um maior potencial de oxidação foi obtido para o RA25 (Tabela 1, [34]).

Para o meio aquoso ácido deuterado há a possibilidade de que outros átomos de nitrogênio do RA25 sejam protonados, não apenas os nitrogênios do anel pirimido-pirimidino.

A Tabela 1 mostra os potenciais eletroquímicos para o DIP e derivados. $O$ RA25 apresenta o maior potencial eletroquímico e menor constante de supressão. O que está de acordo com o grau de atividade antioxidante desta classe de compostos, a qual possui a seguinte ordem DIP>RA47>RA25 [42], o que também está de acordo com dados reportados para outros compostos na literatura $[16,83]$. 
Tabela 1: Valores das constantes de velocidade de supressão física, potencial de meia onda e energia livre para o DIP e derivados nos solventes usados.

\begin{tabular}{|c|c|c|c|c|c|c|c|c|}
\hline \multirow[t]{2}{*}{ Supressor } & \multicolumn{3}{|c|}{$\begin{array}{c}\text { Solução } \mathrm{D}_{2} \mathrm{O} \text { ácida } \\
(\mathrm{pH}=3.0)\end{array}$} & \multicolumn{5}{|c|}{$\overline{A C N}$} \\
\hline & $\begin{array}{l}k_{t} 10^{-7} \\
M^{-1} s^{-1}\end{array}$ & $\mathrm{E}_{1 / 2} \mathrm{~V}^{\mathrm{a}}$ & $\begin{array}{c}\Delta \mathrm{G}_{\text {e.t. }} \\
\mathrm{eV}\end{array}$ & $\begin{array}{l}k_{t} 10^{-8} \\
M^{-1} s^{-1}\end{array}$ & $\begin{array}{c}\mathrm{E}_{1 / 2} \mathrm{~V}^{\mathrm{a}} \\
\text { Primeira } \\
\text { onda }\end{array}$ & $\begin{array}{c}\Delta \mathrm{G}_{\mathrm{e} . \mathrm{t}} \\
\mathrm{eV}\end{array}$ & $\begin{array}{c}\mathrm{E}_{1 / 2} \mathrm{~V}^{\mathrm{a}} \\
\text { Segunda } \\
\text { onda }\end{array}$ & $\begin{array}{c}\Delta \mathrm{G}_{\text {e.t. }} \\
\mathrm{eV}\end{array}$ \\
\hline$\overline{D I P}$ & 2,44 & $\overline{0,8}$ & 0,64 & 6,8 & 0,39 & 0,23 & 0,67 & 0,51 \\
\hline RA47 & 1,88 & ----- & ----- & 5,8 & 0,38 & 0,22 & 0,71 & 0,55 \\
\hline RA25 & 1,05 & ----- & ----- & 3,4 & 0,48 & 0,51 & 0,9 & 0,74 \\
\hline
\end{tabular}

a Potencial de oxidação vs $\mathrm{Ag} / \mathrm{Ag}^{+} 0.01 \mathrm{M} \mathrm{Ag}{ }^{+}$das referências 34 e 35 pela adição de $0,27 \mathrm{~V}$ vs SCE.

Como citado anteriormente (reação 10 e 11) o processo de supressão de $\mathrm{O}_{2}\left({ }^{1} \Delta_{\mathrm{g}}\right)$ está relacionado à constantes de supressão física e química. A supressão total é dada pela somatória dos dois processos $\left(k_{t}=k_{q}+k_{r}\right)$. O efeito do solvente também deve ser considerado, uma vez que pode alterar a importância relativa de cada um dos processos de desativação do $\mathrm{O}_{2}\left({ }^{1} \Delta_{g}\right)$ [15].

Para determinar se o mecanismo de supressão do $\mathrm{O}_{2}\left({ }^{1} \Delta_{g}\right)$ pelo DIP e derivados é um processo predominantemente físico ou químico, calculou-se a constante de reação química, para saber se a quantidade de produto formado é considerável.

\section{2- Cálculo da constante de supressão química $\left(\mathbf{k}_{\mathbf{r}}\right)$}

A constante de reação química para a supressão de $\mathrm{O}_{2}\left({ }^{1} \Delta_{\mathrm{g}}\right)$ pelo DIP e derivados em acetonitrila foi medida observando o decaimento no espectro de absorção em função do tempo com irradiações contínuas (Figura 13). DBPF (1,3- difenillisobenzofurano) foi utilizado como padrão (supressor químico, $\phi_{0 x}=$ 0,52, e $\left._{\mathrm{rR}}=1 \times 10^{9} \mathrm{M}^{-1} \mathrm{~s}^{-1}\right)[78]$. 


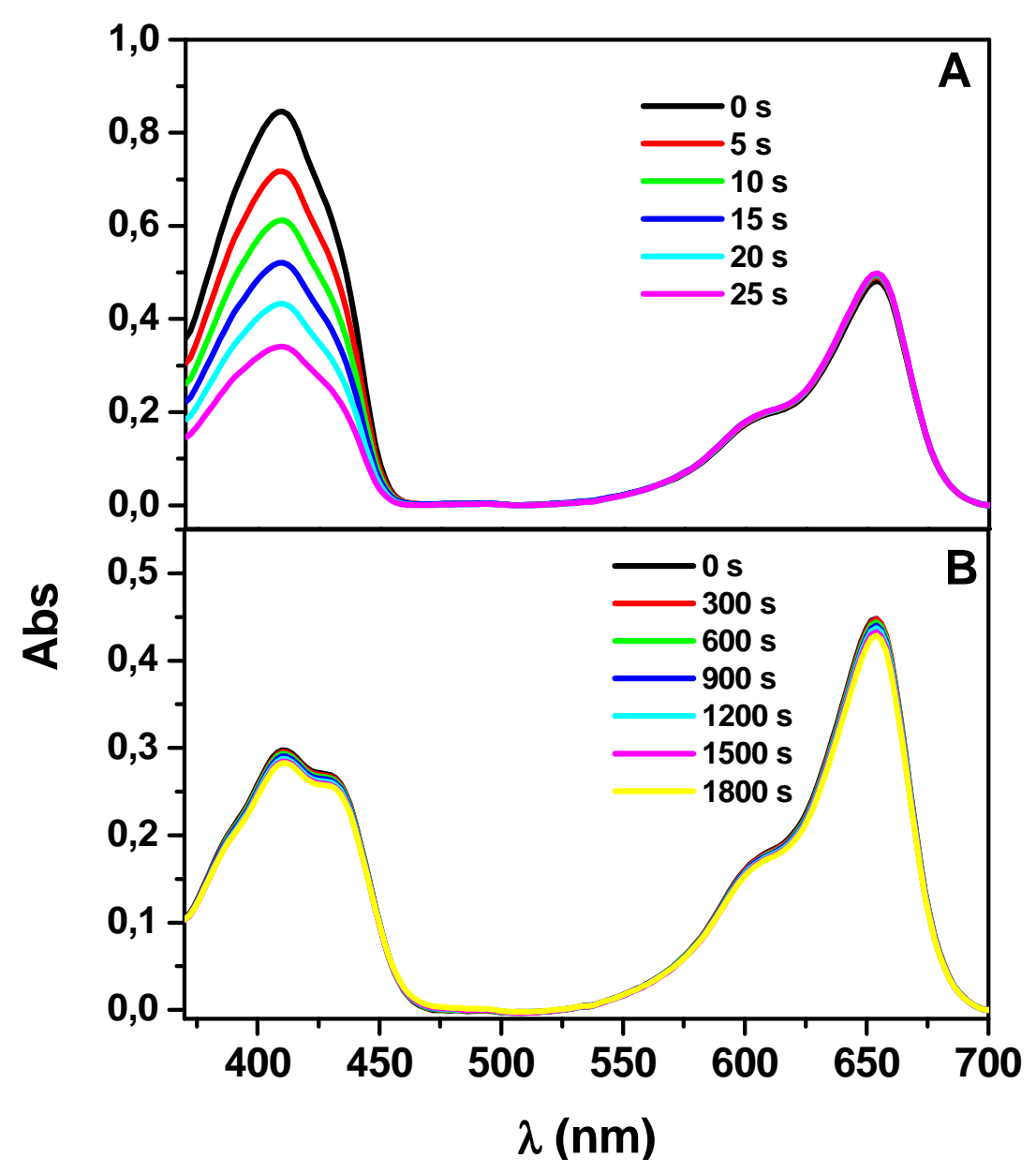

Figura 13: Espectro de absorção óptica em função do tempo de irradiação contínua, em acetonitrila (A) DPBF e (B) DIP, usando AM como fotossensibilizador, utilizando um laser no comprimento de onda de $650 \mathrm{~nm}$.

As curvas de cinéticas de primeira ordem para o consumo do padrão DPBF, do DIP e dos derivados em acetonitrila são apresentadas na figura $14 \mathrm{e}$ os valores obtidos para o $\mathrm{k}_{\mathrm{r}}$ e o rendimento quântico de oxidação são dados na Tabela 2.

Os valores de $\mathrm{k}_{\mathrm{r}}$ obtidos são bem menores do que os valores de $\mathrm{k}_{\mathrm{t}}$ levando à conclusão, desta forma, que a supressão de $\mathrm{O}_{2}\left({ }^{1} \Delta_{\mathrm{g}}\right)$ pelo DIP e derivados é predominantemente física (transferência de carga/energia) sob estas condições. 
É importante mencionar também que nenhuma mudança significativa é observada no espectro de absorção do DIP, confirmando a ausência do radical cátion no processo de supressão.

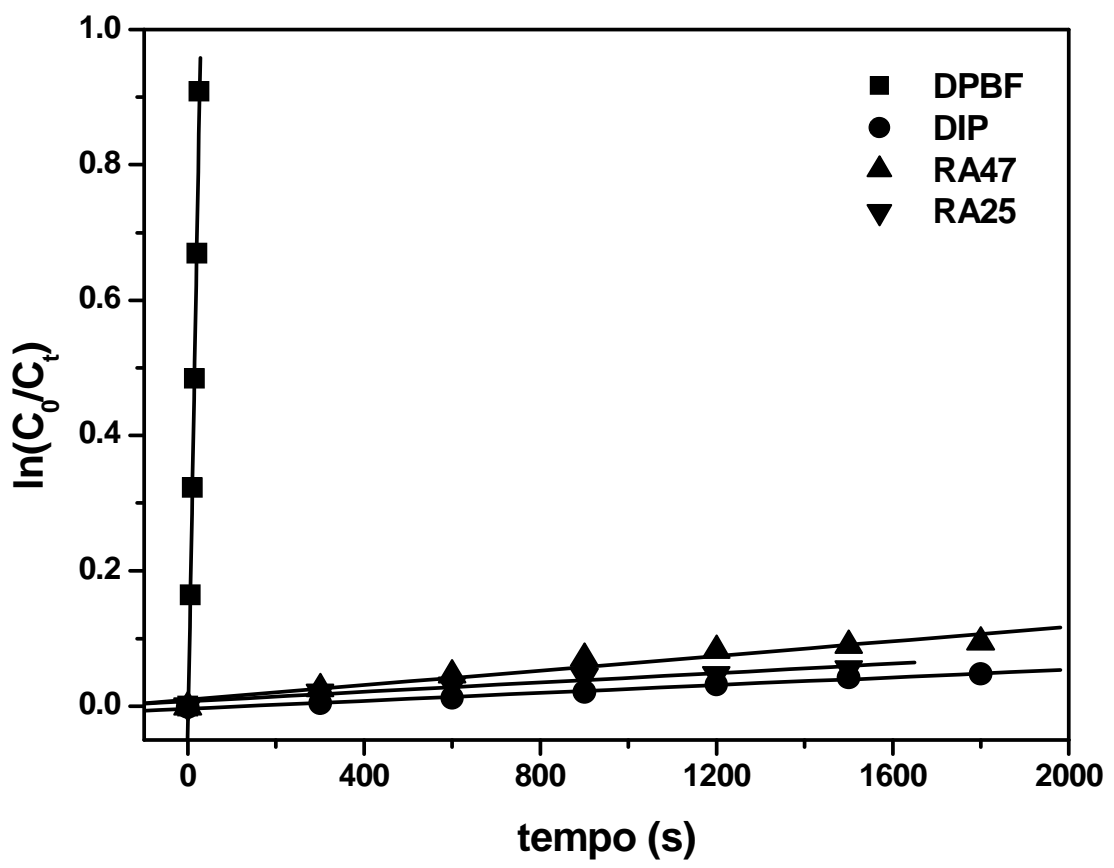

Figure 14: Curvas cinéticas de primeira-ordem para a fotooxidação do DIP, RA47, RA25 e do composto de referência (DPBF), determinadas a partir do espectro de absorção óptica, em acetonitrila usando AM como fotossensibilizador.

Tabela 2: Valores obtidos para as constantes de supressão química $\left(\mathrm{k}_{\mathrm{r}}\right)$ de $\mathrm{O}_{2}\left({ }^{1} \Delta_{\mathrm{g}}\right)$ e rendimento quântico de oxidação para o DIP e derivados RA47 e RA25 em acetonitrila.

\begin{tabular}{c|c|c}
\hline Supressor & $\mathrm{k}_{\mathrm{r}} \times 10^{-5} \mathrm{M}^{-1} \mathrm{~s}^{-1}$ & $\phi_{\text {ox }}$ \\
\hline DIP & 8,3 & 0,0006 \\
RA47 & 15,2 & 0,0014 \\
RA25 & 9,8 & 0,0015 \\
\hline
\end{tabular}




\section{3- Mecanismo de transferência de elétrons}

A via física envolve a interação do $\mathrm{O}_{2}\left({ }^{1} \Delta_{\mathrm{g}}\right)$ com um supressor que acelera sua conversão para o estado fundamental sem consumir $0^{\mathrm{O}_{2}}\left({ }^{1} \Delta_{\mathrm{g}}\right)$ ou formar produto. Existem dois mecanismos principais: transferência de energia e transferência de elétrons.

O mecanismo de transferência de elétrons tem sido correlacionado com a mudança de energia livre $(\Delta \mathrm{G})$ associada ao processo de completa transferência de elétrons, a qual pode ser calculada pela equação de Rehm-Weller [16,84, 85]:

$$
\Delta G^{0}{ }_{\text {e.t. }}=\left(E_{1 / 2}{ }^{\text {ox }}\left(Q / Q^{\bullet+}\right)-E_{1 / 2}{ }^{\text {red }}\left(O_{2} / O_{2}{ }^{\bullet-}\right)\right)-E_{0}\left({ }^{1} \Delta_{g}\right)-e^{2} / a \epsilon
$$

onde $\left(E_{1 / 2}{ }^{0 x}\left(Q / Q^{*+}\right)\right.$ é o potencial de oxidação de meia onda do supressor, $\mathrm{E}_{1 / 2}{ }^{\text {red }}\left(\mathrm{O}_{2} / \mathrm{O}_{2}{ }^{--}\right)=-0,82 \mathrm{~V}$ e $\mathrm{E}_{0}\left({ }^{1} \Delta_{\mathrm{g}}\right)=0,98 \mathrm{eV}$, a energia de excitação do $\mathrm{O}_{2}\left({ }^{1} \Delta_{\mathrm{g}}\right)$. Os potenciais redox foram obtidos das referências 34 e 35 e são convertidos para SCE em acetonitrila. O último termo na Eq. 5 é a energia de interação entre os íons formados após a transferência de elétrons com uma distância internuclear $\mathrm{a}=\mathrm{r}^{+}+\mathrm{r}^{-}$, onde $\mathrm{r}^{+}$é o raio molecular do supressor, para o DIP $\mathrm{r}^{+}=$ $8 \AA \hat{A}$, e $r^{-}$do aceptor de elétrons $\mathrm{O}_{2}$ é $1,73 \AA ̊$. O último termo da equação foi desprezado.

Os valores de $\Delta G_{\text {et }}$ (Tabela 1) foram calculados desta forma e os resultados são consistentes com a supressão física por transferência de cargas, formando um complexo. De acordo com os valores de $\Delta \mathrm{G}^{0}$ et o processo de transferência total de elétrons não é favorável.

Pode-se observar pelos valores da Tabela 1 que a medida que 0 potencial de oxidação aumenta, $O \Delta G^{0}$ et também aumenta e a constante de supressão diminui, levando à conclusão que o composto com maior potencial de oxidação é menos efetivo como supressor de oxigênio singlete, o que está de acordo com a atividade antioxidante que segue a seqüência DIP $\geq$ RA14>RA47>RA25 [41,42]. 
Experimentos de emissão de luz monomolecular característica do $\mathrm{O}_{2}\left({ }^{1} \Delta_{g}\right)$, gerado pelo DIP em clorofórmio e acetonitrila foram realizados e são apresentados na figura 15. Os valores obtidos para o rendimento quântico foram respectivamente, 0,021 e 0,008 pra clorofórmio e acetonitrila. Para comparação, foi utilizada a fenalenona como padrão $(\varphi=1,0$ em clorofórmio e $0,95 \mathrm{em}$ acetonitrila). Nossos resultados mostraram que o rendimento quântico de produção de $\mathrm{O}_{2}\left({ }^{1} \Delta_{g}\right)$ pelo DIP é muito baixo e não interfere na determinação da constante de supressão.

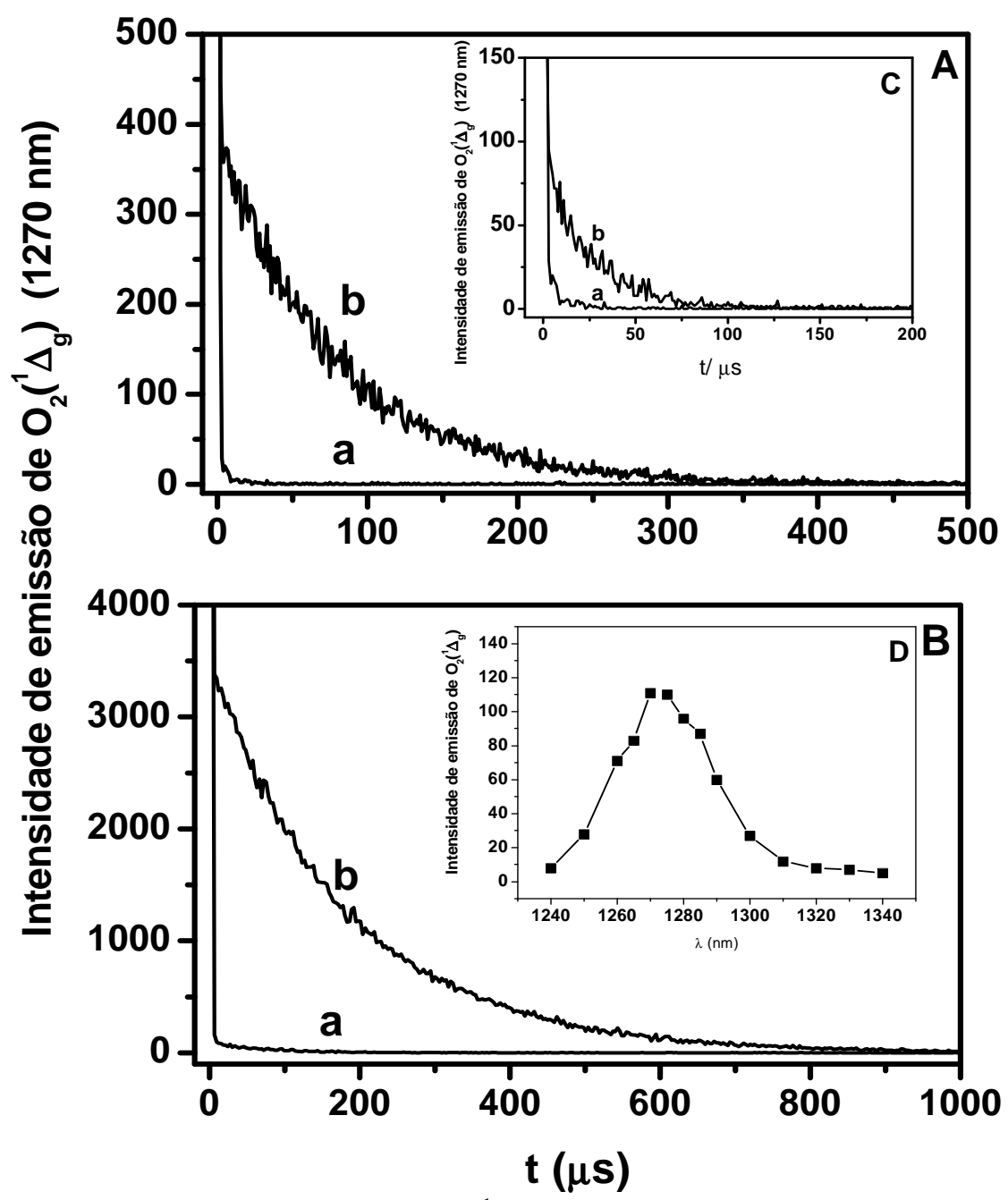

Figure 15: Curvas de emissão de $\mathrm{O}_{2}\left({ }^{1} \Delta_{\mathrm{g}}\right)$ produzido pelo DIP (a) e fenalenona (b) em ACN (A) e clorofórmio (B). O Inserto (C) mostra as curvas de decaimento para o DIP em clorofórmio (b) e ACN (a). Inserto (D) mostra o espectro de emissão de oxigênio singlete produzido pelo DIP em clorofórmio. 
De acordo com nossos dados o mecanismo de supressão física de $\mathrm{O}_{2}\left({ }^{1} \Delta_{\mathrm{g}}\right)$ pelo DIP e derivados é descrito pela reação 16 , que corresponde ao mecanismo de transferência de energia, visto que os dados eletroquímicos e os valores de $\Delta \mathrm{G}_{\mathrm{et}}$ favorecem este processo.

Sens $\stackrel{\mathrm{hv}}{\longrightarrow}{ }^{1}$ Sens $\stackrel{\mathrm{ISC}}{\longrightarrow}$ 年Sens $\stackrel{\mathrm{O}_{2}}{\longrightarrow} \mathrm{O}_{2}\left({ }^{1} \Delta_{\mathrm{g}}\right)$
$\mathrm{DIP}+\mathrm{O}_{2}\left({ }^{1} \Delta_{\mathrm{g}}\right) \stackrel{\mathrm{k}_{\mathrm{q}}}{\longrightarrow}{ }^{1}\left(\mathrm{DIP}^{\delta+} \ldots \mathrm{O}_{2}^{\delta-}\right) \longrightarrow{ }^{3}\left(\mathrm{DIP}^{\delta+} \ldots \mathrm{O}_{2}{ }^{\delta-}\right) \longrightarrow \mathrm{O}_{2}\left({ }^{3} \Sigma_{\mathrm{g}}{ }^{-}\right)+\mathrm{DIP}$

Diante destes resultados podemos concluir que o DIP é um ótimo antioxidante e atua como um ótimo supressor físico de $\mathrm{O}_{2}\left({ }^{1} \Delta_{\mathrm{g}}\right)$, uma das mais importantes espécies reativas de oxigênio, que pode degenerar o meio biológico. O DIP é capaz de suprimir $\mathrm{O}_{2}\left({ }^{1} \Delta_{\mathrm{g}}\right)$ sem sofrer degradação.

Mukai e colaboradores [83] estudaram alguns tipos de tocoferóis e fenóis, e relataram que o processo de supressão é predominantemente físico, isto é, $\mathrm{k}_{\mathrm{q}}>>\mathrm{k}_{\mathrm{r}}$ e o complexo de transferência de carga é o intermediário formado na supressão. Os valores das constantes obtidos estão na faixa de 0,4-36 × $10^{8} \mathrm{M}^{-1}$ $\mathrm{s}^{-1}$ e os potenciais de oxidação correspondentes estão na faixa de $0,81-1,30 \mathrm{~V}$ vs SCE. Em outro trabalho, Kaiser e colaboradores [86] descreveram baixas constantes de supressão para alguns tocoferóis $\left(0,23-3,60 \times 10^{6} \mathrm{M}^{-1} \mathrm{~s}^{-1}\right)$, mas neste caso foram observados produtos de oxidação, o que é diferente do que acontece com o DIP.

DIP tem sido usado em clínica médica por muitos anos e seu mecanismo de ação antioxidante ainda não é bem conhecido. Em trabalhos anteriores [47], foi demonstrado que DIP possui um efeito antioxidante tão potente quanto a vitamina $E$ na inibição da peroxidação de metil linoleato em sistemas homogêneos. Nossos dados mostram que DIP atua como um supressor físico de $\mathrm{O}_{2}\left({ }^{1} \Delta_{g}\right)$ mais potente que a Vitamina $\mathrm{E}$.

Compostos antioxidantes do tipo carotenóides atuam como um eficiente supressor de $\mathrm{O}_{2}\left({ }^{1} \Delta_{\mathrm{g}}\right)$ por via física (transferência de energia) $[87,88]$. Constantes de supressão física de carotenóides estão na faixa de 1,4-3,1 x $10^{10} \mathrm{M}^{-1} \mathrm{~s}^{-1}$, no 
entanto as constantes de supressão química são relativamente baixas, o que é similar ao observado para o DIP. O supressor mais efetivo de $\mathrm{O}_{2}\left({ }^{1} \Delta_{\mathrm{g}}\right)$, o Licopeno, possui uma constante de supressão de $31 \times 10^{9} \mathrm{M}^{-1} \mathrm{~s}^{-1}$, que está no limite difusional [89]

O mecanismo de fotodegradação do DIP tem sido descrito na literatura para baixas concentrações da droga [48]. O envolvimento do $\mathrm{O}_{2}\left({ }^{1} \Delta_{\mathrm{g}}\right)$ é sugerido, mas não foi diretamente demonstrado. Além disso, o mecanismo de fotooxidação não é estudado em detalhes.

Os experimentos descritos nesta seção foram realizados em colaboração com o Prof. Dr. Maurício da Silva Baptista e o Pós-Doutorando Divinomar Severino, no Laboratório de cinética rápida e fototermia.

\section{4- Eletroquímica do Dipiridamol}

Pesquisas em nosso Laboratório têm acumulado uma considerável quantidade de dados relacionados às propriedades do DIP. O potencial de oxidação do par redox apropriado pode ser relacionado com a termodinâmica da reação de transferência de elétrons. Por esta razão, estudos das propriedades eletroquímicas do DIP têm sido desenvolvidos, e a caracterização dos produtos gerados na eletrooxidação é de fundamental importância para explorar sua atividade antioxidante [34-35].

Os estudos eletroquímicos em acetonitrila e meio aquoso ácido foram desenvolvidos em colaboração com a aluna de mestrado Michelle Lima, os quais estão descritos na sua dissertação em fase final de elaboração. A metodologia utilizada e uma caracterização preliminar e parcial dos produtos da eletrooxidação estão descritos nas teses de Doutorado de Marilza Castilho e Adaíla A. M. P. Brasileiro [36,38].

Em ACN a eletroxidação do DIP é caracterizada por duas ondas voltamétricas reversíveis, correspondendo a dois processos consecutivos de um elétron, com a formação do radical cátion e do dicátion, respectivamente [34]. 
Em meio aquoso ácido, onde o DIP está protonado, somente uma onda de oxidação é observada envolvendo um processo único de dois elétrons [35].

Um estudo envolvendo cálculos teóricos da estrutura do DIP mostrou que a protonação da molécula em um único nitrogênio N1 (ou N5) é energeticamente favorável. Este trabalho também mostrou que a remoção de um e dois elétrons leva a mudanças significativas na densidade eletrônica dos nitrogênios, especialmente nos átomos de nitrogênios $\mathrm{N} 11, \mathrm{~N} 12, \mathrm{~N} 13$ e N14. O radical cátion formado pela oxidação de um elétron, está associado a remoção do elétron desses nitrogênios, visto pela forte delocalização do mesmo no anel pirimidopirimidino, observado no espectro de EPR, obtido anteriormente no trabalho de Marilza Castilho [33]. A remoção do segundo elétron também parece estar associada a perda da densidade eletrônica destes mesmos nitrogênios [39].

A eletrooxidação do DIP em acetonitrila produz produtos com características espectroscópicas diferentes, quando comparados ao DIP, tais como o desaparecimento da fluorescência característica e da banda de absorção em torno de $400 \mathrm{~nm}$. Após o tempo necessário para o decaimento do radical gerado na eletrólise, em geral após 24 horas da oxidação, as amostras foram liofilizadas, em seguida ressuspendidas e foram aplicadas numa coluna de extração em fase sólida (SPE) para remoção do eletrólito. Duas frações foram obtidas, uma aquosa e uma metanólica.

As análises de espectrometria de massas mostraram que os produtos obtidos na fração aquosa da primeira e segunda ondas são semelhantes. $\mathrm{Na}$ fração aquosa dois compostos foram caracterizados com $\mathrm{m} / \mathrm{z} 472$. Esta massa pode estar relacionada à perda do um grupo $-\mathrm{CH}_{2} \mathrm{OH}$ das etanolamina e este produto pode ter sido gerado pela retirada do elétron do nitrogênio da etanolamina, visto que, como descrito pelos cálculos teóricos, a remoção do elétron parece estar associada a perda da densidade eletrônica destes nitrogênios. Na tese de Adaíla A. M. P. Brasileiro [38] produtos da eletooxidação em meio aquoso ácido, com $\mathrm{m} / \mathrm{z}$ de 473 foram detectados e a proposta estrutural é apresentada na figura 16. 


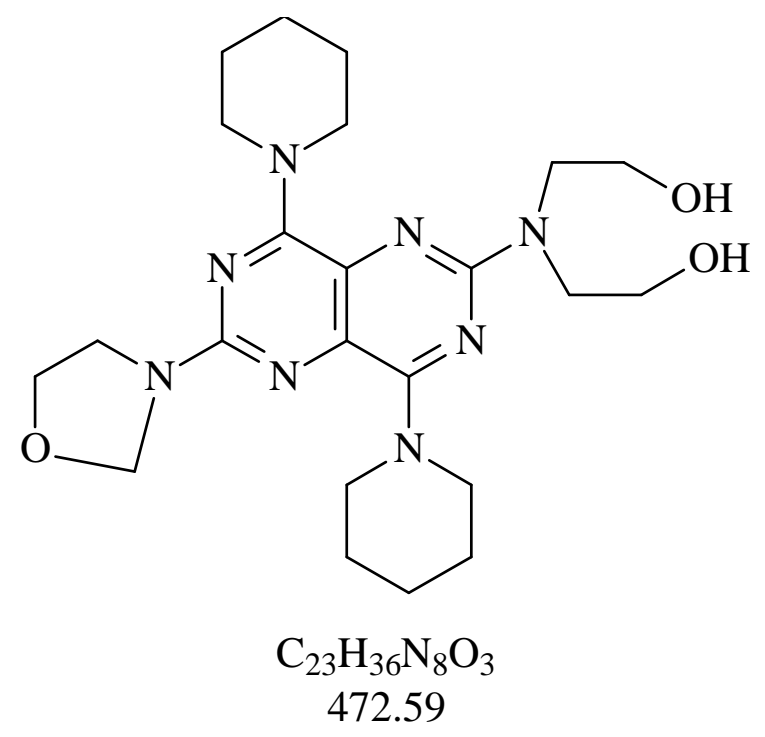

Figura 16: Proposta de estrutura para o produto da eletrooxidação (fração aquosa), $\mathrm{m} / \mathrm{z}$ 472, em acetonitrila [38].

No entanto, na fração metanólica íons com $\mathrm{m} / z$ de 269, 519 e 505 foram observados. O composto com $\mathrm{m} / z$ de 269 pode estar associado a metade da molécula do DIP mais um oxigênio ou a molécula do DIP com dois átomos de oxigênio duplamente protonada. A figura 17 apresenta uma proposta do mecanismo de formação deste composto, onde o cátion radical é formado pela oxidação de um elétron, que está associado ao elétron delocalizado no anel pirimido-pirimidino, observado no espectro de EPR obtido anteriomente no trabalho de Marilza Castilho [33]. Este radical formado em solução poderia reagir com oxigênio dissolvido no solvente ou presente no ambiente, e formar 0 intermediário dioxietano, que por sua vez poderia sofrer rearranjos formando o produto final, como apresentado no esquema da figura 17. 


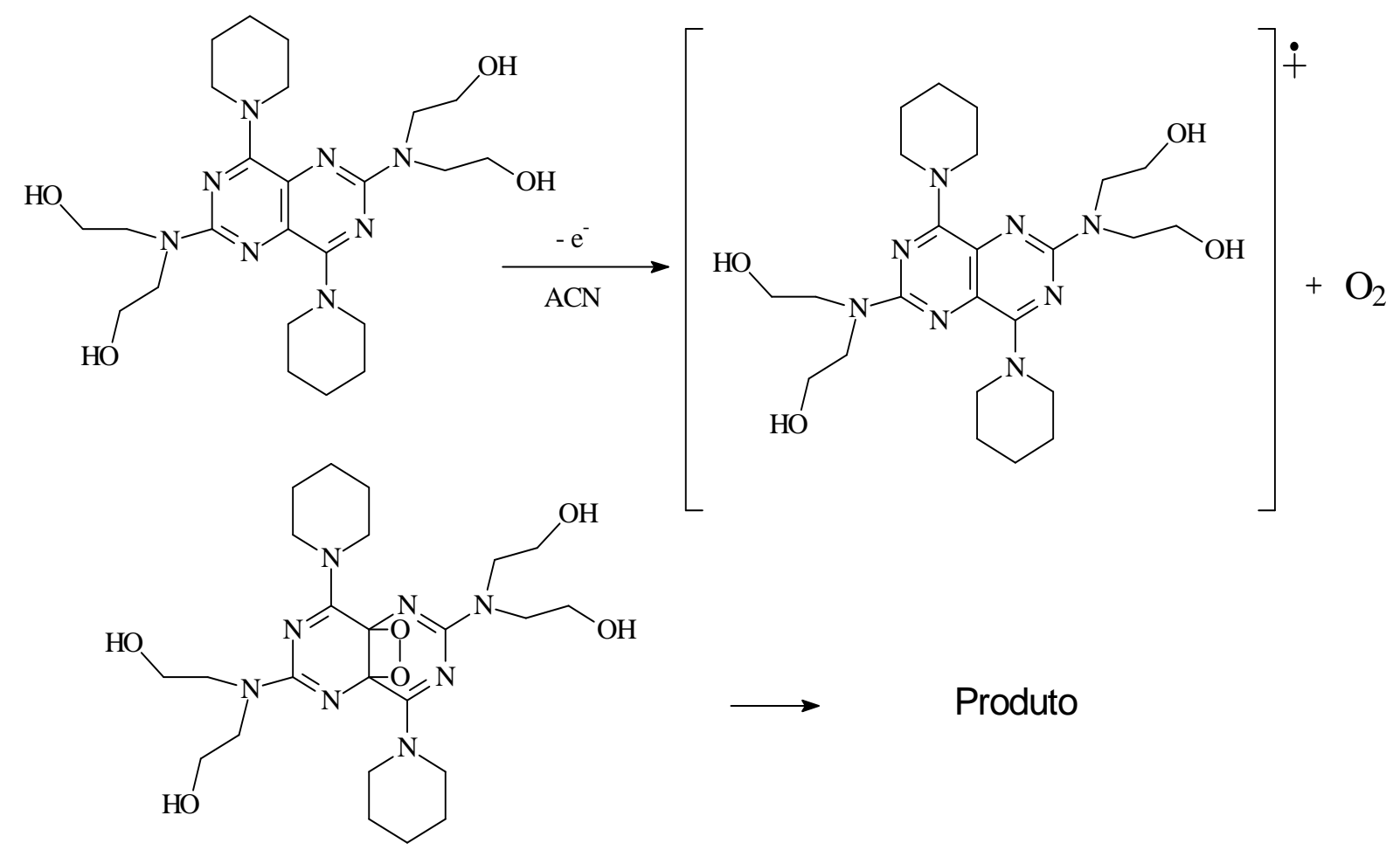

Figura 17: Proposta de mecanismo para a formação do produto da eletrooxidação com $\mathrm{m} / \mathrm{z} 269$ (fração metanólica) na primeira e segunda ondas em acetonitrila.

O íon com $\mathrm{m} / \mathrm{z}$ de 519 pode estar associado à molécula do DIP com um átomo de oxigênio adicional. Adaíla A. M. P Brasileiro [38] em sua tese de doutorado também relata a presença deste composto como produto da eletrooxidação na primeira e segunda ondas em acetonitrila. Vargas e colaboradores [48] relatam em seu trabalho sobre a fotoquímica do DIP, que o produto gerado em metanol possui $\mathrm{m} / \mathrm{z}$ de 519 e a estrutura molecular proposta está apresentada na figura 18. 


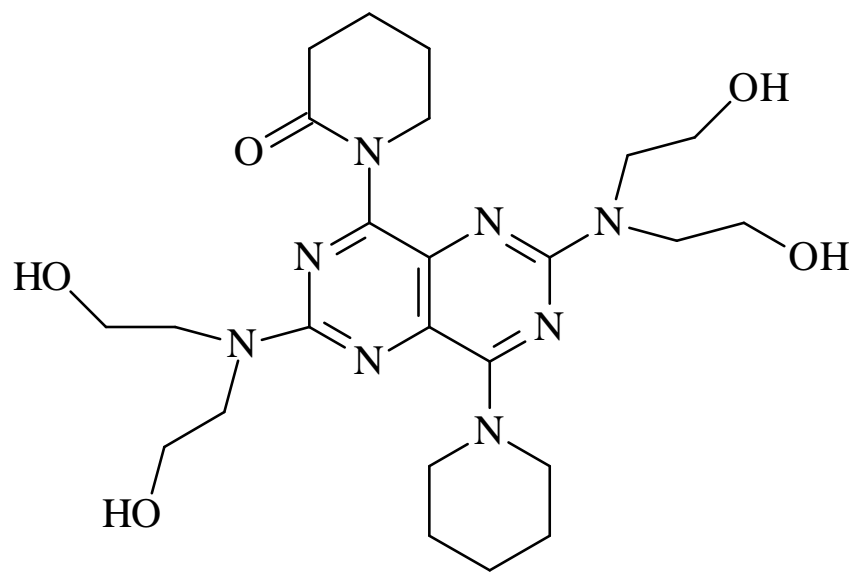

Figura 18: Proposta de estrutura molecular para o produto da eletrooxidação, $\mathrm{m} / z 519$ (fração metanólica) na primeira e segunda ondas em acetonitrila.

O íon com m/z 505 está associado ao DIP que pode ter sido regenerado em solução pela reação de desproporcionamento (reação 17).

$$
2 \mathrm{DIP}^{\bullet+} \rightarrow \mathrm{DIP}^{2+}+\mathrm{DIP}
$$

Como mencionado anteriormente uma caracterização parcial e preliminar dos produtos da eletrooxidação em meio aquoso ácido foi realizada e descrita na tese de doutorado de Adaíla M. P. A. Brasileiro [38]. É relatada a presença de compostos isóbaros de $\mathrm{m} / z 473 \mathrm{Da}$, tendo como íon fragmento $\mathrm{m} / \mathrm{z} 253 \mathrm{Da}$.

Uma análise da fotooxidação do DIP em meio aquoso ácido foi desenvolvido pela aluna de mestrado Michelle Lima, onde também foram detectados isômeros com m/z de 472 e íons de m/z 269, 438, 519 e 505, muito similares às espécies encontradas na eletrooxidação em acetonitrila.

Diante destes resultados podemos observar que o processo de eletroxidação nos dois meios, solvente orgânico ACN e aquoso ácido, produz compostos semelhantes, sendo que no meio ácido é necessário um maior potencial de oxidação para oxidar o DIP. Estes dados comparados com os dados obtidos na fotooxidação poderão contribuir para entender melhor 0 mecanismo antioxidante do DIP. 
Um importante fato a relatar, na caracterização dos produtos de eletrooxidação, é a dificuldade em realizar análises por $\mathrm{RMN}$, devido à pequena quantidade de produto formado, sendo necessário realizar várias eletrólises seguidas, afim de obter quantidade de material adequada. A instabilidade destes compostos também é um ponto a considerar, pois para obter os cromatogramas as amostras tiveram que ser congeladas após a retirada do sal eletrolítico. Sendo que, para a caracterização definitiva dos produtos da eletrooxidação, ainda se fazem necessárias as análises por RMN, pois as caracterizações destes compostos. O conhecimento destas estruturas possibilitará um entendimento maior do mecanismo de oxidação, podendo assim contribuir para a elucidação do mecanismo de ação antioxidante deste composto. As análises por espectrometria de massas da reação de eletrooxidação foram realizadas em colaboração com o Prof. Dr. Paolo Di Mascio e a doutoranda Fernanda M. Prado do Laboratório de Estudo de Lesões em Biomoléculas do Departamento de Bioquímica, Instituto de Química, USP, São Paulo.

\section{5- Oxidação do Dipiridamol usando uma fonte química de $\mathrm{O}_{2}\left({ }^{1} \Delta_{\mathrm{g}}\right)$, o $\mathrm{DHPNO}_{2}$.}

A oxidação do DIP foi acompanhada utilizando uma fonte química como gerador de $\mathrm{O}_{2}\left({ }^{1} \Delta_{\mathrm{g}}\right)$. O uso de endoperóxidos que se decompõem térmicamente tem se tornado uma ferramenta valiosa, pois é uma fonte limpa de $\mathrm{O}_{2}\left({ }^{1} \Delta_{\mathrm{g}}\right)$, não gera subprodutos e não necessita de condições drásticas de trabalho. O N,N'di(2,3-dihidroxipropil)-1,4 naftalenodipropanamida $\left(\mathrm{DHPNO}_{2}\right)$ é capaz de gerar $\mathrm{O}_{2}\left({ }^{1} \Delta_{\mathrm{g}}\right)$ a $37^{\circ} \mathrm{C}$ com um rendimento de $59 \%$ [23]. O DIP foi incubado com $\mathrm{DHPNO}_{2}$ num banho termostático a $37^{\circ} \mathrm{C}$ por duas horas, sendo que o solvente utilizado foi água deuterada ácida. A figura 19 apresenta o espectro de massa obtido por injeção direta da solução. Observa-se o pico do produto oxidado com $\mathrm{m} / \mathrm{z}$ de 269 e os picos relacionados à troca do hidrogênio pelo deutério. O pico do DHPN, com $\mathrm{m} / \mathrm{z}$ de 419 , também é observado visto que este composto não sofre degradação. 
Observa-se que neste sistema o produto da fotooxidação com m/z de 269 pode estar relacionado à metade da molécula do DIP com a adição de um átomo de oxigênio ou a molécula do DIP com dois átomos de oxigênio duplamente protonada. Também observado na eletrooxidação em meio aquoso ácido. $O$ produto é formado a partir do intermediário dioxetano, o mecanismo proposto aqui é do tipo II, ou seja via reação com $\mathrm{O}_{2}\left({ }^{1} \Delta_{\mathrm{g}}\right)$, como apresentado no esquema da figura 20 , sendo clara a participação do oxigênio singlete na oxidação do DIP.

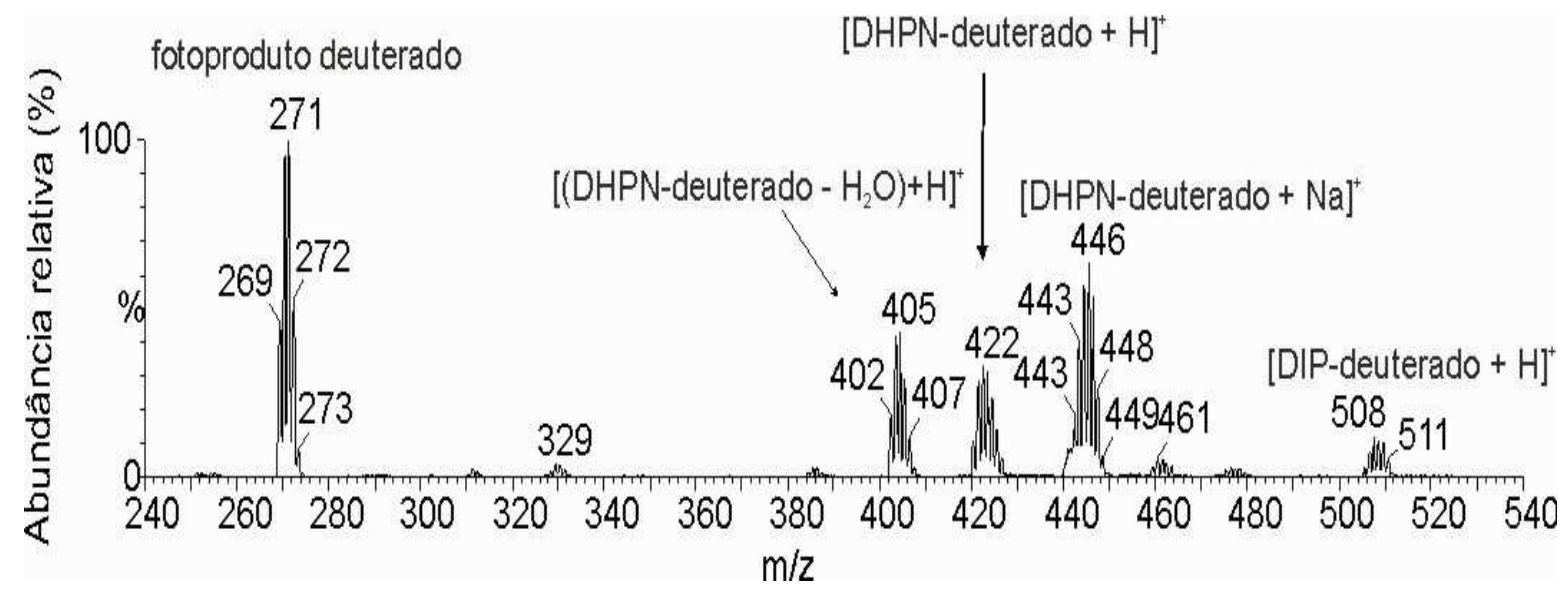

Figura 19: Espectro de massas da fotooxidação do DIP utilizando uma fonte química de $\mathrm{O}_{2}\left({ }^{1} \Delta_{g}\right)$ em meio aquoso deuterado.
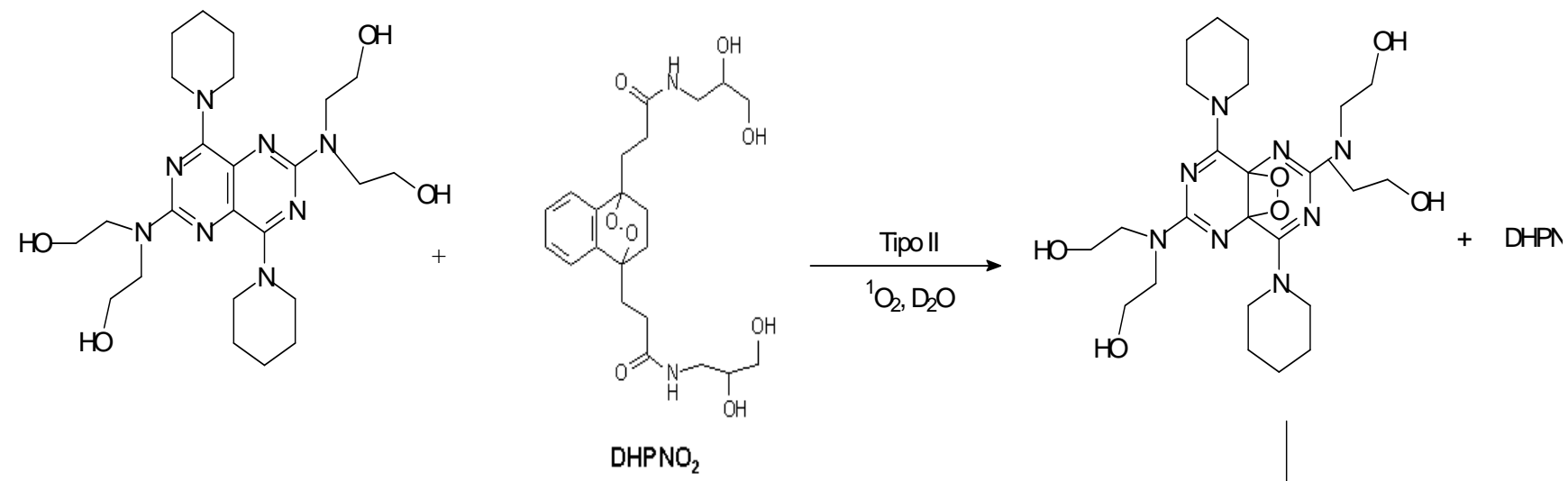

Figura 20: Esquema proposto para o mecanismo de fotodegradação do dipiridamol em meio aquoso ácido $\mathrm{pH}=3,0$. 


\section{6- Comportamento fotoquímico do DIP em acetonitrila e meio aquoso ácido.}

\subsubsection{Fotooxidação do Dipiridamol em acetonitrila}

Experimentos de fotooxidação do DIP $0,5 \mathrm{mM}$ em acetonitrila foram realizados da seguinte forma: as amostras foram irradiadas por $4 \mathrm{~h}$ conforme descrito na parte experimental e os espectros foram obtidos de 30 em 30 minutos e são apresentados na figura 21. O DIP apresenta um comportamento peculiar em acetonitrila, o que pode estar associado a algumas propriedades características deste solvente no que se refere à presença de orbitais $\pi^{\star}$ em baixo nível de energia, o que é constatado em trabalhos de química de coordenação que identificam a acidez $\pi$ do ligante acetonitrila. Desta maneira, a presença da acetonitrila poderia favorecer o mecanismo de fotooxidação do dipiridamol, que é conhecido por suas propriedades redutoras. Pelos espectros de absorção apresentados na figura 21, observa-se o decaimento da banda característica do DIP em 412 nm, e o aparecimento de uma nova banda em 350 $\mathrm{nm}$, o que pode estar relacionado à fooxidação do dipiridamol. 


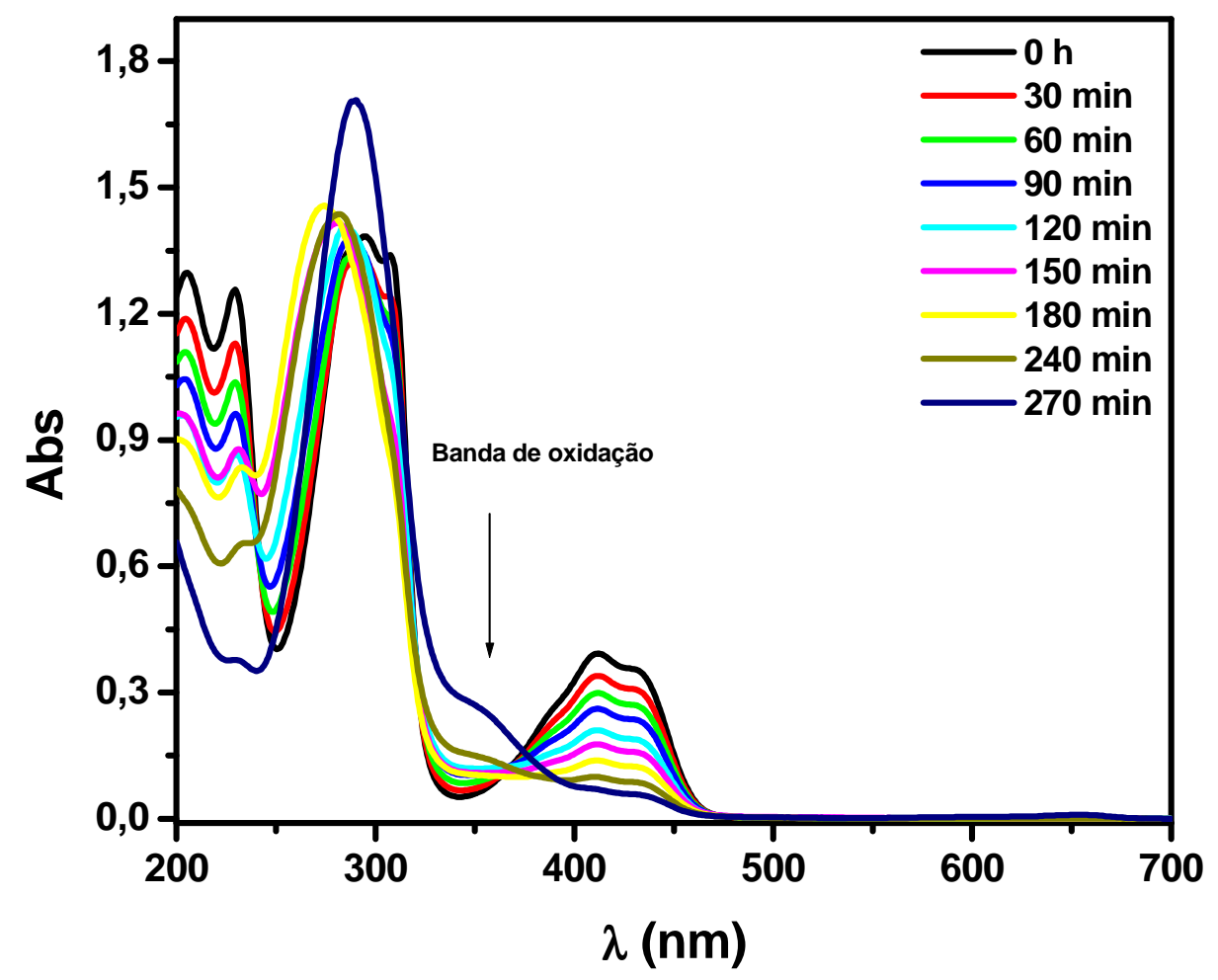

Figura 21: Espectros de absorção ótica da reação de fotooxidação do DIP 0,5 $\mathrm{mM}$ em acetonitrila.

Inicialmente a metodologia aplicada para as análises de HPLC foi à mesma utilizada por Adaíla A. M. P. Brasileiro na sua tese de doutorado [38]. A Fig. 22 apresenta o cromatograma após $4 \mathrm{~h}$ de fotooxidação, utilizando uma coluna analítica C18 Luna ( $250 \times 4,6 \mathrm{~mm}, 5 \mu \mathrm{m}$ - Phenomenex), e como fase móvel tampão acetato $40 \mathrm{mM}, \mathrm{pH} 4.0 / \mathrm{MeOH}$, num gradiente de: 20 min 5-95\% de $\mathrm{MeOH}, 95-5 \%$ de $\mathrm{MeOH}$, stop em 35 min. Observa-se a presença de pelo menos três compostos com tempos de retenção muito próximos em torno de 11 min e o pico do DIP não fotooxidado em 19 min. 


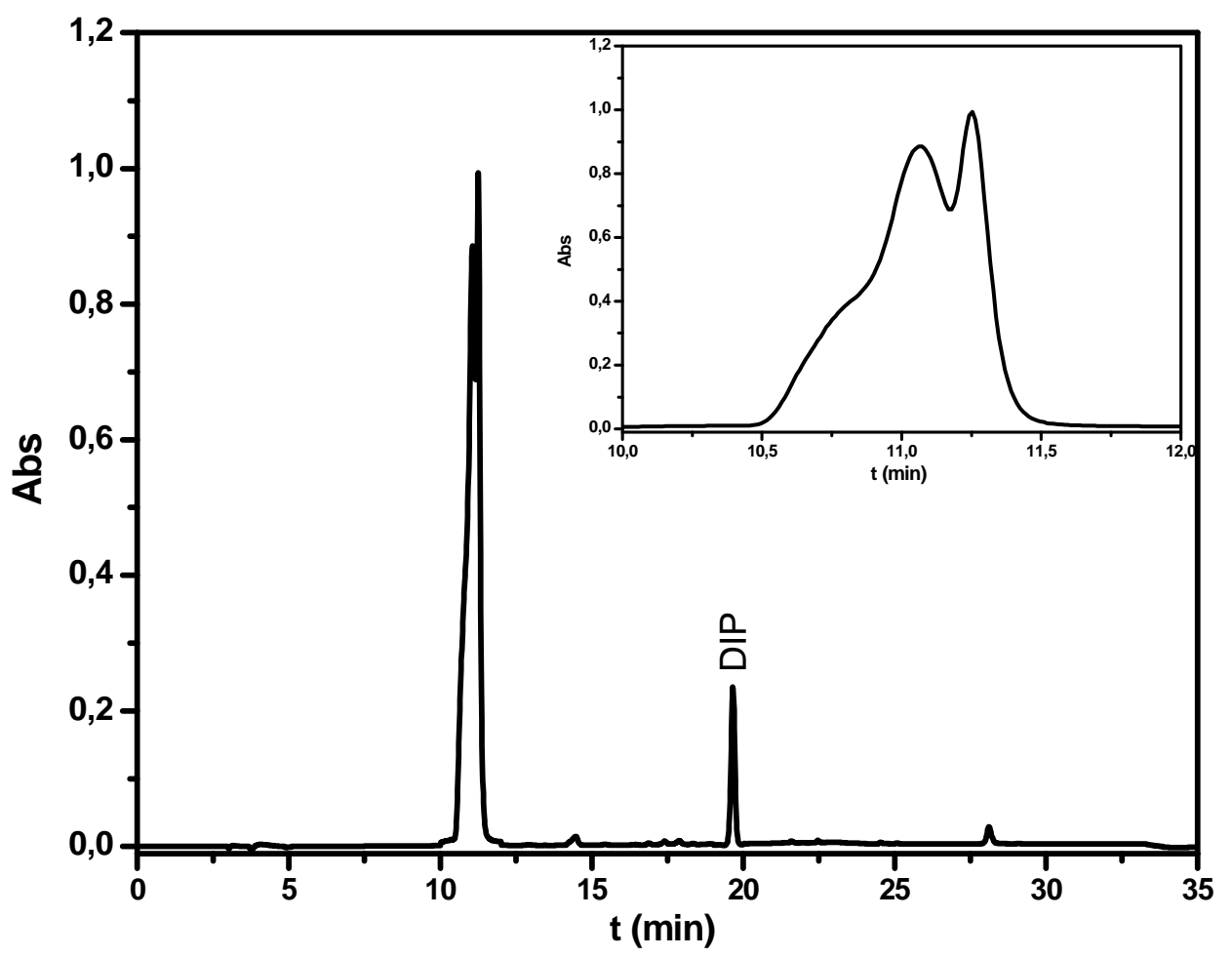

Figura 22: Cromatograma da fotooxidação do DIP em acetonitrila submetido a irradiação. Método de eluição: gradiente; tampão acetato $40 \mathrm{mM}, \mathrm{pH} 4.0 / \mathrm{MeOH}$; 20 min 5-95\% de $\mathrm{MeOH}, 95-5 \%$ de $\mathrm{MeOH}$, stop em 35 min, utilizando uma coluna C18 Luna (250 x 4,6 mm, $5 \mu \mathrm{m}$ - Phenomenex) como fase estacionária. Volume de injeção: $20 \mu \mathrm{L}$ com fluxo de $1 \mathrm{~mL} / \mathrm{min}$.

Este método possuiu uma desvantagem que é a presença do sal do tampão acetato. Deste modo, para uma melhor separação dos produtos e para as análises de espectrometria de massas e possível análise por RMN, outros sistemas de eluição foram testados, para eliminar o sal do tampão. Sistemas de eluição tais como: $\mathrm{MeOH} / \mathrm{H}_{2} \mathrm{O}, \mathrm{MeOH} /$ formiato de amônio $30 \mathrm{mM}, \mathrm{ACN} / \mathrm{H}_{2} \mathrm{O}$ e ácido fórmico $0,1 \% / \mathrm{ACN}$ foram testados. Sendo que o sistema que apresentou melhor separação foi o sistema ácido fórmico $0,1 \% / \mathrm{ACN}$ no gradiente $5-70 \%$ de ACN em 10 min, 70 - 5\% de ACN de 10-15 min e stop em 20 min.

Com este sistema foi obtido o cromatograma da figura 23 para uma solução de DIP $0,5 \mathrm{mM}$ e para a solução da reação de fotooxidação do dipiridamol em acetonitrila após $4 \mathrm{~h}$ de irradiação. 
O DIP apresenta um tempo de retenção de 9,9 min neste sistema (Fig. 23A). O cromatograma da figura 23B apresenta três picos distintos com tempos de retenção de 3,87, 6,01, 7,24 e 9,75 min.

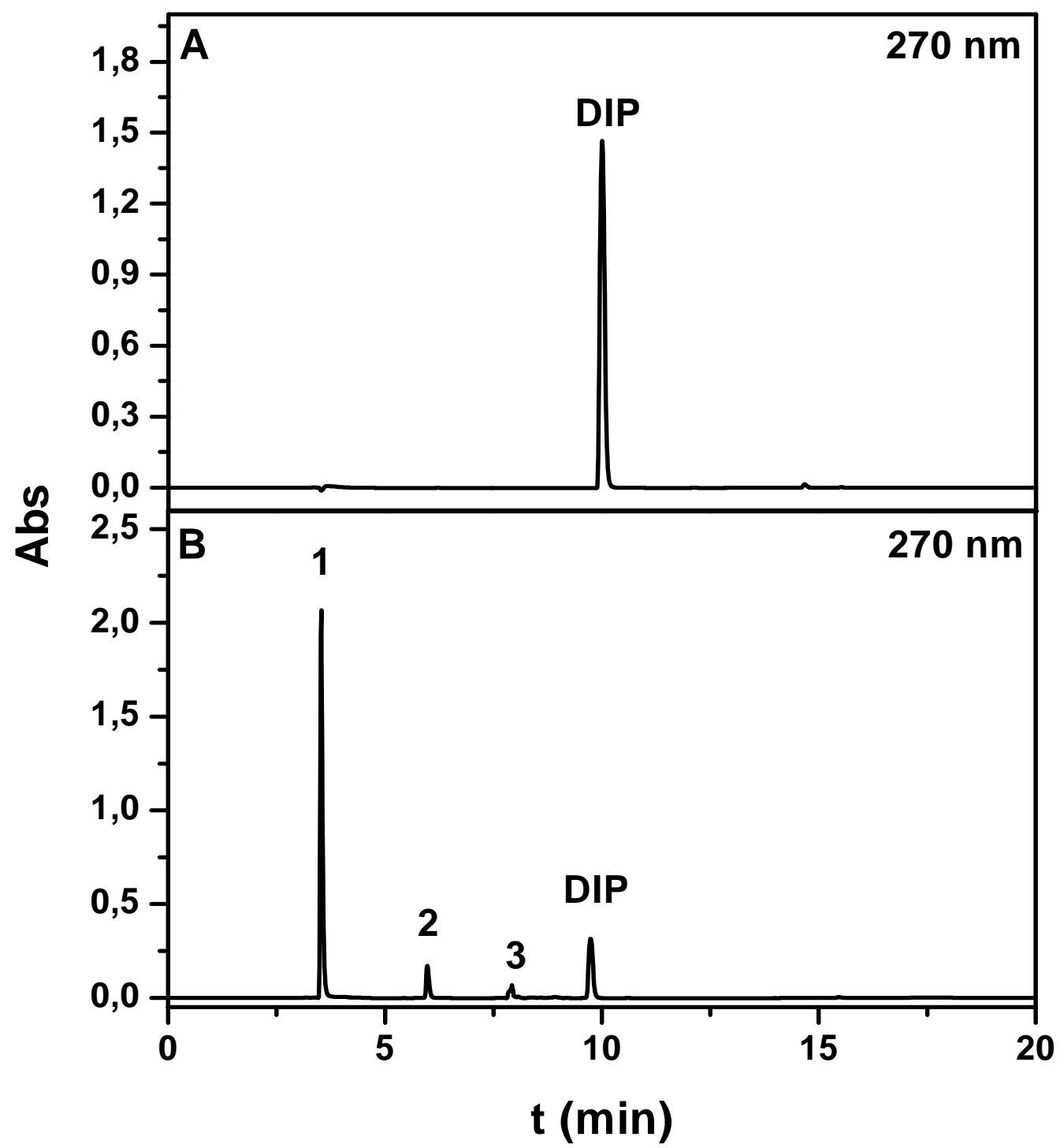

Figura 23: Cromatograma do DIP (A) e da reação de fotooxidação do DIP (B) em acetonitrila. Método de eluição: gradiente; solução de ácido fórmico 0,1\%/ACN, $5-70 \%$ de ACN em $10 \mathrm{~min}, 70-5 \%$ de ACN de $10-15$ min e stop em 20 min. utilizando uma coluna C18 Luna $(250 \times 4,6 \mathrm{~mm}, 5 \mu \mathrm{m}-$ Phenomenex) como fase estacionária. Volume de injeção: $20 \mu \mathrm{L}$ com fluxo de $1 \mathrm{~mL} / \mathrm{min}$. 
Durante a irradiação da solução alíquotas foram retiradas de meia em meia hora e analisadas por HPLC. As áreas dos picos foram transformadas em porcentagens e estão apresentadas na figura 24 em função do tempo de irradiação. Observa-se o consumo do DIP à medida que se forma o produto de fotooxidação. Além disso, o produto com tempo de retenção de 6,01 min é formado em baixíssima porcentagem em torno de $10 \%$.

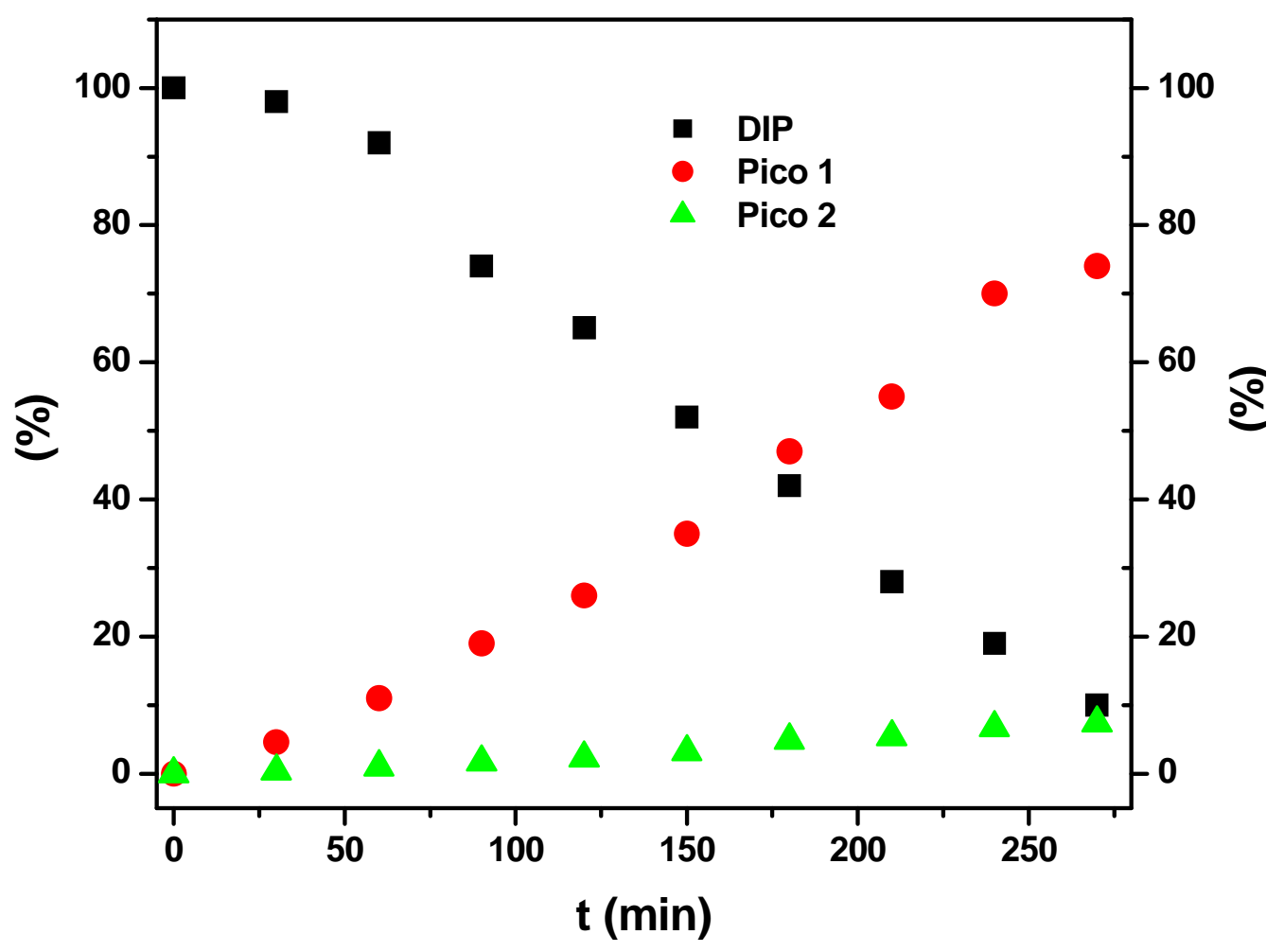

Figura 24: Porcentagens de reagentes e produtos na reação de fotooxidação do DIP em função do tempo em acetonitrila, obtidas a partir de cromatogramas similares ao apresentado na figura 23B. Nota-se o consumo do DIP (घ) e formação majoritária do produto correspondente ao pico $1(\bullet)$.

O espectro de massas para esta solução foi obtido e é apresentado na figura 25. Observa-se que os dois compostos com tempo de retenção de 3,87 e $6,01 \mathrm{~min}$ são isóbaros com $\mathrm{m} / \mathrm{z}$ de 269 . Este produto pode estar relacionado à metade da molécula do DIP com a adição de um átomo de oxigênio ou a molécula do DIP com dois átomos de oxigênio duplamente protonada. Esta 
interpretação pode ser confirmada pelo espectro dos íons fragmentos (Fig. 25B e D). Este composto também é observado como produto na eletrooxidação do DIP.

A primeira perda de massa produz o fragmento de $\mathrm{m} / \mathrm{z} 251$, está relacionada à perda de água, que pode ser proveniente do substituinte etanolamínico. A segunda perda de massa correspondente ao fragmento de 225 Da está relacionada a perda de um grupo $-\mathrm{CH}_{2} \mathrm{CH}_{2} \mathrm{OH}$. A partir do íon de $\mathrm{m} / \mathrm{z}$ 225 ocorre outra perda de água que correspondente ao íon de $\mathrm{m} / z 207 \mathrm{D}$. O íon de $m / z 181$ está relacionado à perda de outro grupo $-\mathrm{CH}_{2} \mathrm{CH}_{2} \mathrm{OH}$, sendo este um fragmento do íon de $\mathrm{m} / \mathrm{z} 225$. O íon de $\mathrm{m} / \mathrm{z} 164$ está relacionado à perda do substituinte, etanolamina. $\mathrm{O}$ íon de $\mathrm{m} / \mathrm{z} 111$ está relacionado à perda de $84 \mathrm{Da}$ a partir do íon de $m / z 195$, referente ao anel piperidina.
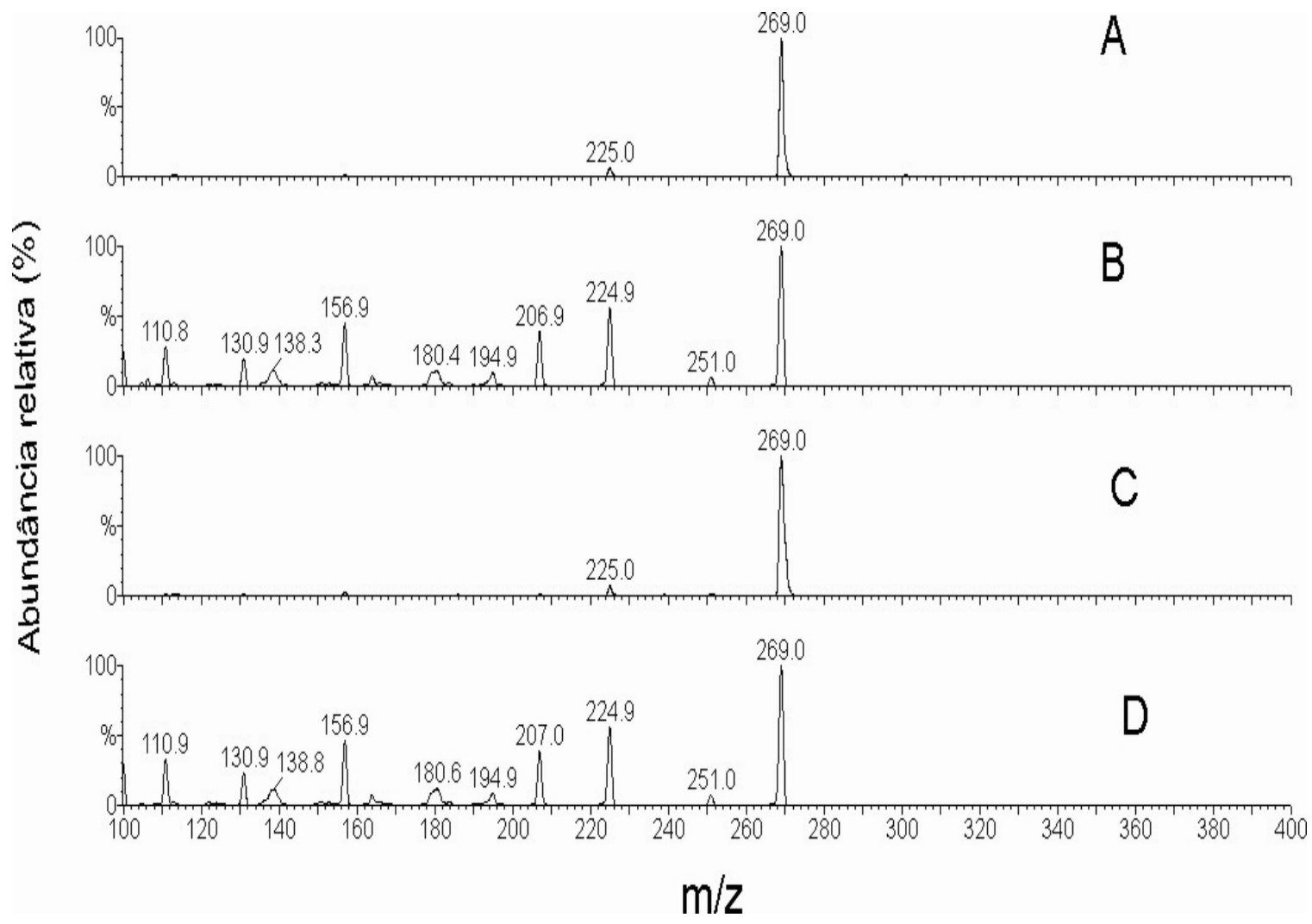

Figura 25: Espectros de massas dos produtos da fotooxidação em acetonitrila com tempos de retenção de 3,87 e 6,01 min. (A e C) ESI/EM no modo positivo, voltagem do cone $40 \mathrm{~V}$, voltagem do capilar $3,6 \mathrm{kV}$. (B e D) Respectivos íons fragmentos do $\mathrm{m} / \mathrm{z} 269$, energia de colisão de $30 \mathrm{eV}$. 
A figura 26 apresenta o espectro de massas correspondente ao pico com tempo de retenção de 7,24 min. Observa-se que este composto apresenta $\mathrm{m} / \mathrm{z}$ 519. Esta massa molecular pode estar associada a molécula do DIP com a adição de um oxigênio, o que também é observado na eletrooxidação. Como mencionado anteriormente a estrutura molecular para esse composto foi proposta por Vargas e colaboradores [48] no seu trabalho sobre a fotoquímica do dipiridamol. A figura 27 apresenta uma proposta da estrutura química para este composto. Esta molécula é bem estável sendo necessário uma energia de colisão de 70 eV para fragmentá-la.

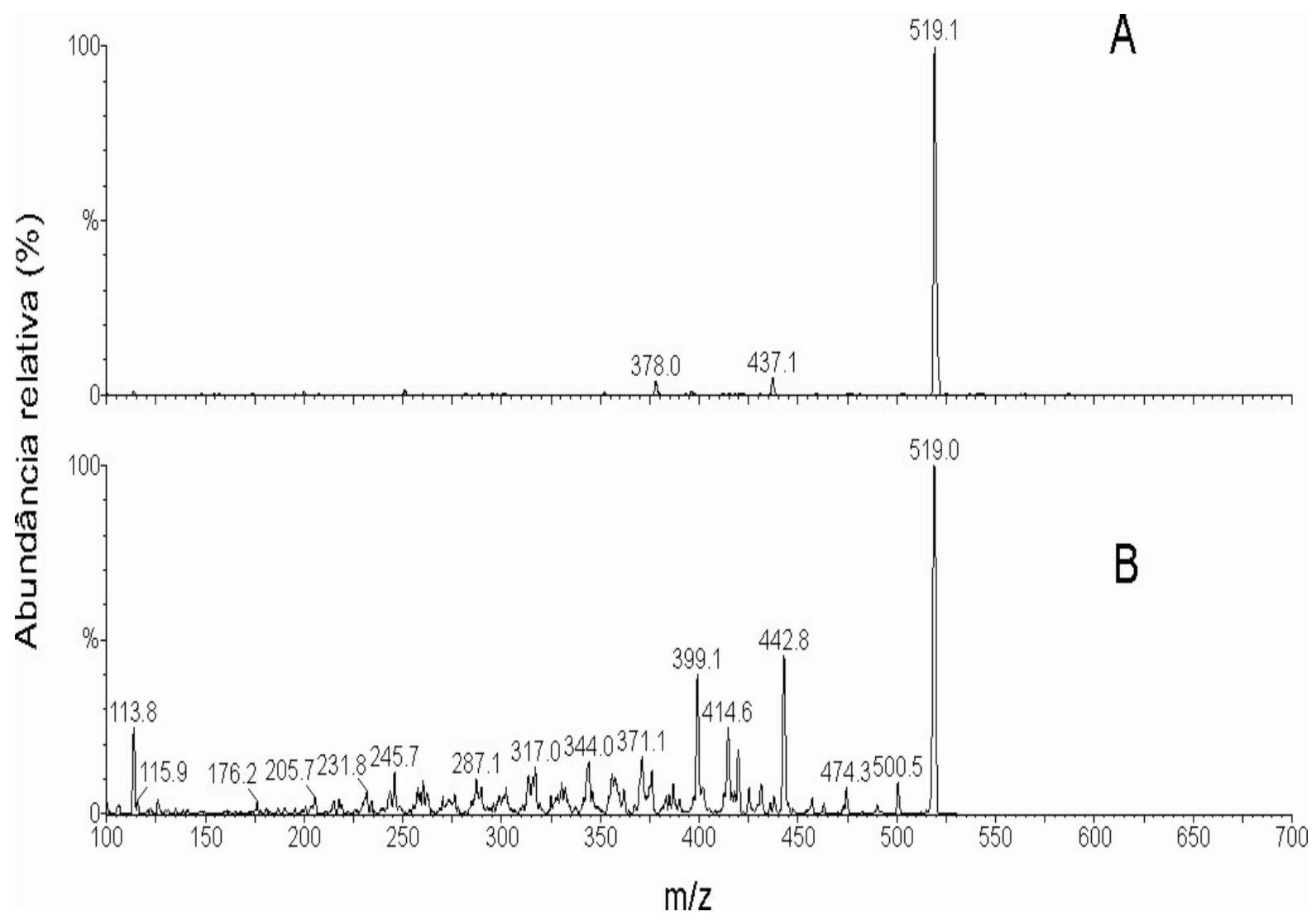

Figura 26: Espectros de massas do produto da fotooxidação em acetonitrila com tempo de retenção de 7,24 min. (A) ESI/EM no modo positivo, voltagem do cone $40 \mathrm{~V}$, voltagem do capilar 3,6 kV. (B) Respectivos íons fragmentos do $\mathrm{m} / z$ 519, energia de colisão de $70 \mathrm{eV}$. 


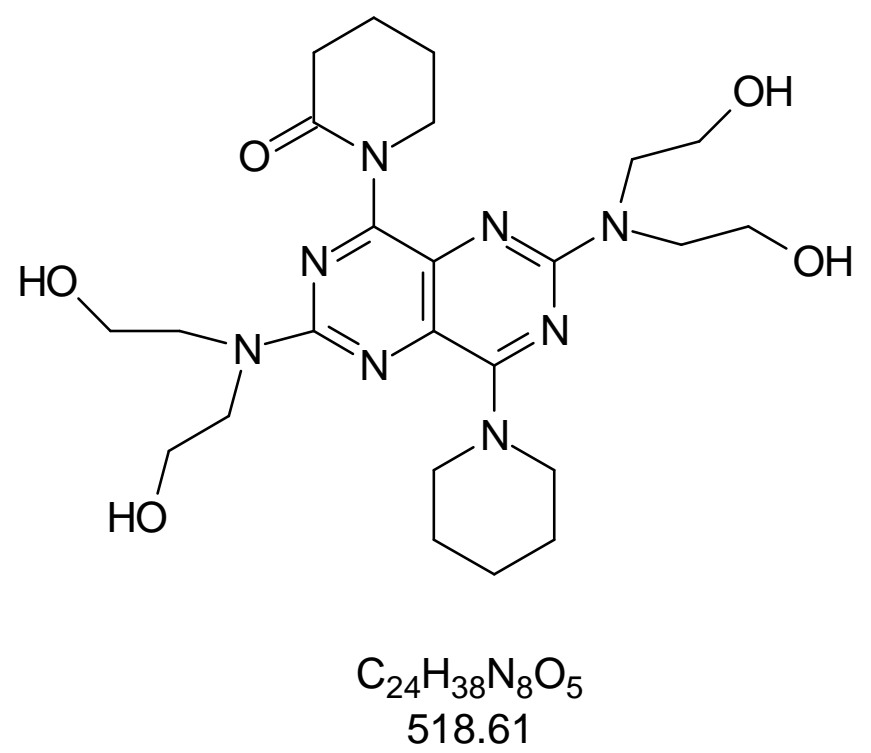

Figura 27: Proposta estrutural para o produto da fotooxidação em acetonitrila com tempo de retenção de 7,24 min.

O pico com tempo de retenção de 9,75 min (Fig. 23C) está associado ao DIP que não foi fotooxidado, pois um maior tempo de irradiação leva a formação de produtos secundários provenientes do produto primário obtido inicialmente. $\mathrm{O}$ espectro de massas "fullscan" apresentado na figura 28 mostra o íon do pico molecular do dipiridamol. Estudos sobre a fragmentação do DIP e alguns de seus derivados foram realizados e são apresentados na referência 49. 


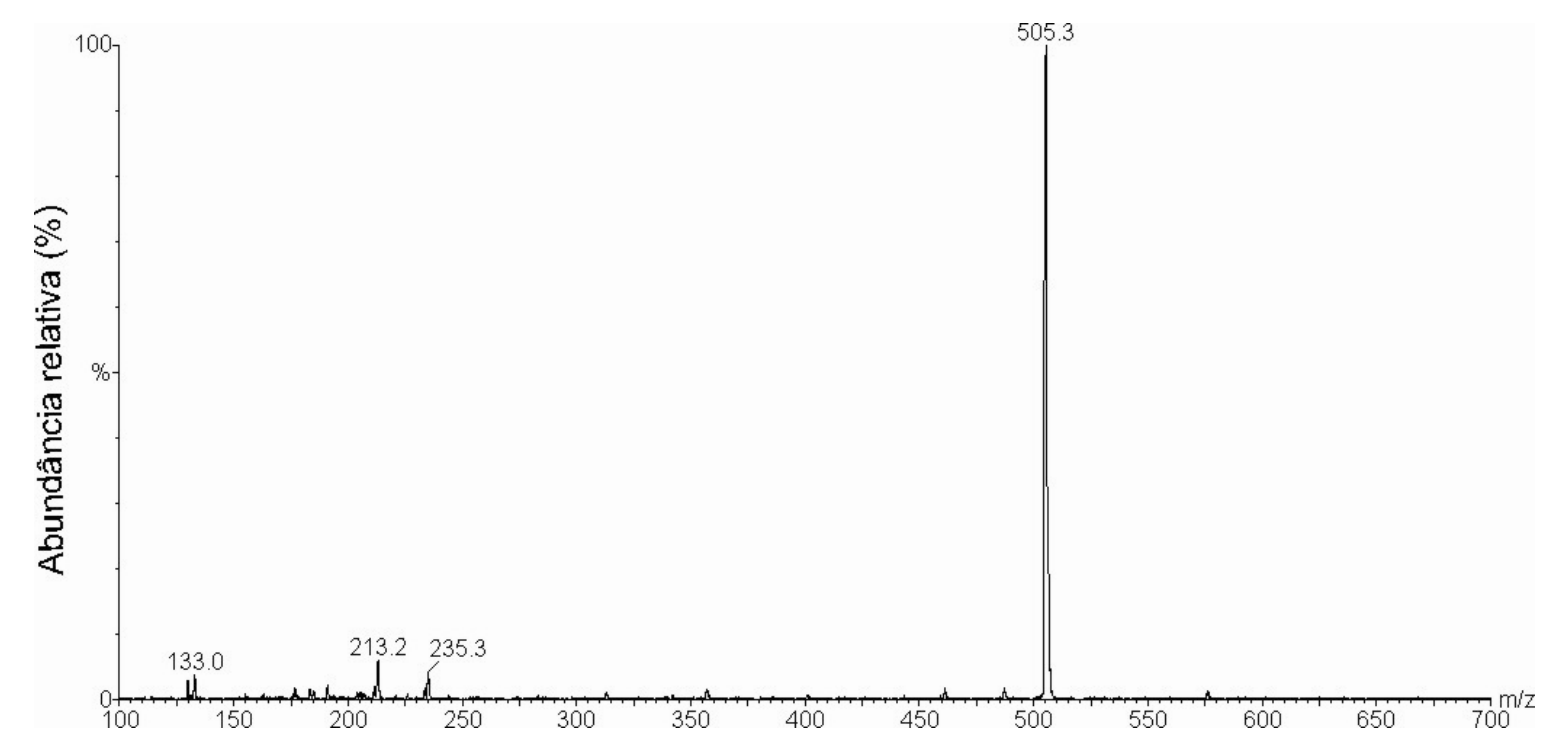

Figura 28: Espectros de massas do DIP não fotooxidado em acetonitrila com tempo de retenção de 9,75 min. ESI/EM no modo positivo, voltagem do cone 40 $\mathrm{V}$, voltagem do capilar $3,6 \mathrm{kV}$.

Para confirmar o envolvimento do oxigênio na reação de fotooxidação em acetonitrila foram realizados experimentos com oxigênio-18. A figura 29 apresenta o espectro de massas, obtido por injeção direta, para a fotooxidação do DIP em acetonitrila na presença de oxigênio-18. Observa-se a incorporação do oxigênio-18 pela diferença de duas unidades de massa referente ao pico com $m / z 271$, confirmando o envolvimento do oxigênio na reação de fotooxidação em acetonitrila. 


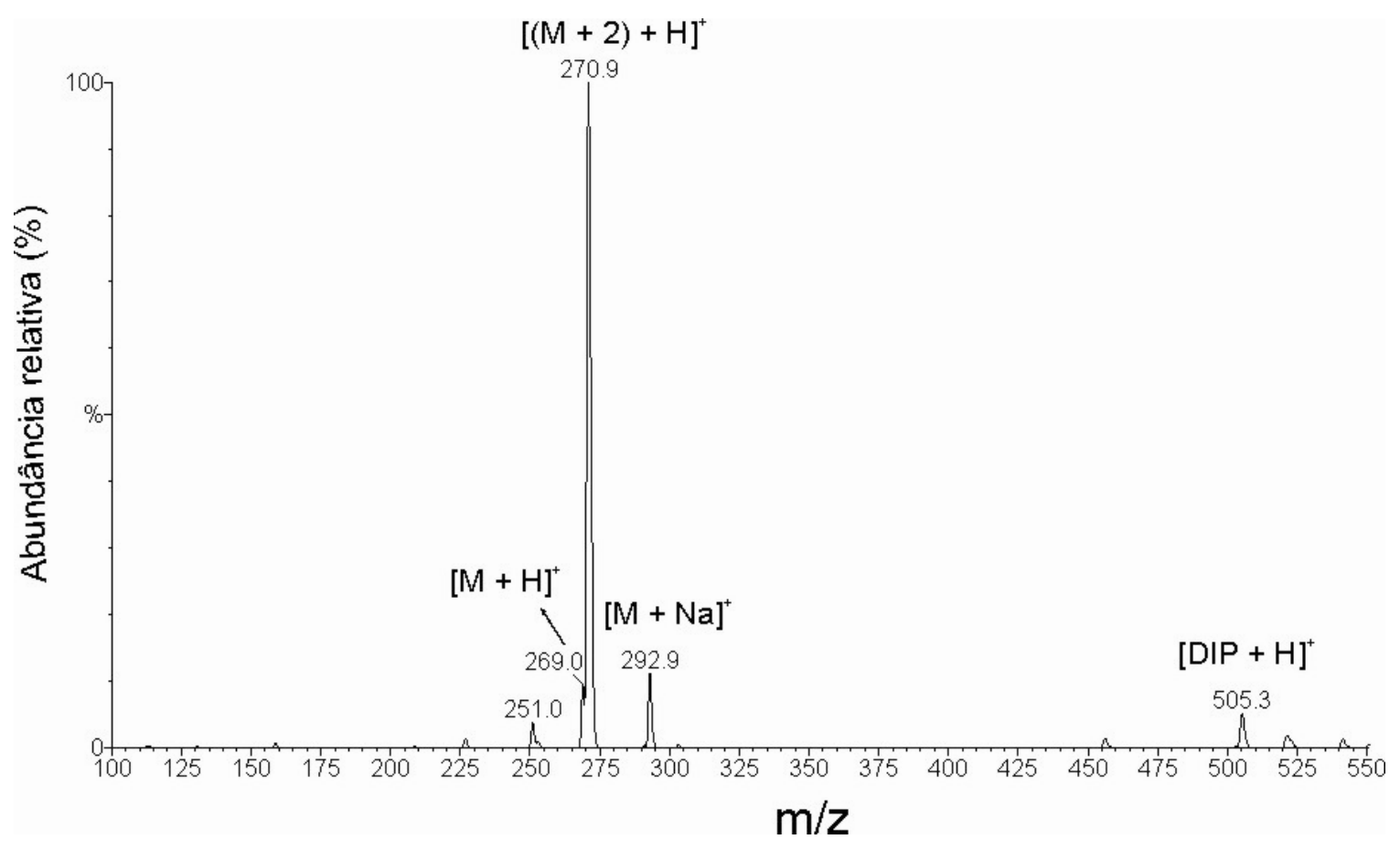

Figura 29: Espectro de massas do produto da fotooxidação em acetonitrila após $4 \mathrm{~h}$ de irradiação na presença de oxigênio-18. ESI/EM no modo positivo, voltage do cone $40 \mathrm{~V}$, voltagem do capilar $3,6 \mathrm{kV}$.

Irradiações em volumes maiores de DIP $(0,5 \mathrm{mM})$ em acetonitrila foram realizadas utilizando duas lâmpadas OSRAM HWL E40 de 500 W de potência, em banho de gelo, irradiadas por 6h. Os picos com tempos de retenção de 3,87 e 6,01 min foram coletados para possível caracterização por RMN de ${ }^{1} \mathrm{H}$ e ${ }^{13} \mathrm{C}$. Após várias tentativas de separação houve uma dificuldade no acúmulo desse material. Após a sua coleta, observou-se que o composto com tempo de retenção de 3,87 min se converte no composto com tempo de retenção de 6,01 min. Este comportamento foi observado após reinjeção dos compostos coletados no HPLC, como apresentado na figura 30. Outra possibilidade é que em solução ocorra um equilíbrio de formação entre estes compostos. Quanto à estabilidade do composto gerado, a mesma ainda não é conhecida em detalhes, pois após a reinjeção observa-se um pequeno pico com tempo de retenção de 6,9 min. 


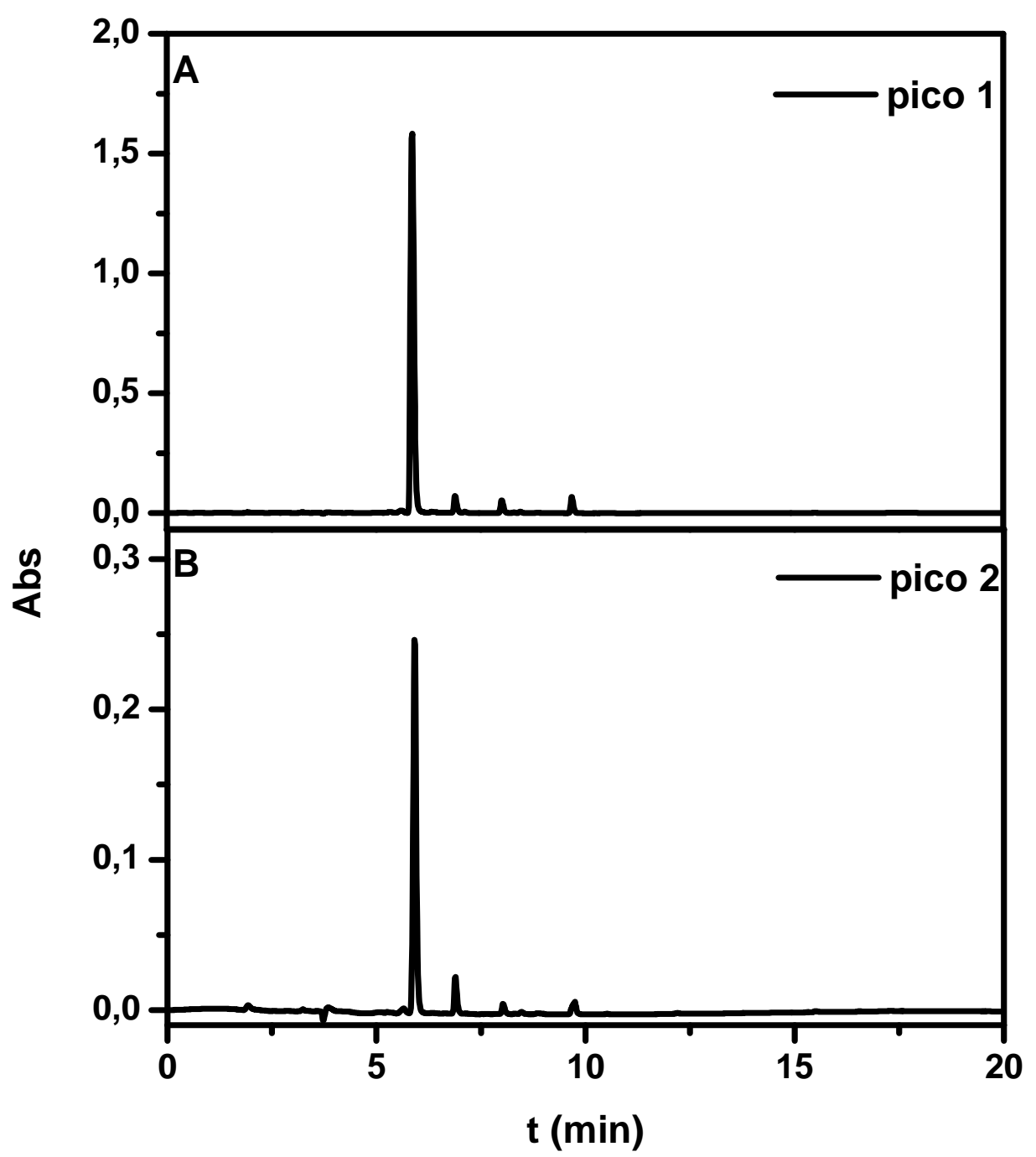

Figura 30: Cromatograma dos produtos da fotooxidação do DIP em acetonitrila, obtidos após a coleta dos picos 1 e 2 do cromatograma da figura 23B e reinjeção no HPLC. Método de eluição: gradiente; solução de ácido fórmico 0,1\%/ACN, 5 - 70\% de ACN em 10 min, 70 - 5\% de ACN de 10 - 15 min e stop em 20 min, utilizando uma coluna C18 Luna ( $250 \times 4,6 \mathrm{~mm}, 5 \mu \mathrm{m}$ - Phenomenex). Volume de injeção: $20 \mu \mathrm{L}$ com fluxo de $1 \mathrm{~mL} / \mathrm{min}$.

\subsection{2- Fotooxidação do DIP na ausência de oxigênio}

Experimentos de fotodegradação do DIP 0,25 mM em ACN na ausência de oxigênio também foram realizados. Ciclos de congelamento - vácuo - 
descongelamento utilizando nitrogênio líquido como congelante foram realizados, com controle de vácuo, para assegurar a total eliminação do oxigênio, evitando assim que o mesmo participasse da reação de fotodecomposição do DIP. A amostra de concentração $0,25 \mathrm{mM}$ foi irradiada por $6 \mathrm{~h}$, em seguida foi deixada em repouso por 24 horas em temperatura ambiente e o cromatograma obtido para esta solução está apresentado na figura 31. Os resultados obtidos apresentaram uma decomposição de aproximadamente $50 \%$ (picos 1, 2 e 3, Fig. 31) em relação ao pico do cromatograma obtido para o DIP antes da fotodegradação, o que pode estar relacionado à formação de alguma espécie radicalar. O pico em 19,7 min está relacionado ao DIP que não foi fotodegradado. Os compostos encontrados apresentaram menor polaridade quando comparado com o DIP. O experimento realizado com a solução $0,5 \mathrm{mM}$ apresentou o mesmo comportamento. Neste caso foi utilizado um sistema de eluição tampão acetato $40 \mathrm{mM} \mathrm{pH}=4,0 / \mathrm{MeOH}, 5-95 \%$ de $\mathrm{MeOH}$ em $20 \mathrm{~min}$, de $20-35 \min 95 \%$ de $\mathrm{MeOH}$, de $35-45 \min 95-5 \%$ de $\mathrm{MeOH}$.

Uma solução de DIP $0,5 \mathrm{mM}$ também foi preparada no escuro e deixada em repouso por uma semana, na ausência de luz, para certificar-se que o DIP não sofre nenhuma reação em acetonitrila no estado fundamental, em seguida foi analisada por HPLC. Neste caso não foi constatado nenhum processo de decomposição. 


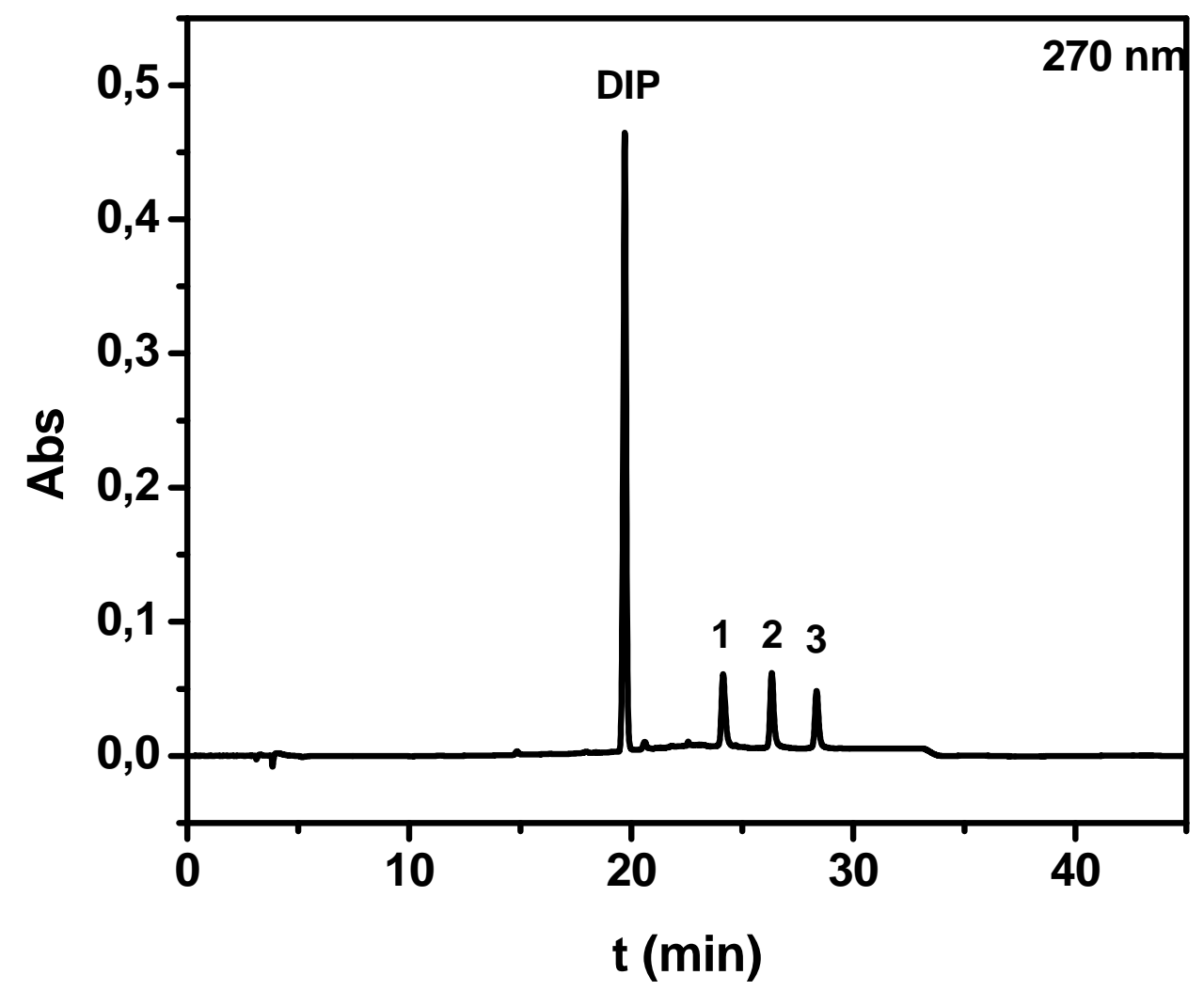

Figura 31: Cromatograma da fotooxidação do DIP $0,25 \mathrm{mM}$ na ausência de oxigênio em acetonitrila obtido após a irradiação por seis horas seguido pó repouso por 24 horas em temperatura ambiente. Método de eluição: tampão acetato $40 \mathrm{mM} \mathrm{pH}=4,0 / \mathrm{MeOH}, 5-95 \%$ de $\mathrm{MeOH}$ em $20 \mathrm{~min}$, de $20-35 \mathrm{~min}$ $95 \%$ de $\mathrm{MeOH}$, de $35-45 \min 95-5 \%$ de $\mathrm{MeOH}$, utilizando uma coluna $\mathrm{C} 18$ Luna (250 x 4,6 mm, $5 \mu \mathrm{m}$ - Phenomenex). Volume de injeção: $20 \mu \mathrm{L}$ com fluxo de $1 \mathrm{~mL} / \mathrm{min}$.

Uma evidência adicional para a formação de uma espécie radicalar na fotólise do DIP em acetonitrila, foi obtida pela técnica de ressonância paramagnética eletrônica (RPE). A figura 32 apresenta o espectro de RPE do marcador de spin nitróxido 2,2,6,6 - tetrametilpiperidino-1-N-oxil (TEMPO) sendo suprimido pela presença da espécie radicalar do DIP gerado após o pulso do laser na ausência de oxigênio. 


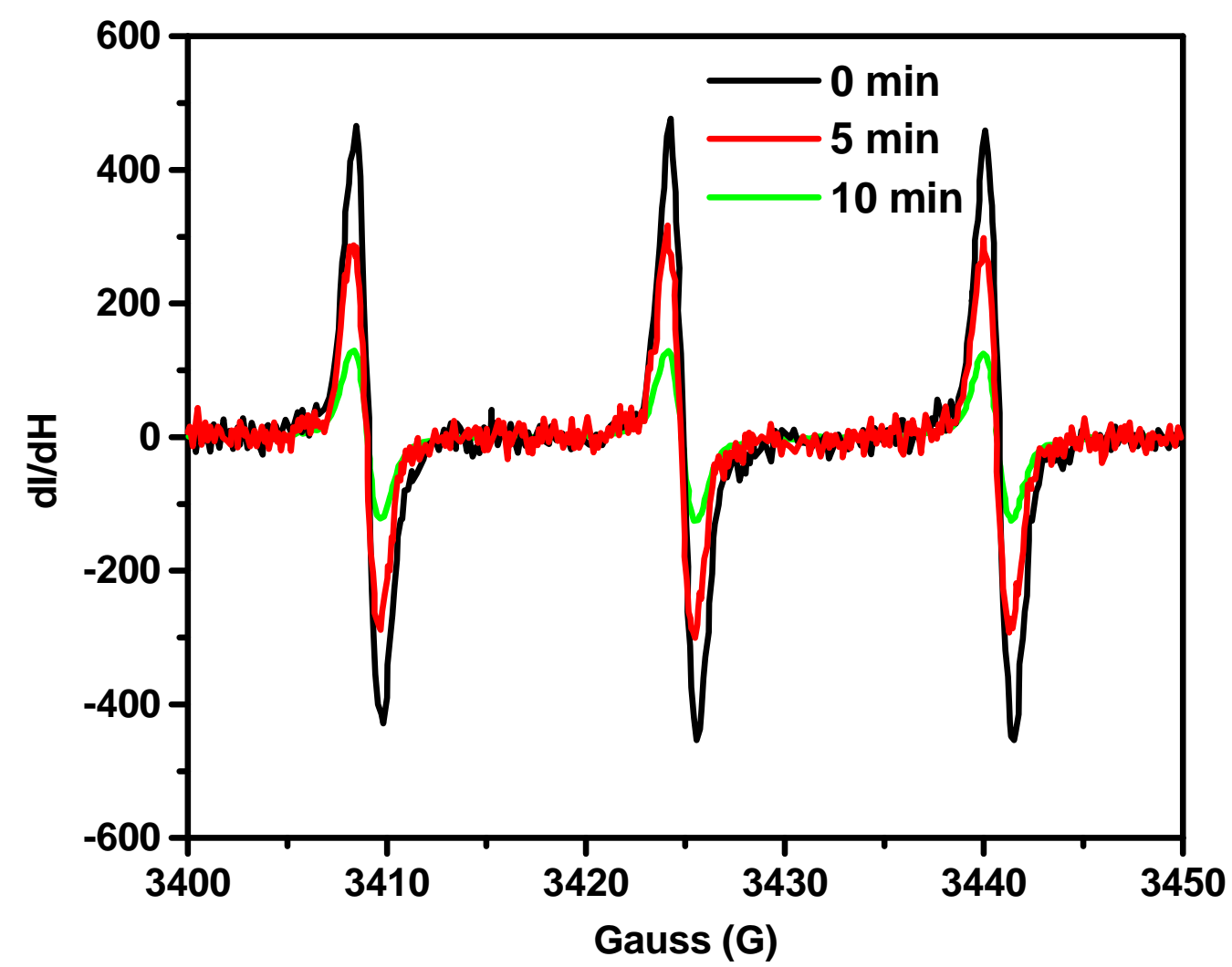

Figura 32: Espectros de EPR obtidos para uma solução de DIP $(0,6 \mathrm{mM})$ na presença do radical nitroxido TEMPO $(0,6 \mathrm{mM})$ em acetonitrila, e saturado com argônio, antes e após irradiação de 5 e 10 min, utilizando um laser de Nd:YAG ajustado para $440 \mathrm{~nm}$ irradiando direto na cavidade do EPR.

O mesmo experimento foi realizado na presença de oxigênio, onde não foi observado nenhum descaimento ou mudança na área do pico, mas uma diferença foi observada na largura de linha devido ao consumo de oxigênio pela espécie transiente gerada pelo DIP. Obteve-se valores de 3,1 G para o TEMPO antes da irradiação e 2,4 $\mathrm{G}$ após 15 min de irradiação.

Como mencionado anteriormente (figura 15) o DIP não produz oxigênio singlete em acetonitrila. De acordo com os dados obtidos pelo EPR e pela fotólise na ausência de oxigênio, o mecanismo de fotooxidação, neste caso, pode ser via radicalar, diferente do que acontece em meio aquoso ácido onde o mecanismo pode ser via reação com oxigênio singlete. Ocorre a formação de uma espécie radicalar que reage com oxigênio molecular formando o dioxietano 
via mecanismo de cicloadição $(2+2)$, o qual não é estável e se decompõe formando produtos.

Se na molécula há átomos doadores de elétrons, tais como $\mathrm{N}$ ou $\mathrm{S}$ adjacentes à dupla ligação, o $\mathrm{O}_{2}\left({ }^{1} \Delta_{g}\right)$ pode reagir formando um dioxetano. Dioxetanos são instáveis e decompõem-se formando compostos contendo grupos carbonílicos ou metanólicos [20, 90]. O intermediário $\mathrm{DIPO}_{2}$, não é muito estável e pode sofrer rearranjo gerando produtos oxidados.

O mecanismo fotoquímico do DIP em acetonitrila pode ser do tipo I, via radicalar como apresentado na figura 33.
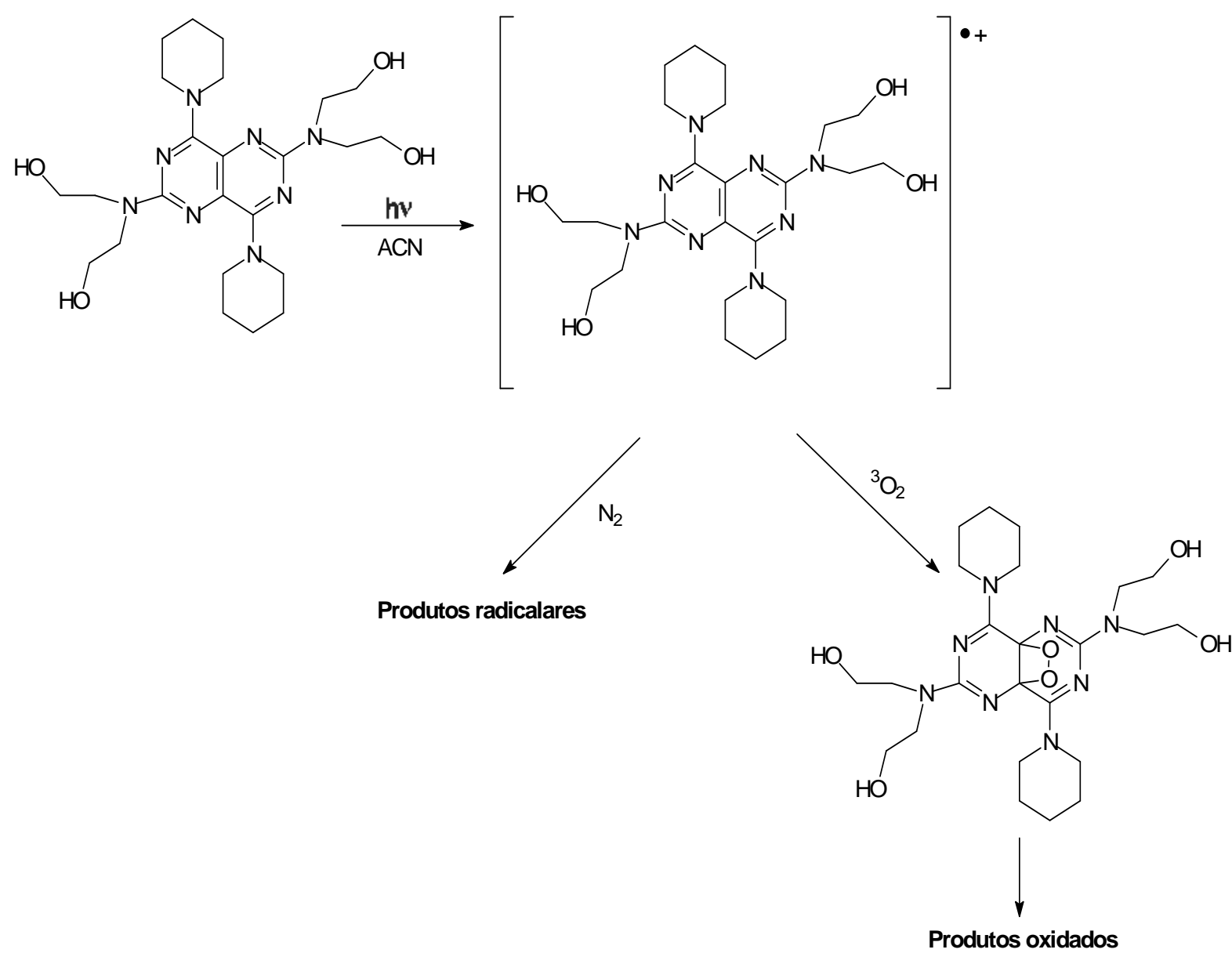

Figura 33: Esquema proposto para o mecanismo de fotodegradação do dipiridamol em acetonitrila. 


\section{7- Fotodegradação do Dipiridamol em meio aquoso ácido}

A fotooxidação do DIP em meio aquoso ácido $\mathrm{pH}=3,0$ foi estudada na presença e na ausência de azul de metileno. Uma solução de DIP $0,5 \mathrm{mM}$ foi irradiada por 6h e a cada hora foi retirada uma alíquota e feita análise por absorção óptica e HPLC.

A figura 34A apresenta resultados do estudo da fotólise do DIP na ausência de azul de metileno em meio aquoso ácido. Neste meio DIP é muito estável a variação do seu espectro de absorção óptica é pequena e o processo de fotooxidação não é tão efetivo.

Pela figura 34B observa-se que a fotooxidação na presença do fotossensibilizador leva ao desaparecimento da banda de absorção do DIP em torno de $400 \mathrm{~nm}$ e ao aparecimento de uma nova banda em torno de $340 \mathrm{~nm}$ que pode estar relacionada à oxidação do DIP pelo $\mathrm{O}_{2}\left({ }^{1} \Delta_{\mathrm{g}}\right)$, sendo que ocorre também a diminuição das bandas centradas em torno de 290 nm e 240nm.

$O$ azul de metileno (AM) (Fig. 5) é um fotossensibilizador que tem características fotoquímicas interessantes, incluindo um alto rendimento quântico de cruzamento intersistemas e uma eficiente produção de oxigênio singlete, tempo de vida longo no estado triplete, tempo de vida curto e baixo rendimento quântico de fluorescência, e baixo potencial de redução. AM pode absorver luz $(h v)$ produzindo AM no estado singlete excitado $\left({ }^{1} \mathrm{AM}^{*}\right)$, e, por um processo de cruzamento intersistemas (ISC), o fotossensibilizador é levado ao estado triplete $\left({ }^{3} \mathrm{AM}^{*}\right) .{ }^{3} \mathrm{AM}^{*}$ transfere sua energia para o estado fundamental triplete do oxigênio molecular $\left(\mathrm{O}_{2}\left({ }^{3} \Sigma_{\mathrm{g}}{ }^{-}\right)\right)$gerando $\mathrm{O}_{2}\left({ }^{1} \Delta_{\mathrm{g}}\right)$ [81].

Um pequeno decaimento na banda do azul de metileno também é observado na figura 34A. De acordo com a literatura o azul de metileno também pode formar espécies radicalares no processo de fotólise, via mecanismo do tipo I [81]. 


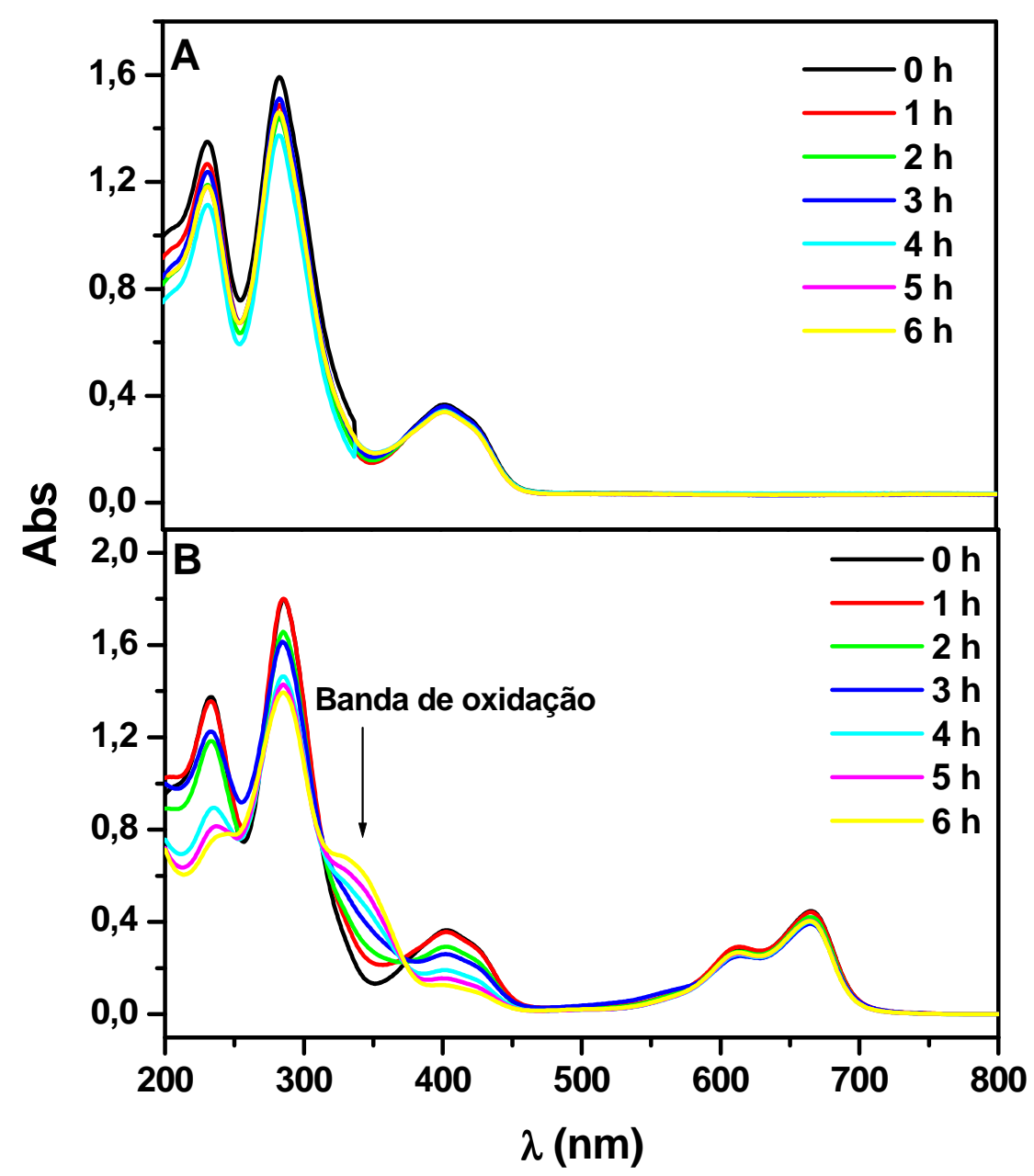

Figura 34: Espectros de absorção óptica da fotooxidação do DIP $0,5 \mathrm{mM}$ em meio ácido $\mathrm{pH}=3,0$, na ausência $(A)$ e na presença $(B)$ de azul de metileno.

Análises cromatográficas foram realizadas antes e após a fotooxidação e são apresentadas na figura 35 .

Para a solução de DIP fotooxidada na ausência de azul de metileno, o cromatograma não apresentou formação de produto.

A figura $35 \mathrm{~A}$ apresenta o cromatograma em meio aquoso ácido para a solução de DIP com azul de metileno. Dois picos com tempos de retenção de 8,9 e 9,3 min foram observados, relacionados ao azul de metileno e ao DIP, respectivamente. As figuras $35 \mathrm{~B}$ e $\mathrm{C}$ apresentam os cromatogramas da 
fotooxidação na presença e na ausência de azul de metileno após $6 \mathrm{~h}$ de irradiação.

A figura 35B apresenta o cromatograma obtido para fotodegradação, na presença de azul de metileno, onde observa-se a presença de três picos com tempos de retenção de 6,3, 9,1 e 9,3 min, respectivamente. Sendo que o pico com tempo de retenção de 6,3 min está relacionado ao produto gerado na reação do DIP com $\mathrm{O}_{2}\left({ }^{1} \Delta_{\mathrm{g}}\right)$, e os outros dois picos correspondem ao azul de metileno e ao DIP não fotooxidados, respectivamente.

O cromatograma da figura $35 \mathrm{C}$ foi obtido após a remoção do azul de metileno com uma resina de troca iônica (Cellex). Observa-se o aparecimento de dois picos adicionais de baixa intensidade, quando comparado com o cromatograma da figura 35B, com tempos de retenção de 3,3 e 5,5 min.

Uma solução de azul de metileno $100 \mu \mathrm{M}$ em meio aquoso ácido foi irradiada por 6 horas. A análise dos espectros de absorção coletados de hora em hora e o cromatograma da solução final não mostraram nenhuma formação de produto, sendo assim, os picos adicionais observados no cromatograma da figura 34C podem não estar relacionados a produtos do azul de metileno. 


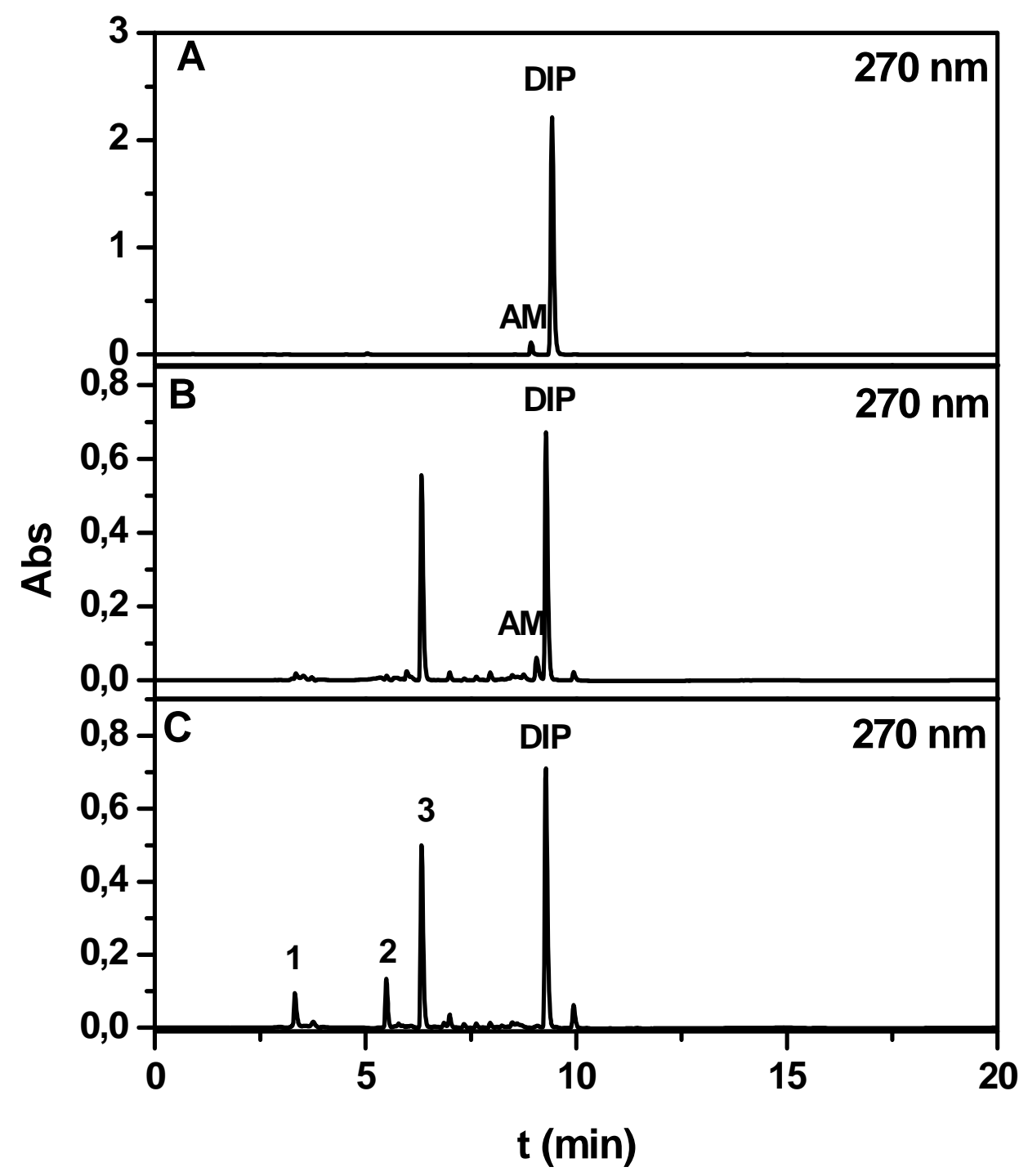

Figura 35: Cromatograma do DIP em meio ácido $\mathrm{pH}=3.0 \mathrm{com}$ azul de metileno (A) e após seis horas de irradiação na presença (B) e na ausência (C) de azul de metileno (AM). Método de eluição: gradiente; ácido fórmico 01\%/ACN, $5-70 \%$ de ACN em $10 \mathrm{~min}, 70-5 \%$ de $A C N$ de $10-15$ min e stop em $20 \mathrm{~min}$, utilizando uma coluna C18 Luna ( $250 \times 4,6 \mathrm{~mm}, 5 \mu \mathrm{m}$ - Phenomenex). Volume de injeção: $20 \mu \mathrm{L}$ com fluxo de $1 \mathrm{~mL} / \mathrm{min}$.

Durante a irradiação alíquotas foram retiradas de hora em hora e analisadas por HPLC. As áreas dos picos obtidos no cromatograma da figura 35C foram transformadas em porcentagem e estão apresentadas na figura 36 em função do tempo de irradiação. Observa-se o consumo de DIP à medida que 
se forma o produto de fotooxidação, sendo que neste meio em $6 \mathrm{~h}$ de irradiação praticamente $50 \%$ de produto oxidado é formado.

Observa-se também que os produtos com tempos de retenção de 3,3 e 5,5 min são formados em baixíssima porcentagem em torno de 5\%.

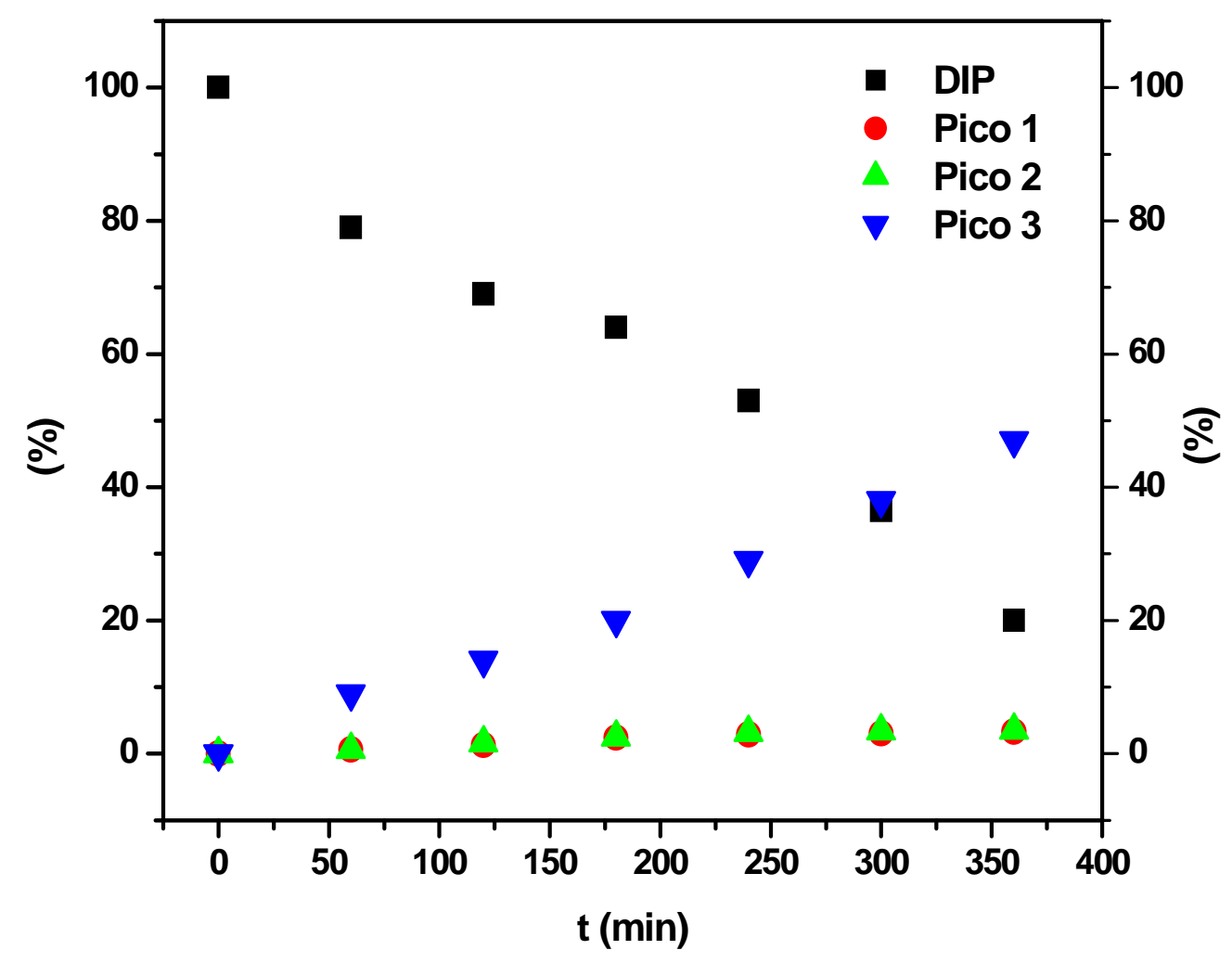

Figura 36: Porcentagens das áreas dos picos obtidos na reação de fotooxidação do DIP (Fig. 35C) em função do tempo de irradiação. Os picos 1,2 e 3 correspondem aos tempos de retenção 3,3, 5,5 e 6,3 min da figura 35C.

A solução utilizada na análise correspondente ao cromatograma da figura 35 C foi monitorada por LC-MS-MS. Para esta análise foi necessária a remoção do azul de metileno, com a resina de troca iônica (Cellex), pois este composto pode contaminar o equipamento. A figura 37 apresenta os espectros de massas para os compostos com tempos de retenção de 3,3 e 5,5 min. Observa-se que 
esses compostos são isóbaros e apresentam $\mathrm{m} / z$ de 472 e íons fragmentos de $m / z 253$.

Este composto também foi detectado como produto na eletrooxidação do DIP no meio aquoso ácido [38], onde a formação do mesmo pode ser via radicalar. Sabendo que o azul de metileno pode formar espécies radicalares sob fotólise, este composto pode ter sido formado pela reação com o radical do azul de metileno.

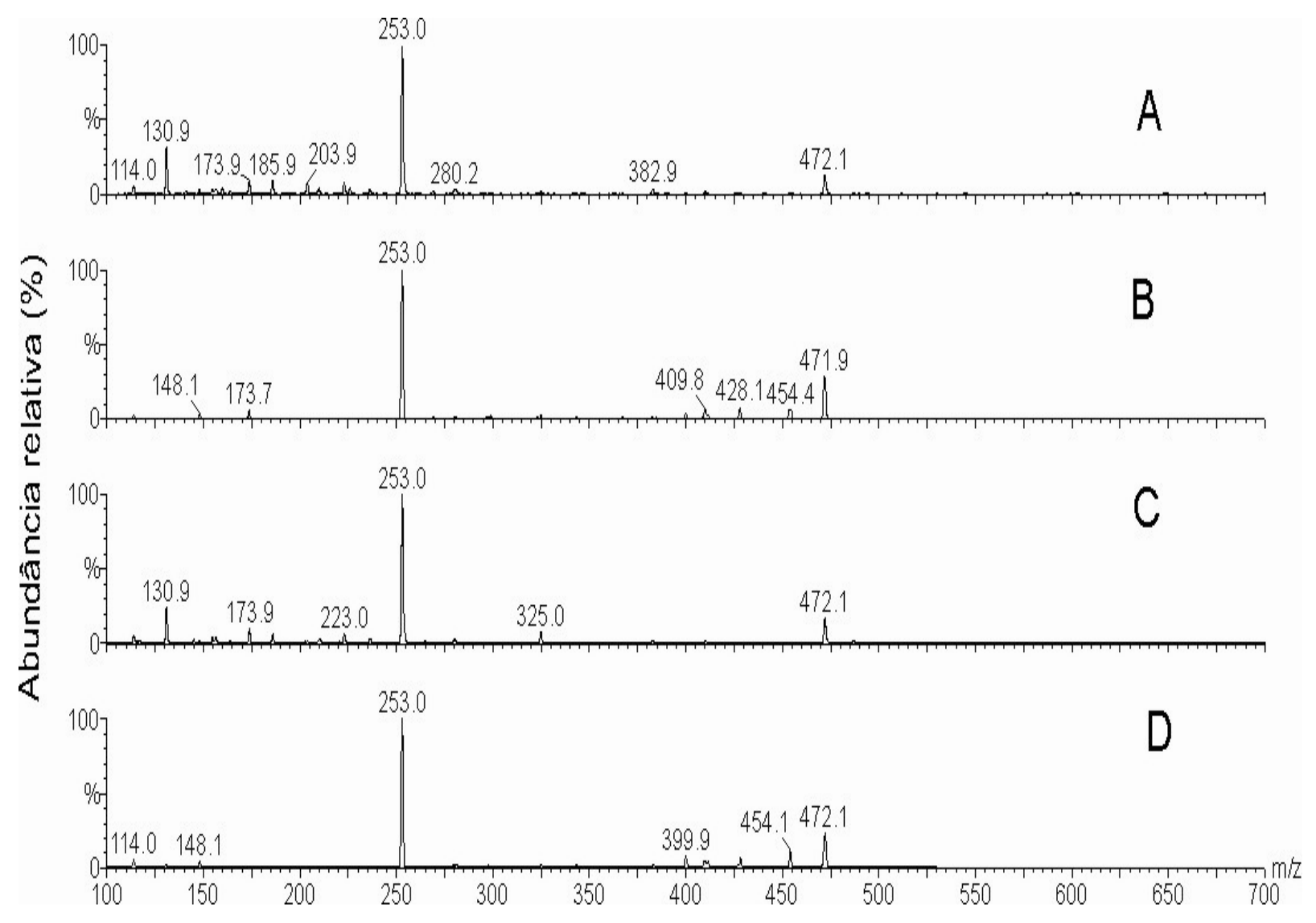

Figura 37: Espectros de massas dos produtos da fotooxidação em meio aquoso ácido $\mathrm{pH}=3,0$ após $6 \mathrm{~h}$ de irradiação, com tempos de retenção de 3,3 e 5,5 min (Fig. 35C). (A e C) ESI/EM no modo positivo, voltagem do cone $40 \mathrm{~V}$, voltagem do capilar 3,6 kV. (B e D) Respectivos íons fragmentos do produto de $\mathrm{m} / \mathrm{z} 472$ $\mathrm{Da}$, energia de colisão de $30 \mathrm{eV}$. 
O produto majoritário gerado pela reação do DIP com $\mathrm{O}_{2}\left({ }^{1} \Delta_{\mathrm{g}}\right)$ apresenta peso molecular de $268 \mathrm{Da}$, como visto pelo espectro de massas apresentado na figura 38. Este composto também foi detectado na fotooxidação em acetonitrila e na eletrooxidação. De acordo com a fragmentação obtida para os íons fragmentos, a primeira perda de massa correspondente ao pico de $m / z 251$, pode estar relacionada à perda de água, que pode ser proveniente do substituinte etanolamínico, a segunda perda de massa correspondente ao pico de $m / z 225$ está relacionada à perda de um grupo $-\mathrm{CH}_{2} \mathrm{CH}_{2} \mathrm{OH}$. A partir do íon de $m / z 225$ ocorre outra perda de água que corresponde ao íon de $m / z 207$, o íon de $\mathrm{m} / \mathrm{z} 181$ está relacionado à perda de outro grupo $-\mathrm{CH}_{2} \mathrm{CH}_{2} \mathrm{OH}$, sendo este um fragmento do íon de $\mathrm{m} / \mathrm{z} 225$. O íon de $\mathrm{m} / \mathrm{z} 164$ está relacionado à perda completa do substituinte, etanolamina. O íon de $\mathrm{m} / \mathrm{z} 111$ está relacionado à perda de 84 Da a partir do íon de $\mathrm{m} / \mathrm{z} 195$, referente ao anel piperidina.

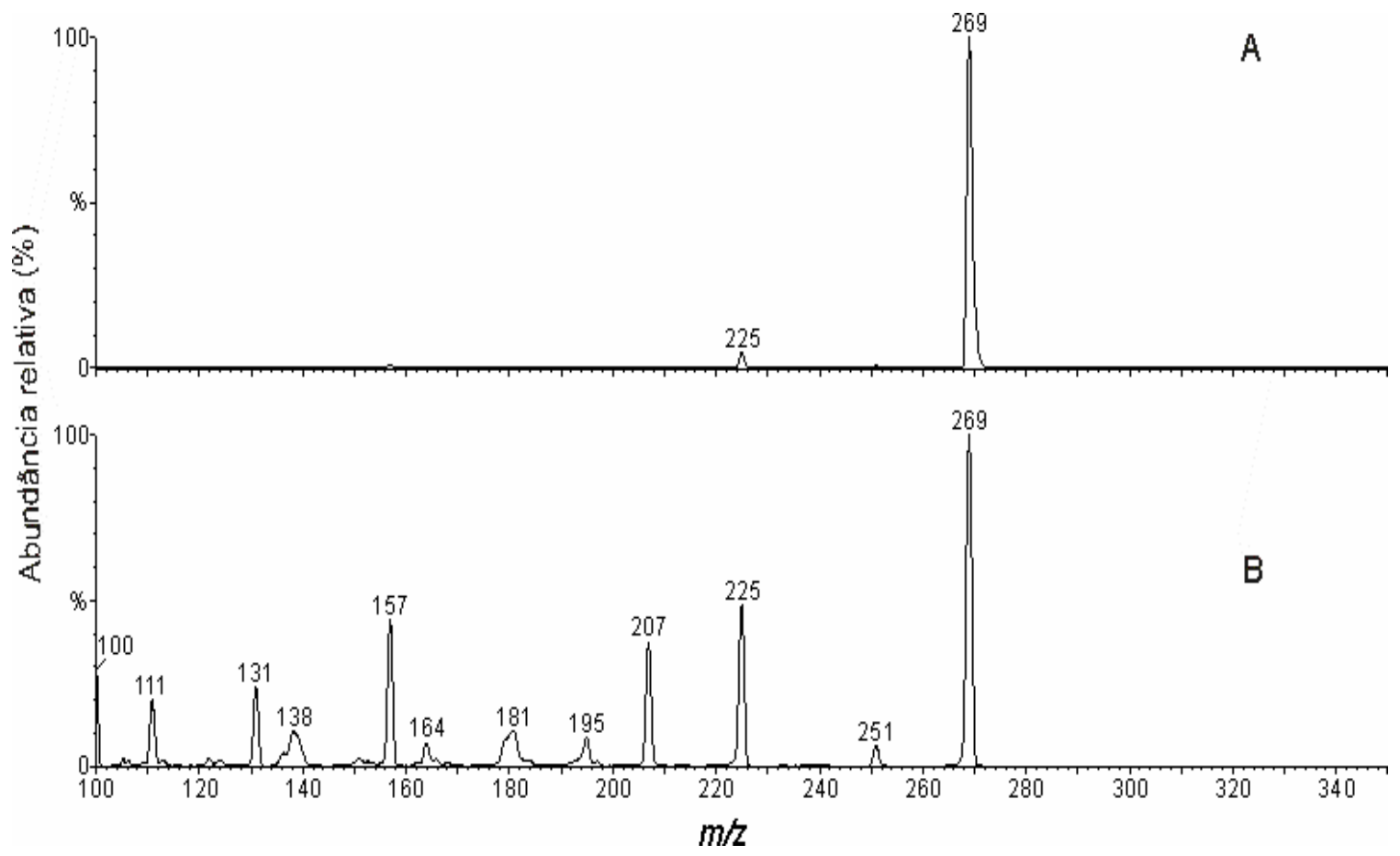

Figura 38: Espectros de massas do produto da fotooxidação em meio aquoso ácido $\mathrm{pH}=3,0$ após $6 \mathrm{~h}$ de irradiação, com tempo de retenção de 6,3 min. (A) $\mathrm{ESI} / \mathrm{EM}$ no modo positivo, voltagem do cone $40 \mathrm{~V}$, voltagem do capilar $3,6 \mathrm{kV}$. (B) Respectivos íons fragmentos do produto de $\mathrm{m} / z 269$, energia de colisão de $30 \mathrm{eV}$. 
Para confirmar o envolvimento do oxigênio na reação de fotooxidação, experimentos com oxigênio-18 foram realizados. A figura 39 apresenta 0 espectro de massas, obtido por injeção direta, para a fotooxidação do DIP em meio aquoso ácido na presença de oxigênio-18. Observa-se a incorporação do oxigênio-18 pela diferença de duas unidades de massa referente ao pico com $m / z 271$.

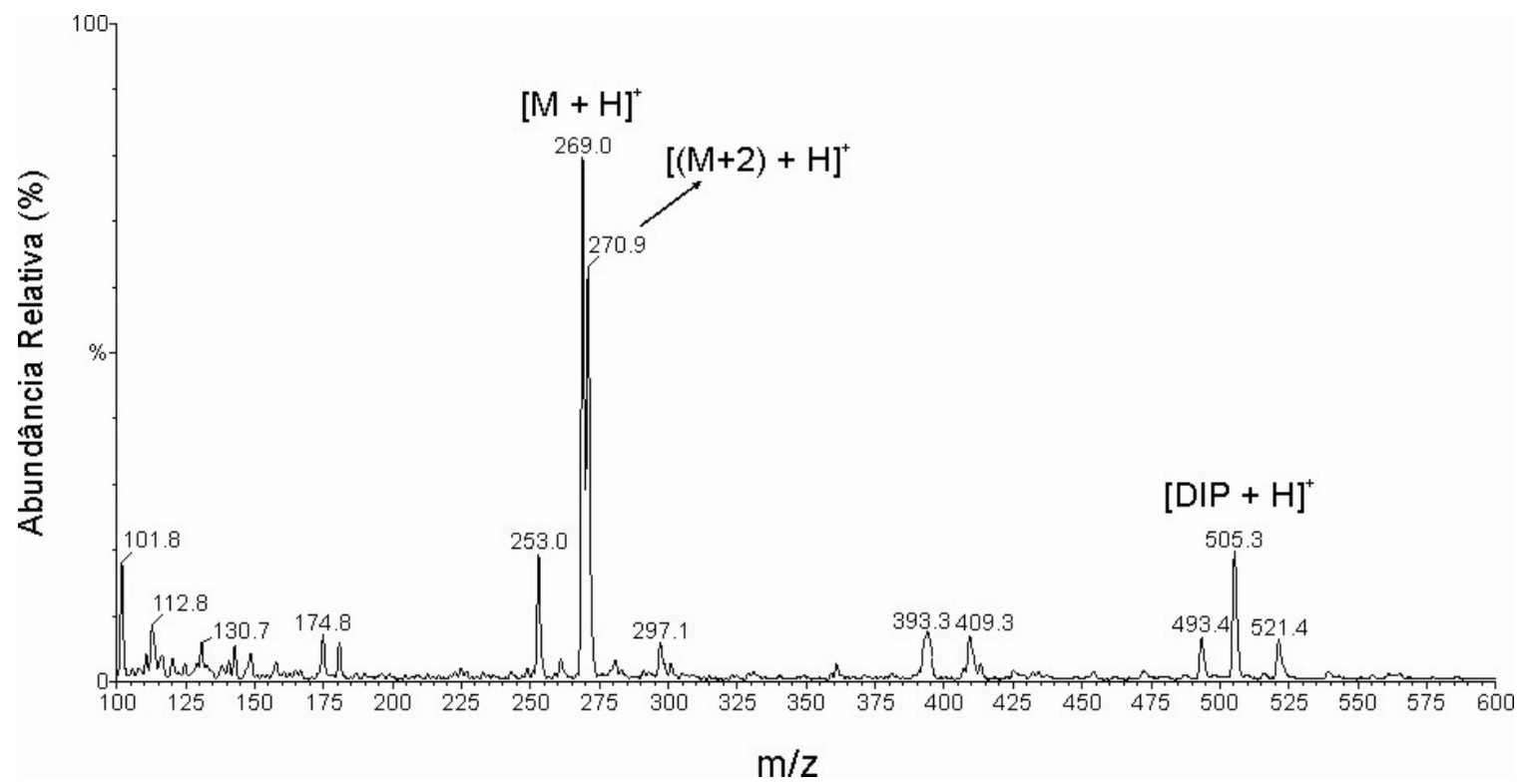

Figura 39: Espectro de massas do produto da fotooxidação em meio aquoso ácido $\mathrm{pH}=3.0$ após $6 \mathrm{~h}$ de irradiação na presença de oxigênio-18. ESI/EM no modo positivo, voltagem do cone $40 \mathrm{~V}$, voltagem do capilar $3,6 \mathrm{kV}$.

$\mathrm{Na}$ fotooxidação em meio aquoso ácido, podemos observar que o mecanismo predominante é do tipo II, ou seja, o DIP reage com o $\mathrm{O}_{2}\left({ }^{1} \Delta_{\mathrm{g}}\right)$ gerado pelo azul de metileno. Mas uma pequena contribuição radicalar via mecanismo do Tipo I, também foi observada.

A figura 40 apresenta uma proposta para 0 mecanismo de fotodegradação em meio ácido $\mathrm{pH}=3,0$. O DIP reage com $\mathrm{O}_{2}\left({ }^{1} \Delta_{\mathrm{g}}\right)$ formando o dioxetano pela reação de cicloadição (2+2). 
Para oxidar o DIP em meio aquoso ácido é necessário um maior potencial eletroquímico, quando comparado com acetonitrila [35], sendo que no meio aquoso não ocorre a formação do radical cátion. Este fato pode estar relacionado com a dificuldade de fotooxidar o DIP neste meio, ou seja, ocorre uma competição do próton do meio que se liga ao anel pirimido-pirimidino pela presença do $\mathrm{O}_{2}\left({ }^{1} \Delta_{\mathrm{g}}\right)$.<smiles>CCOC(=O)OCCO</smiles>

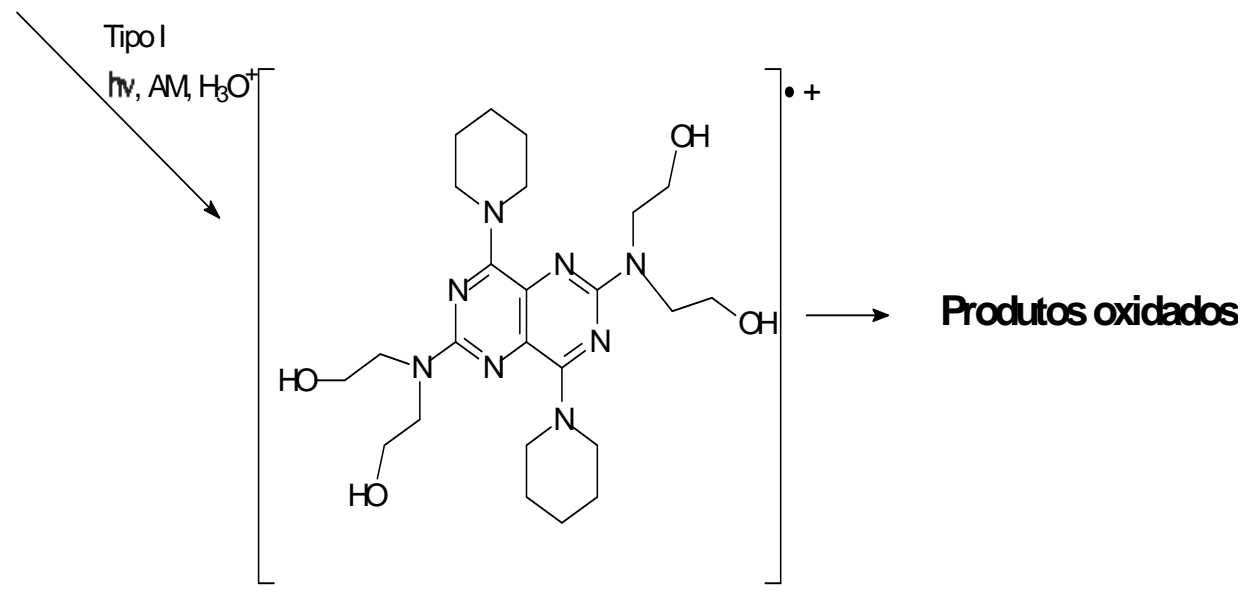

Figura 40: Esquema proposto para o mecanismo de fotodegradação do dipiridamol em meio aquoso ácido $\mathrm{pH}=3,0$. 


\section{8- Caracterização parcial da hemoglobina gigante de Glossoscolex paulistus por MALDI-TOF-MS.}

Análises utilizando a técnica de MALDI-TOF-MS foram realizadas para obter informações sobre a massa molecular das diferentes subunidades da hemoglobina extracelular gigante de Glossoscolex paulistus (HbGp) na forma Oxy. Os resultados obtidos foram comparados com a hemoglobina homóloga de Lumbricus terrestris ( $\mathrm{HbLt}$ ) para a atribuição das massas das subunidades da HbGp.

A figura 41 apresenta o espectro de massas para $\mathrm{HbGp}$ em $\mathrm{pH} 7,0$ obtido utilizando a técnica de MALDI-TOF-MS no modo positivo. A matriz utilizada foi ácido sinápico na proporção de 1:10 (v/v). A figura 41A mostra os picos designados para as subunidades do monômero $d$, o trímero $(a b c)$ e as cadeias linkers (L). Os picos de maiores intensidades correspondem ao monômero $d$ com uma e duas protonações, denominados como: $d^{+}$e $d^{2+}$. Observa-se que a subunidade do monômero d é facilmente detectada, fornecendo picos intensos.

$\mathrm{O}$ espectro da figura $41 \mathrm{~A}$ apresenta picos com massas de $25.817 \pm 50 \mathrm{e}$ 26.761 $\pm 16 \mathrm{Da}$ que podem estar relacionadas às cadeias linkers, $L_{1}$ e $L_{2}$. Picos duplos de baixa intensidade com massas de 12.875 e $13.375 \mathrm{Da}$, são observados e podem estar associados aos linkers duplamente protonados, $\mathrm{L}^{2+}$. Podemos considerar também que nesta faixa de massa, os picos que foram atribuidos às cadeias linkers, correspondam também às moléculas do trímero duplamente protonadas $(\mathrm{abc})^{2+}$.

Os picos com massas de 51.111 e $51.933 \mathrm{Da}$, foram atribuídos ao trímero $(\mathrm{abc})^{+}$. Mas é também possível que a molécula do trímero triplamente protonada $(a b c)^{3+}$ possa ser responsável pela largura dos picos do monômero $d$, os quais aparecem com uma baixa intensidade em torno de $16.820 \mathrm{Da}$ (Fig. 41B).

$\mathrm{O}$ inserto da figura $41 \mathrm{~A}$ mostra alguns picos de baixa intensidade, os quais correspondem às espécies do trímero e linkers. Os picos relacionados às cadeias linkers, $\mathrm{L}_{1}{ }^{+} \mathrm{e} \mathrm{L}_{2}{ }^{+}$, têm intensidade em torno de 13-15\% comparado com o pico do monômero $\mathrm{d}^{+}$. O dímero de monômero com uma protonação, $(2 \mathrm{~d})^{+}$, o 
qual tem uma massa de $32.530 \mathrm{Da}$, corresponde a $3 \%$ da intensidade do $\mathrm{d}^{+}$. É possível que ocorra uma superposição deste dímero, $(2 \mathrm{~d})^{+}$, com uma terceira cadeia linker, $L_{3}$, mas em baixa concentrações quando comparado a $L_{1}$ e $L_{2}$. $O$ pico relacionado ao trímero $(a b c)^{+}$, é relativamente largo e pode conter alguma contribuição do dímero do linker, (2L) ${ }^{+}$, não bem resolvido.

As figuras 41B e C mostram as regiões expandidas de 15.600 a 18.800 e 8.050 a 8.600 , correspondendo, respectivamente, a uma e duas protonações do monômero $d, d^{+}$e $d^{2+}$. As intensidades dos picos denominados $d_{3}$ e $d_{4}$ na figura 1C sugerem que eles podem estar associados às isoformas minoritárias do monômero $\mathrm{d}$. De acordo com as figuras $41 \mathrm{~B}$ e $\mathrm{C}$ as massas paras as isoformas do monômero d foram estimadas e são apresentadas na Tabela 41.

Os resultados obtidos para HbGp integra, parcialmente dissociada em $\mathrm{pH}$ 9,0, foram similares aos obtidos em pH 7,0 (Fig. 41A).

A comparação entre as massas das subunidades das hemoglobinas HbGp e HbLt está apresentada na Tabela 3. Dados da literatura sobre a hemoglobina de Lumbricus terrestris relata a existência de quatro diferentes espécies de cadeias linker [54,91]. De fato, Martin e colaboradores [92] encontraram massas de $27.702 \mathrm{Da}\left(L_{1}\right), 32.104 \mathrm{Da}\left(\mathrm{L}_{2}\right), 24.913 \mathrm{Da}\left(\mathrm{L}_{3}\right)$ e 24.170 Da $\left(L_{4}\right)$ para quatro cadeias linker da $\mathrm{HbLt}$, usando a técnica de electrospray (ESI - MS). No presente estudo somente duas cadeias linker foram encontradas para $\mathrm{HbGp}$.

Os nossos resultados sugerem uma similaridade entre as subunidades da HbGp e HbLt, mas nossas análises ainda são preliminares e é necessário uma separação das subunidades da hemoglobina para obter uma melhor caracterização. Os picos observados para as duas cadeias linkers e os trímeros são bem largos sugerindo que pode existir alguma heterogenidade para estas cadeias na proteína, visto que a ionização destas subunidades não é tão eficiente quanto para o monômero, não há uma boa resolução na separação das isoformas. Além disso, outros trabalhos com HbLt também reportam dificuldades na completa caracterização das quatro cadeias linkers [93]. Nossas atribuições 
para a figura 41A são baseados na comparação das massas encontradas para HbLt em análises de MALDI-TOF-MS [92,93].
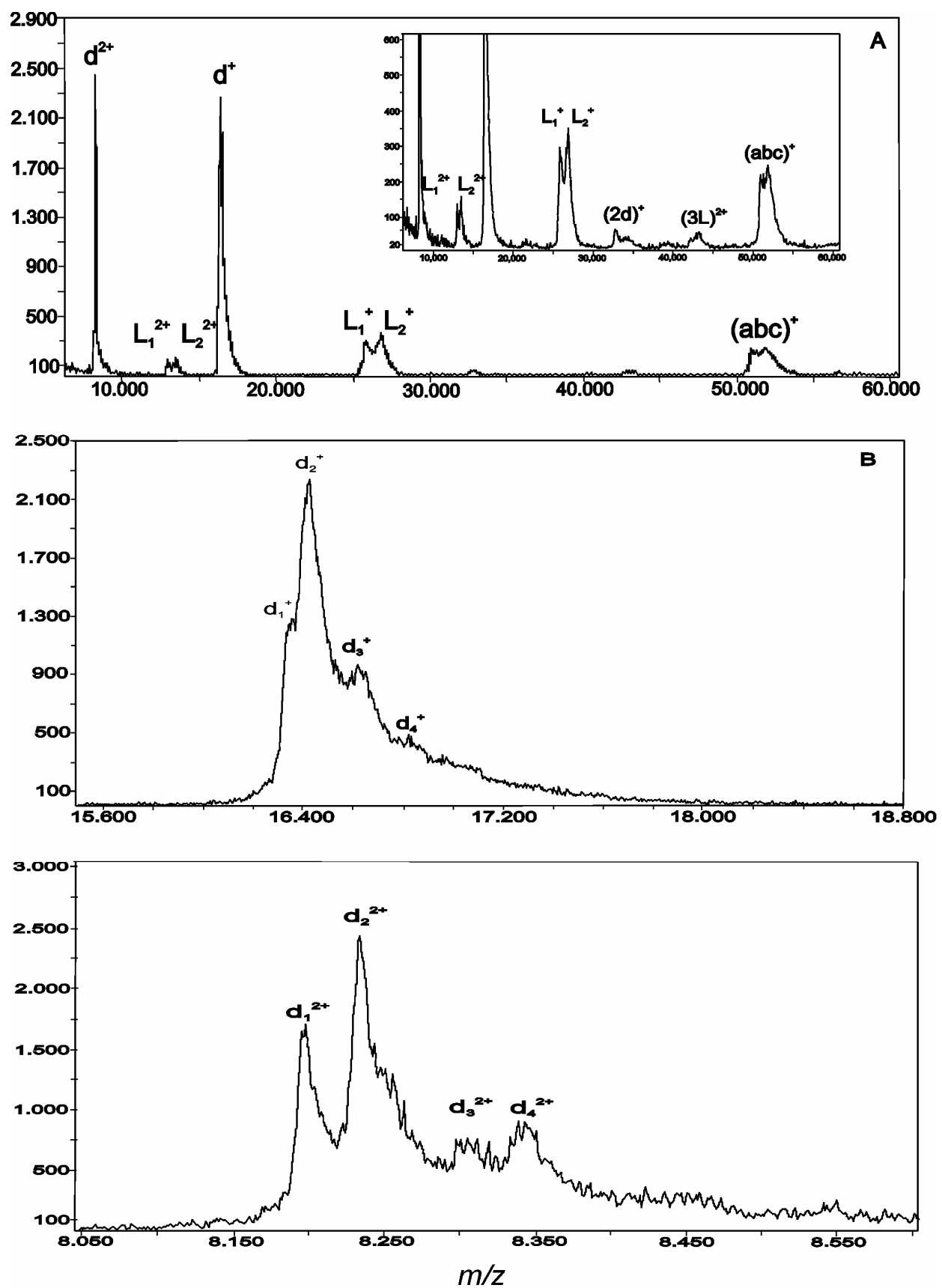

Figura 41: (A) Espectro de massas da HbGp íntegra na forma Oxy em pH 7,0. O inserto mostra a região ampliada, enfatizando os picos de menor intensidade; (B) região expandida de 15.600 a $18.800 \mathrm{Da}$, correspondente ao monômero protonado $\mathrm{d}^{+}$. (C) região expandida de 8.050 a $8.600 \mathrm{Da}$, correspondente ao monômero duplamente protonado $\mathrm{d}^{2+}$. 
Os valores para as massas das subunidades da $\mathrm{HbGp}$, apresentados na Tabela 3, foram calculados como as médias das massas obtidas para as moléculas com uma e duas protonações. A comparação é feita para dados da proteína íntegra (Fig. 41), a fração do monômero d na forma pura (Fig. 42) e a proteína integra submetida a redução das ligações disulfeto com 2mercaptoetanol (Fig. 43).

Tabela 3. Massas obtidas por MALDI-TOF-MS em Da para as cadeias e subunidades das hemoglobinas extracelulares de Glossoscolex paulistus (HbGp) e Lumbricus terrestris (HbLt).

\begin{tabular}{c|c|c|c|c}
\hline Cadeias/subunidades & HbGp (Fig. 41) & HbGp (Fig. 42) & HbGp (Fig. 43) & HbLt $^{\mathrm{cd}}$ \\
\hline $\mathrm{d} 1$ & $\begin{array}{c}16.372 \pm 18 \\
(16.188)^{\mathrm{a}}\end{array}$ & $16.355 \pm 25$ & $16.366 \pm 22$ & 15.991 \\
\hline $\mathrm{d} 2$ & $16.447 \pm 19$ & $16.428 \pm 24$ & $16.436 \pm 24$ & 15.988 \\
\hline $\mathrm{d} 3$ & $16.613 \pm 7$ & $16.580 \pm 24$ & $16.610 \pm 16$ & 15.958 \\
\hline $\mathrm{d} 4$ & $16.750 \pm 70$ & $16.650 \pm 26$ & $16.681 \pm 5$ & ----- \\
\hline $\mathrm{b}$ & & & $16.492 \pm 24$ & 16.248 \\
\hline $\mathrm{c}$ & & & $17.363 \pm 17$ & 17.290 \\
\hline $\mathrm{A}$ & $25.817 \pm 50$ & & $18.258 \pm 30$ & 19.386 \\
\hline L1 & $26.761 \pm 16$ & & $25.869 \pm 5$ & 27.728 \\
\hline L2 & $34.130^{\mathrm{b}}(?)$ & & $26.912 \pm 32$ & 32.251 \\
\hline L3 & & & $34.630^{\mathrm{b}}(?)$ & 24.919 \\
\hline L4 & $51.111 / 51.933$ & & & 24.170 \\
\hline T (abc) & & & 52.868 \\
\hline
\end{tabular}

${ }^{a}$ O valor entre parenteses é referente ao sequenciamento relatado na referência 67.

b Este linker L3 é sobreposto pelo dímero de monômero (2d). A sua quantidade presente é provavelmente muito menor comparado com L1 and L2.

${ }^{c}$ Retirado das referências 92 e 93.

${ }^{d}$ A referência 91 relata estimativas recentes para as quatro cadeias linkers da HbLt. As cadeias L3 e L4 são bastante similares aos valores encontrados para HbGp, mas L1 e L2 são bastante diferentes. 
A Figura 42A mostra o espectro de massas para o monômero d, obtido na cromatografia por filtração em gel da $\mathrm{HbGp}$ em $\mathrm{pH}$ 9.0. Três picos são claramente observados no espectro: o pico da molécula do monômero protonado, $\mathrm{d}^{+}$, o pico correspondente ao dímero do monômero protonado, $(2 \mathrm{~d})^{+}$, e o monômero com duas protonações, $d^{2+}$, com massas de $16.355 \pm 25,32.710 \mathrm{e}$ 8.177 $\pm 25 \mathrm{Da}$, respectivamente. No inserto da Figura 42A são apresentados os picos de menor intensidade associados aos dímeros e trímeros do monômero d. É interessante observar que os picos correspondendo ao dímero de monômero com uma protonação, $(2 \mathrm{~d})^{+}$, parece ter uma melhor homogenidade quando comparados com o inserto da figura 41A. Isto pode explicar a existência de uma terceira cadeia linker, $L_{3}$, nesta região de massa, não bem resolvida devido sua baixa quantidade. Este pico corresponde a $10 \%$ da intensidade do pico do monômero com uma protonação, $\mathrm{d}^{+}$, entretanto os outros picos menores associados as moléculas duplamente e triplamente protonadas tem uma intensidade relativa de $2-3 \%$. Como mostra a figura $42 \mathrm{~B}$, ao menos duas isoformas do monômero são observadas com intensidades maiores (aproximadamente numa proporção de 1:1), $d_{1}$ e $d_{2}$. Dois picos adicionais de menor intensidade, $d_{3}$ e $d_{4}$, foram também observados com uma resolução, relativamente baixa.

Pode-se observar também que a análise do monômero d na Figura 42B aparece com melhor resolução quando comparada com a análise do monômero na proteína intrega (figura 41B). A figura $42 \mathrm{C}$ mostra a parte do espectro expandida que corresponde ao monômero com duas protonações, $d^{2+}$. A resolução dos picos é bem melhor quando comparada com a figura $41 \mathrm{C}$, reforçando a questão de que os picos $d_{3}$ e $d_{4}$ correspondem a isoformas minoritárias do monômero d. Baseando-se nas figuras 42B e $\mathrm{C}$ as massas estimadas para as isoformas do monômero d foram estimadas e são apresentadas na Tabela 3.

Considerando que a massa molecular do grupo heme é $616 \mathrm{Da}$, a diferença entre os picos na figura 42B não pode estar associada a perda do grupo heme das cadeias globinas e por esta razão corresponde a diferentes 
isoformas do monômero d. Estas massas distintas podem estar relacionadas aos diferentes números de resíduos de aminoácidos nas respectivas cadeias. A massa molecular média por resíduo de aminoácido é aproximadamente de 114 Da e a diferença de massa encontrada para as isoformas do monômero d corresponde a no máximo dois ou três resíduos de aminoácidos.

Para o monômero da $\mathrm{HbLt}$ três isoformas foram relatadas com intensidades relativas de 1:0,5:0,3 e com massas de 15.991, 15.988 e $15.958 \mathrm{Da}$ [92,93]. Cabral e colaboradores [94], usando o método de degradação de Edman, determinaram a estrutura primária do monômero d da HbGp. Neste estudo 142 resíduos de aminoácidos foram encontrados na seqüência do monômero $\mathrm{d}$. Visto que a massa média de um resíduo de aminoácido é em torno de $114 \mathrm{Da}$, uma massa média de 16.188 Da foi obtida para o monômero d com base nesta seqüência. Este valor é menor quando comparado aos valores encontrados para as isoformas do monômero d por MALDI-TOF-MS (Tabela 3), sugerindo que na massa obtida pelo seqüênciamento [94] falta de um a dois resíduos de aminoácidos. Ownby e colaboradores [87] também relataram uma massa de 15.989 para o monômero d da HbLt usando espectrometria de massas, entretanto eles também obtiveram uma massa de 16.131 Da através da seqüência de resíduos de aminoácidos. Estas diferenças podem ser atribuídas às limitações do método de seqüênciamento, especialmente quando relacionados a determinação das diferentes isoformas das subunidades da proteína que apresentam massas diferentes e contribuições diferentes na solução de monômeros analisada. 

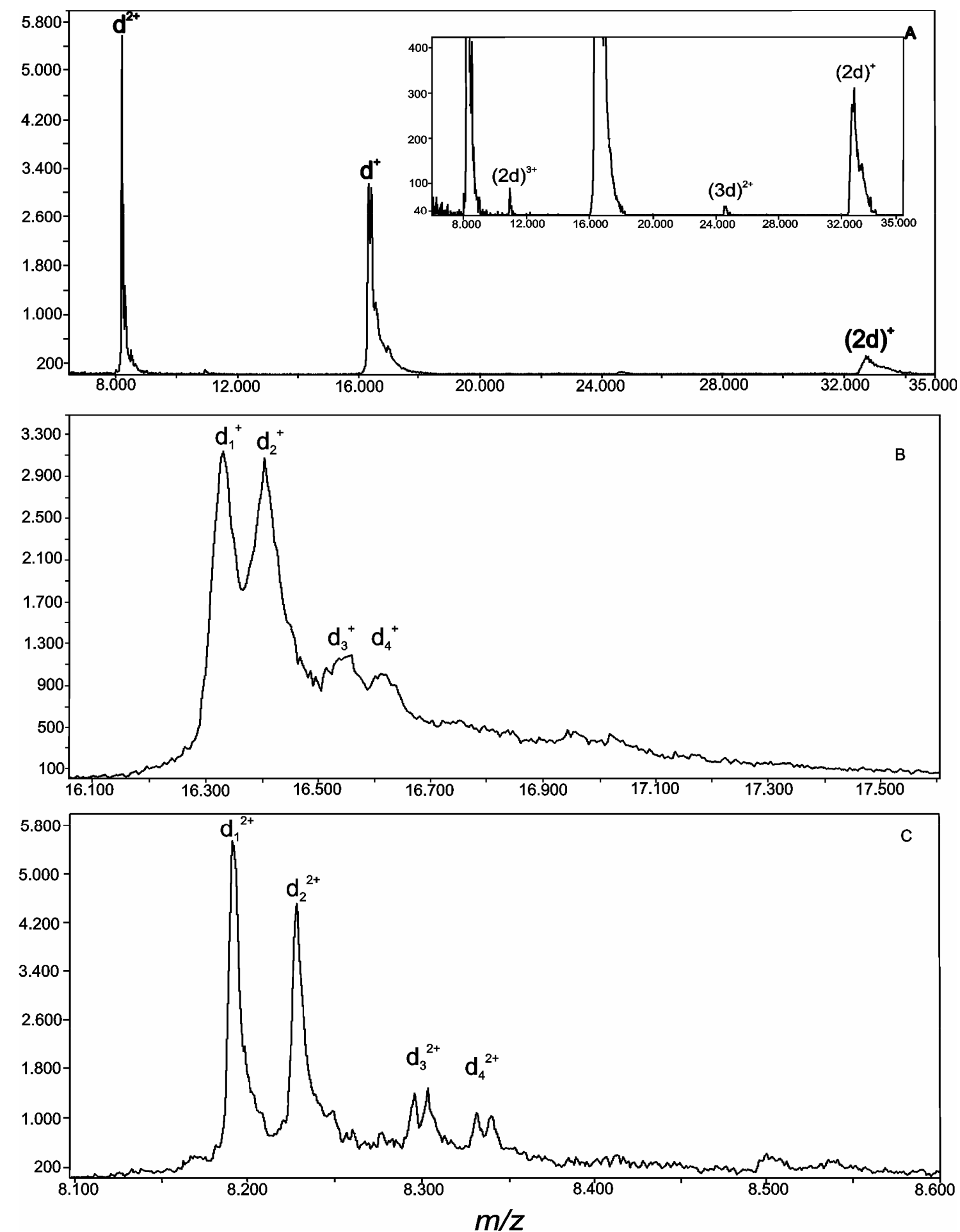

Figura 42: (A) Espectro de massas do monômero d obtido na filtração em gel em $\mathrm{pH}$ 9,0. O inserto mostra a região do espectro ampliada, enfatizando os picos de menor intensidade; (B) região expandida de 16.000 a $17.600 \mathrm{Da}$, correspondente ao monômero protonado $\mathrm{d}^{+}$. (C) região expandida de $8.100 \mathrm{a}$ 8.600 Da, correspondente ao monômero duplamente protonado $\mathrm{d}^{2+}$. 
HbGp foi submetida a reação para a redução das pontes de sulfeto do trímero na presença de 2-mercaptoetanol. A figura 43A mostra o espectro de MALDI-TOF-MS para esta amostra. Observa-se que os picos de baixa intensidade relacionados ao trímero em torno de 51-52 kDa desapareceram. Picos de baixa intensidade aparecem em torno de 33 e $26 \mathrm{kDa}$, os quais, de acordo com a interpretação da figura $41 \mathrm{~A}$, podem estar relacionados: aos dímeros de monômeros, (2d), (2b), (2c), ao Linker $L_{3}$ em baixa quantidade ou aos linkers $L_{1}$ e $L_{2}$.

No inserto da figura 43A estes picos minoritários são mostrados mais claramente. O pico em torno de $10,4 \mathrm{kDa}$ foi interpretado como o dímero de monômero triplamente protonado, $(2 \mathrm{~d})^{3+}$, de acordo com os resultados da figura 42A. Estudos anteriores de Shlom e Vinogradov [89], envolvendo a redução de HbLt com mercaptoetanol, reportaram cadeias adicionais de massas em torno de 24-33 kDa que foram designadas como dímeros de pequenos polipeptídeos, monitorados por eletroforese. Estas massas foram posteriormente associadas as cadeias linkers [69, 92, 95].

Por outro lado, na faixa de $33 \mathrm{kDa}$ os dímeros de monômeros, mencionados acima, pode também incluir misturas de dímeros mistos como ab, bc ou ac, os quais ocorrem devido a redução incompleta das ligações disulfeto dos trímeros.

$\mathrm{Na}$ faixa de massa associada ao monômero d, centrado em 16 kDa, alguns novos picos são observados, os quais estão associados as cadeias monoméricas, originadas a partir da redução das ligações disulfeto do trímero, cadeias a, b e c. A figura 43B mostra uma expansão do espectro na faixa de massa de 16,0 a 18,8 kDa. Um pico de baixa intensidade é observado em 18.258 $\pm 30 \mathrm{Da}$, dois picos adicionais de intensidade média aparecem em $17.363 \pm 17$ e $16.492 \pm 24 \mathrm{Da}$, os quais provavelmente correspondem aos monômeros dissociados do trímero (abc).

A figura 43C mostra o espectro de massas na região de $\mathrm{d}^{2+}$, mostrando os monômeros duplamente protonados, originados pela redução do trímero. Observa-se um aumento na resolução para os picos centrados em 8,1-8,3 kDa, 
correlacionando com os dados apresentados nas figuras $41 \mathrm{C}$ e $42 \mathrm{C}$. Baseado nas massas para as isoformas do monômero d na HbGp total obtidos da figura 43B e C as massas moleculares foram estimadas e são apresentadas na Tabela 3.

Comparando os picos originados no processo de redução com dados reportados na literatura para $\mathrm{HbLt}$, por Ownby e colaboradores, observou-se uma similaridade nas massas das cadeias $\mathrm{a}$, b e c do trímero da HbGp com a HbLt. Ownby e colaboradores [93] encontraram massas de 19.386, 16.248 e 17.290 Da para as cadeias a, b e c respectivamente, enquanto que para a HbGp, após o processo de redução, foram encontradas massas de 18.258 \pm 30 , $16.492 \pm 24$ e $17.363 \pm 17 \mathrm{Da}$, respectivamente. Os valores acima foram obtidos da média dos valores das massas das subunidades com uma e duas protonações.

É importante mencionar que Ownby e colaboradores [93] sugerem que o valor de massa maior atribuido a cadeia $a$, quando comparado com as cadeias $b$ e c, é atribuído a presença de carboidratos, os quais no caso da HbLt somente são encontrados na cadeia a.

Picos adicionais de baixa intensidade marcados com $\left(^{*}\right)$ podem corresponder a íons de adutos da mistura matriz/proteína gerados fotoquimicamente, os quais podem ocorrer em experimentos de MALDI-TOF-MS [93].

Em trabalhos anteriores, experimentos de eletroforese em gel de SDSpoliacrilamida da HbGp apresentaram bandas características de polipeptideos correspondendo ao trímero de massa molecular em torno de $53,0 \mathrm{kDa}$, o qual foi reduzido pelo mercaptoetanol originando três monômeros de peso molecular de $14,8,15,8$ e 16,6 kDa [96]. Neste caso podemos explicar a diferença de massa tendo em vista que eletroforese é uma técnica limitada devido a uma incerteza experimental, em torno de 1-5\% [68] na determinação da massa molecular. Além disso, pode apresentar algum erro se a mobilidade da proteína em estudo é afetada por sua estrutura, diferindo da proteína padrão usada para calibração. Por esta razão, a diferença significante entre estes valores e os valores de 
massa obtidos no presente trabalho, pode ser explicada pela maior precisão associada a técnica de MALDI-TOF-MS.
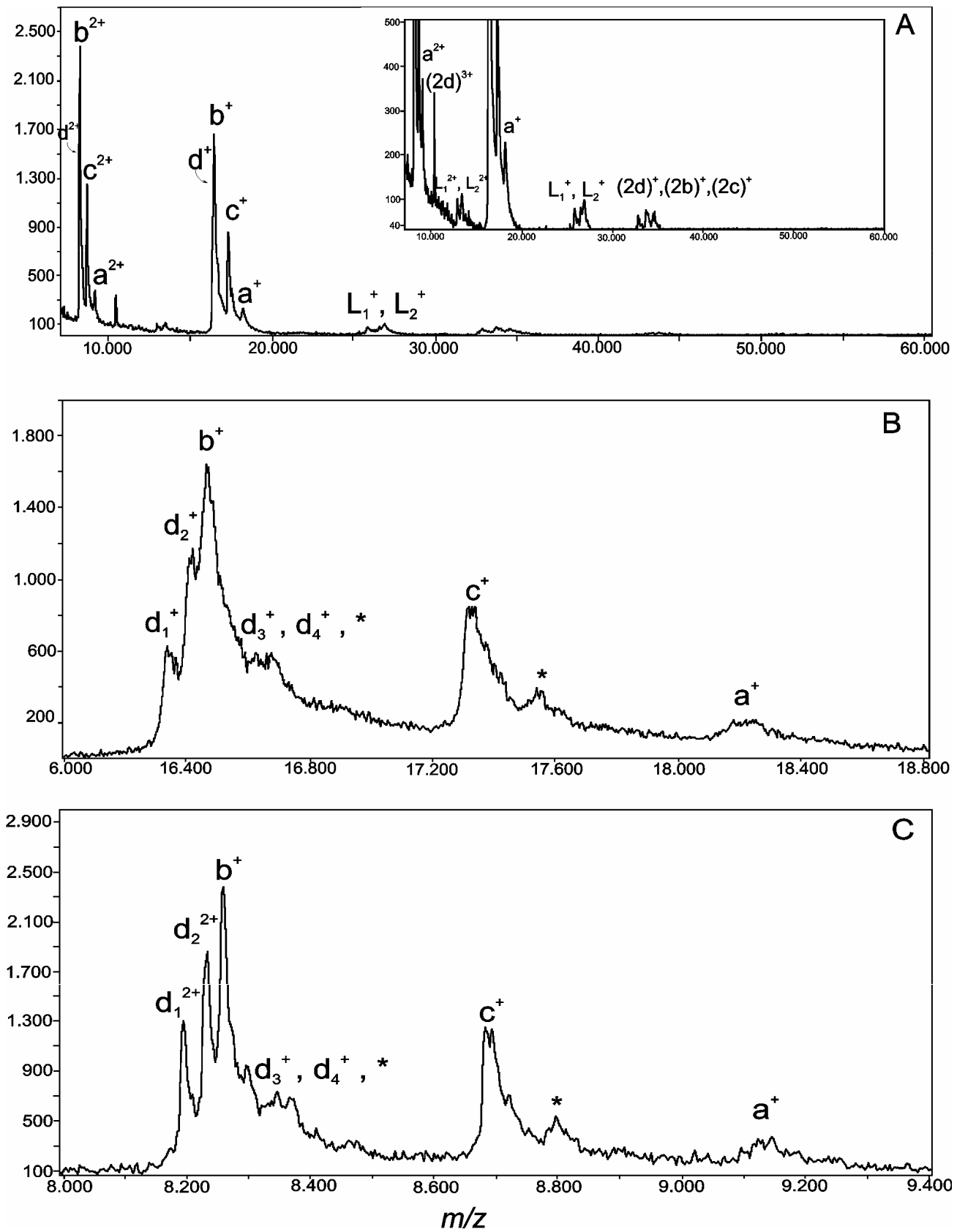

Figura 43: (A) Espectro de massas da HbGp íntegra na forma Oxy em pH 7,0 submetida a reação com 2-mercaptoetanol. O inserto mostra a região do espectro ampliada enfatizando aos picos de menor intensidade; (B) região expandida de 16.000 a $18.800 \mathrm{Da}$, correspondente ao monômero protonado $\mathrm{d}^{+}$. (C) região expandida de 8.000 a $9.400 \mathrm{Da}$, correspondente ao monômero duplamente protonado. 
Lamy e colaboradores [97] relataram diferentes valores de massas para a HbLt, utilizando diferentes técnicas na determinação da massa. HbGp apresenta uma massa molecular mínima de 3,1 MDa, determinada por ultracentrifugação [66]. Para HbLt o valor de massa encontrado mais aceito foi de 3,6 MDa [91, 97], determinado por equilíbrio de sedimentação [97]. Entretanto, usando filtração em gel, a massa da HbLt foi estimada em 3,23 MDa, que é um valor próximo ao encontrado para $\mathrm{HbGp}$.

\section{9- Interação da hemoglobina extracelular gigante de Glossoscolex paulistus com sufactantes iônicos.}

Estudos espectroscópicos recentes reportados na literatura, relatam uma forte interação entre CTAC e HbGp em pH fisiológico [71].

Para entender melhor a interação entre surfactantes iônicos e a hemoglobina de Glossoscolex paulistus, escolhida com base em estudos spectroscópicos anteriores. Experimentos foram realizados utilizando a técnica de MALDI-TOF-MS. A concentração de sufactante utilizada foi na faixa de 0,21,0 mM, esta concentração de sufactante não causou interferência nas análises, dos espectros de massas.

A figura 44 mostra o espectro de MALDI-TOF-MS para a subunidade do monômero d com adição de 0,2 mM de CTAC. Ácido sinápico foi usado como matriz, em uma proporção de 1:10 (v/v) utilizando detecção no modo positivo. Picos adicionais foram detectados quando comparados ao monômero puro na ausência de surfactante (Fig. 42).

Como relatado anteriormente duas isoformas majoritárias de maior intensidade foram detectadas na análise por MALDI-TOF-MS ( $d_{1}$ e $\left.d_{2}\right)$ com proporções idênticas e massas de $16.355 \pm 25$ e 16.428 $\pm 24 \mathrm{Da}$, respectivamente, além de duas isoformas minoritárias $\left(d_{3}\right.$ e $\left.d_{4}\right)$ com massas em torno de 16,6 $\mathrm{kDa}$.

Observa-se na figura 44A a presença do pico em $8.185 \pm 13 \mathrm{Da}$, correspondente ao pico do monômero duplamente protonado $\left(\mathrm{d}^{2+}\right)$, o pico 
correspondente a molécula do monômero protonada, $\mathrm{d}^{+}$, com incremento de $\mathrm{n}$ moléculas de CTAC, na faixa de 15.000-20.000 Da, e o pico correspondente ao dímero de monômero protonado $(2 \mathrm{~d})^{+}$com massa de $32.721 \pm 29 \mathrm{Da}$.

A figura 44B mostra a região expandida de 15.000 a $20.000 \mathrm{Da}$ que corresponde ao monômero protonado $\mathrm{d}^{+}$. As duas isoformas majoritárias, $\mathrm{d}_{1} \mathrm{e}$ $d_{2}$, são claramente observadas com massas de $16.371 \pm 25$ e 16.445 $\pm 24 \mathrm{Da}$, muito próximas aos valores citados anteriormente (Tabela 3). Picos adicionais relacionados com a interação de $\mathrm{n}$ moléculas de CTAC com cada isoforma de monômero $d, d_{1}$ e $d_{2}$, foram também detectados. Sabendo que a massa do CTA ${ }^{+}$ é $284 \mathrm{Da}$ podemos afirmar que os picos adicionais estão relacionados à interação de moléculas de $\mathrm{CTA}^{+}$com cada isoforma do monômero d. Podem ser observados incrementos de massa de até 10 moléculas de CTAC, apresentados na Tabela 4.

A terceira coluna na Tabela 4, mostra os incrementos de massa para cada isoforma, os valores apresentados são múltiplos de uma molécula de $\mathrm{CTA}^{+}$. Na primeira coluna e na figura 4B os picos identificados como 1-10 correspondem a 1-10 moléculas de CTAC ligadas as isoformas $d_{1}$ e $d_{2}$.

A figura $44 \mathrm{C}$ mostra a região do espectro correspondendo ao monômero duplamente protonado, $\mathrm{d}^{2+}$, e é observado que as massas não são afetadas pela presença do surfactante. Este é um resultado interessante, sugerindo que a segunda protonação impede a formação do aduto CTA-monômero. A presença do surfactante catiônico na mistura sólida reduz a afinidade por próton do ácido sinápico, aumentando a ionização da proteína. Isto pode estar relacionado também a pouca incorporação da proteína na matriz cristalina visto que a interação proteína-surfactante é mais forte do que a interação proteína-matriz [74,98]. A adição de uma molécula de CTAC produz picos com massas de $16.654 \pm 25$ e $16.729 \pm 24 \mathrm{Da}$ e intensidade similar quando comparado com os picos dos monômeros sem sufactante, $d_{1}$ e $d_{2}$. $O$ aumento subseqüente no número de moléculas de CTAC ligadas ao monômero leva a uma perda gradual de intensidade do pico, respectivo. 
Duas isoformas de menor intensidade, $d_{3}$ e $d_{4}$, foram relatadas anteriormente (Figs. 41C e 42C), mas nossos resultados sugerem uma sobreposição dos picos de menor intensidade com os picos originários da interação com sufactante, isto é, do sistema CTAC-monômero d. 

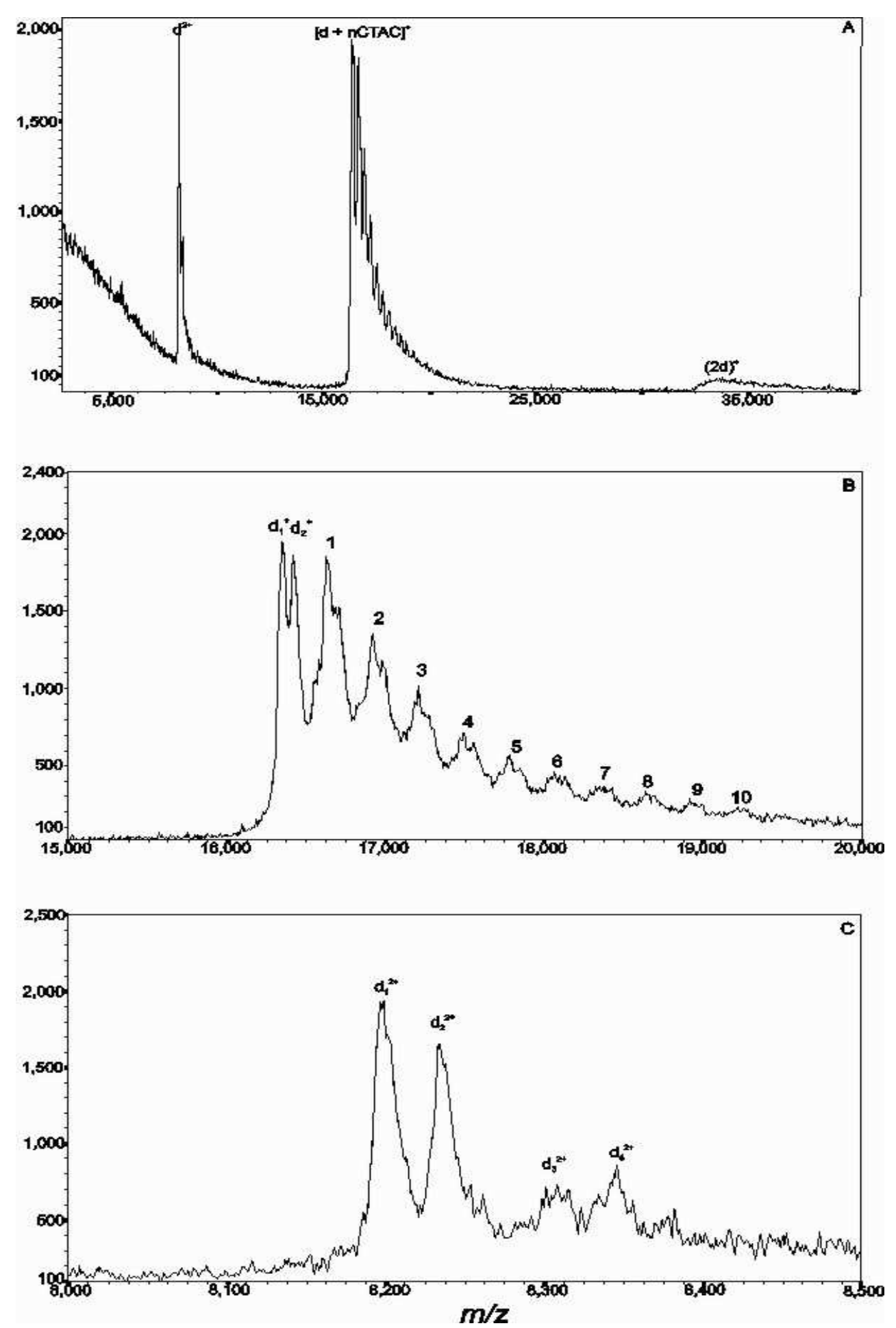

Figura 44: (A) Espectro de massas do monômero d com 0,2 mM de CTAC. (B) região expandida de 15.000 a $20.000 \mathrm{Da}$, correspondente ao monômero protonado $\mathrm{d}^{+}$com incremento de $\mathrm{n}$ moléculas de CTAC. (C) região expandida de 8.000 a $8.500 \mathrm{Da}$, correspondente ao monômero duplamente protonado, $\mathrm{d}^{2+}$. 
Table 4. Massas obtidas por MALDI-TOF-MS para as isoformas do monômero $d$, $\mathbf{d}_{1}$ and $\mathbf{d}_{2}$, da hemoglobina extracelular Glossoscolex paulistus ( $\mathrm{HbGp}$ ). A coluna com os incrementos de massa corresponde as diferenças de massas dos picos das figuras 41-43.

\begin{tabular}{|c|c|c|c|c|c|c|}
\hline $\begin{array}{c}\text { Monômero } \\
\text { d }\end{array}$ & $\begin{array}{c}\text { Monômero d } \\
\text { (Figs.41, 42) } \\
\text { CTAC }\end{array}$ & $\begin{array}{l}\text { Incrementos } \\
\text { de massa } \\
\text { (Da) }\end{array}$ & $\begin{array}{c}\text { HbGp } \\
\text { (Fig. 43) } \\
\text { CTAC }\end{array}$ & $\begin{array}{c}\text { Incrementos } \\
\text { de massa } \\
\text { (Da) }\end{array}$ & $\begin{array}{l}\text { Monômero } \\
\text { d (Fig. 44) } \\
\text { SDS }\end{array}$ & $\begin{array}{l}\text { HbGp } \\
\text { (Fig. 45) } \\
\text { SDS }\end{array}$ \\
\hline d1 & $\begin{array}{c}16.371 \pm 25 \\
(16.372 \pm 18)^{a}\end{array}$ & ------- & $16.446 \pm 40$ & ------ & $16.364 \pm 40$ & $16.360 \pm 40$ \\
\hline d2 & $\begin{array}{c}16.445 \pm 24 \\
(16.447 \pm 19)^{a}\end{array}$ & ------ & $16.446 \pm 40$ & -------- & $16.446 \pm 40$ & $16.436 \pm 40$ \\
\hline 1 & $\begin{array}{l}16.654 \pm 25^{b} \\
16.729 \pm 24^{b}\end{array}$ & $\begin{array}{l}283 \\
284\end{array}$ & $16.758 \pm 40$ & 312 & ------ & ----- \\
\hline 2 & $\begin{array}{l}16.939 \pm 25 \\
17.013 \pm 24\end{array}$ & $\begin{array}{l}568 \\
568\end{array}$ & $17.035 \pm 40$ & 589 & ----- & ----- \\
\hline 3 & $\begin{array}{l}17.232 \pm 25 \\
17.305 \pm 24\end{array}$ & $\begin{array}{l}861 \\
860\end{array}$ & $17.304 \pm 40$ & 858 & ----- & ---- \\
\hline 4 & $\begin{array}{l}17.515 \pm 25 \\
17.586 \pm 24\end{array}$ & $\begin{array}{l}1144 \\
1141\end{array}$ & $17.577 \pm 40$ & 1131 & ------ & ----- \\
\hline 5 & $\begin{array}{l}17.805 \pm 25 \\
17.867 \pm 24\end{array}$ & $\begin{array}{l}1434 \\
1422\end{array}$ & $17.841 \pm 40$ & 1395 & & \\
\hline 6 & $\begin{array}{l}18.086 \pm 25 \\
18.159 \pm 24\end{array}$ & $\begin{array}{l}1715 \\
1714\end{array}$ & & & & \\
\hline 7 & $18.375 \pm 37$ & 1967 & & & & \\
\hline 8 & $18.685 \pm 37$ & 2277 & & & & \\
\hline 9 & $18.962 \pm 37$ & 2554 & & & & \\
\hline 10 & $19.275 \pm 37$ & 2867 & & & & \\
\hline $\mathrm{L}_{1}$ and $\mathrm{L}_{2}$ & & & $\begin{array}{c}26.932 \\
(26.289)^{\mathrm{c}}\end{array}$ & & & $\begin{array}{l}26.741 \pm 7 \\
(26.289)^{c}\end{array}$ \\
\hline $\mathrm{T}(\mathbf{a b c})$ & & & $\begin{array}{c}52.290 \\
(51.522)^{c}\end{array}$ & & & $\begin{array}{c}51.875 \\
(51.522)^{c}\end{array}$ \\
\hline
\end{tabular}

${ }^{a}$ Os valores entre parentese foram retirados da referência 69.

${ }^{\text {b}}$ Os valores para os picos 1-6 correspondem as massas das isoformas do monômero $\mathbf{d}_{1}$ e $\mathbf{d}_{2}$ com 1-6 moleculas de CTA ${ }^{+}$ligadas.

${ }^{\circ}$ Os valores entre parentese são as médias dos valores apresentados na Tabela 3. 
A diferença na proporção entre amostra/matriz promove mudanças no espectro de massas relacionado a interação do sufactante catiônico CTAC com o monômero d. A figura 45 apresenta o espectro de MALDI-TOF-MS para o monômero d usando ácido sinápico numa proporção de 1:5 (v/v). Nesta concentração de CTAC $(0,2 \mathrm{mM})$ o monômero pode apresentar alguma precipitação, seguida de uma solubilização pelo aumento da quantidade da matriz e uma redução significante na quantidade de picos adicionais é observada.

Um resultado similar foi obtido quando a concentração do sufactante foi aumentada para 0,4 mM de CTAC numa proporção monômero d/matriz de 1:10. Cinco incrementos de massa, correspondendo à massa do $\mathrm{CTA}^{+}$, foram observados (dado não mostrado). É importante mencionar que 0,4 mM de CTAC corresponde a uma condição pré-micelar para o sufactante em solução tampão. Deste modo, 0,2 mM de CTAC corresponde a uma ótima condição para a interação máxima do CTAC com a subunidade monomérica da proteína, visto que moléculas monoméricas de sufactantes $\mathrm{CTA}^{+}$interagem melhor com os sítios na superfície do monômero neste meio. Por outro lado, este valor de concentração de CTAC de 0,4 mM está associado a algum processo inicial de agregação, inerente a condição pré-micelar, que compete com os sítios aniônicos da proteína pelas moléculas monoméricas de sufactante, $\mathrm{CTA}^{+}$. Além disso, a mudança na proporção amostra/matriz de 1:10 para 1:5 significa um aumento de duas vezes na concentração do CTAC comparado com a matriz. Este aumento pode facilitar a dissociação do próton do ácido sinápico aumentando a ionização da proteína e favorecendo a competição dos prótons e do CTAC pelos sítios aniônicos da proteína.

Amado e colaboradores [74] relataram que em concentrações subcríticas de proteína, pode ocorrer uma precipitação parcial da mesma, pela formação do par iônico com os monômeros de surfactante. Em concentrações maiores de surfactante este efeito pode ser impedido devido a solubilização da proteína. A formação do par iônico proteína-surfactante reduz a quantidade de proteína disponível para co-cristalizar com a matriz. O surfactante restante em solução 
recobre eficientemente os cristais formados sobre a amostra seca, impedindo a desorção da proteína. Com base nestes argumentos 0 aumento na concentração de CTAC de 0,2 para $0,4 \mathrm{mM}$ promove a redução dos picos devido a adutos CTAC-Monômero d associados a (1) uma redução do analito disponível por desorção e (2) uma diminuição na transferência de energia, visto que o surfactante não absorve no comprimento de onda do laser. O balanço de interações proteína-surfactante e proteína-matriz é provavelmente, o principal responsável pelo espectro de massas observado.

Um trabalho realizado recentemente em nosso grupo [71], utilizando técnicas espectroscópicas, mostrou uma interação significante entre CTAC e HbGp. Neste trabalho foi observado que em baixas concentrações de CTAC (0,03-0,15 mM) ocorre a precipitação da HbGp. A concentração das amostras de HbGp usada nos experimentos espectroscópicos, de $0,08 \mathrm{mg} / \mathrm{ml}$ [71], é comparável às usadas nas análises de MALDI-TOF-MS numa proporção de amostra/matriz de 1:10.

Este fenômeno de precipitação pode ser explicado pela formação do par iônico entre os sítios aniônicos da proteína e os monômeros catiônicos de surfactante CTAC. Um processo de neutralização ocorre no sistema CTAC$\mathrm{HbGp}$ visto que o ponto isoelétrico $(\mathrm{pl})$ desta hemoglobina é ácido (em torno de $5,5)$ e consequentemente, em valores de $\mathrm{pH}$ neutro e alcalino um grande número de sítios aniônicos na superfície da hemoglobina podem estar disponíveis para ligação. Deste modo, a interação eletrostática entre estes resíduos de aminoácidos aniônicos e o surfactante catiônico CTAC é muito efetivo, podendo ser responsável pelo mecanismo de dissociação da hemoglobina. Em concentrações de CTAC acima de 0,3 $\mathrm{mM}$ o precipitado é ressolubilizado, consistente com o papel do surfactante como um co-solvente na solubilização da proteína.

A massa adicional de $284 \mathrm{Da}$, corresponde a uma molécula de $\mathrm{CTA}^{+}$, ligada às cadeias peptídicas do monômero $d$, de acordo com as figuras $41 \mathrm{~B} e$ 42B, demonstrando a interação eletrostática significante entre CTAC e o monômero d. Esta observação é também consistente com a existência de um 
sítio especifico de maior energia na proteína e com um comportamento esperado de interações proteína-surfactante. Além disso, o valor do pl para o monômero d é bastante ácido, provavelmente, não muito diferente do valor observado para a proteína integra. 

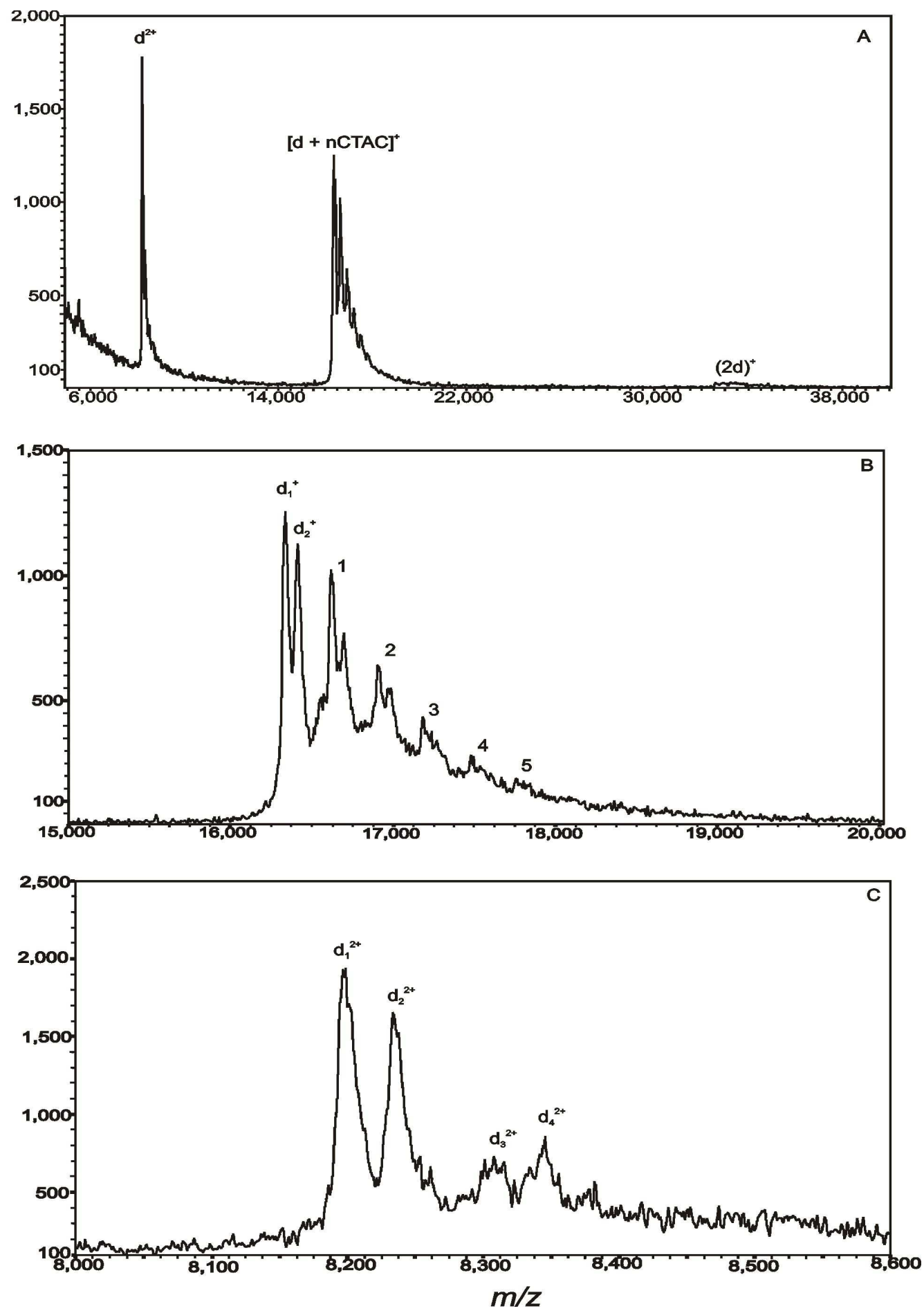

Figura 45: (A) Espectro de massas do monômero d com 0,2 mM de CTAC. (B) região expandida de 15.000 a $20.000 \mathrm{Da}$, correspondente ao monômero protonado $\mathrm{d}^{+}$com incremento de $\mathrm{n}$ moléculas de CTAC. (C) região expandida de 8.000 a $8.600 \mathrm{Da}$, correspondente ao monômero duplamente protonado. 
A figura 46 mostra o espectro de MALDI-TOF-MS para HbGp íntegra em pH 7,0 com adição de 1,0 mM de CTAC, numa proporção amostra/matriz de $1: 10$.

Em concentrações maiores de surfactante, agregados pré-micelares ou micelas podem ser formadas em solução e interagir com a HbGp, o que pode dificultar o processo de ionização. O espectro de massas da figura 46A mostra 0 pico correspondente ao monômero protonado com incremento de $\mathrm{n}$ moléculas de surfactante e os picos obtidos para o monômero duplamente protonado $\mathrm{d}^{2+}$, os quais aparecem com baixa intensidade quando comparado com as figuras 41 e 42. Este efeito pode estar relacionado com a presença do surfactante na concentração de 1,0 mM, que parece afetar o processo de ionização, visto que a intensidade dos picos neste espectro é bem menor quando comparado ao obtido para a proteína íntegra na ausência de surfactante [71].

Os picos associados às cadeias linkers $\left(\mathrm{L}_{1}{ }^{+}\right.$e $\left.\mathrm{L}_{2}{ }^{+}\right)$, caracterizados

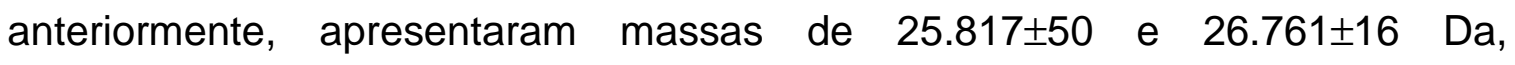
respectivamente, e uma massa média de $26.289 \mathrm{Da}$. Na presença de CTAC foi observado um pico largo com massa de $26.932 \mathrm{Da}$, atribuído as cadeias linkers, $L_{1}$ e $L_{2}$. A diferença de massa de 643 Da para os picos designados aos linkers em relação a média das massas de $L_{1}$ e $L_{2}$ observados anteriormente (Tabela 3 ), pode estar relacionada a ligação de duas moléculas de $\mathrm{CTA}^{+}$às cadeias linkers. Entretanto o alargamento dos picos é claramente notado. É importante mencionar que as cadeias linkers têm sido estudadas como sítios de ligação para íons cálcio, os quais são conhecidos como agentes que mantem a estrutura oligomérica da proteína íntegra [62,74]. Por esta razão, estas subunidades podem apresentar grupos aniônicos ácidos, os quais podem se ligar a compostos catiônicos, incluindo moléculas de CTAC. É também possível que eles possuam um pl ácido. Pequenos picos designados anteriormente para $\mathrm{L}^{2+}$ com massas de 12.875 e 13.375 não foram detectados na presença de CTAC.

Íons com massa de 52.290 Da foram observados no espectro, e foram atribuídos ao trímero $(\mathrm{abc})$. A massa média para os trímeros na ausência de surfactante, reportada anteriormente, foi de 51.522 (tabela 3). Neste caso um 
aumento de massa foi observado, o que pode estar relacionado também a ligação de poucas moléculas de $\mathrm{CTA}^{+}$ao trímero.

A figura 46B mostra a região expandida de 15.000 a $20.000 \mathrm{Da}$ que corresponde ao monômero protonado, $\mathrm{d}^{+}$. Observam-se picos adicionais com incrementos de massa não bem resolvidos quando comparados com a Figura 44, mostrando que neste caso também ocorre a interação do surfactante com o monômero na proteína íntegra, mas com uma pobre resolução quando comparado com as figuras 44B e 45B, correspondendo ao monômero puro. Os picos designados como $d_{1}$ e $d_{2}$, não são bem resolvidos.

Experimentos para a HbGp com adição de 0,2 mM de CTAC também foram realizados e não foram observados picos adicionais, o que está associado ao baixo número de moléculas de $\mathrm{CTA}^{+}$em solução e ao fato de que o monômero está protegido dentro da estrutura oligomérica da proteína. No caso da HbGp íntegra uma maior concentração de CTAC é necessário para promover alguma dissociação oligomérica e expor os sítios de ligação do monômero d para interagir com o surfactante.

$\mathrm{Na}$ ausência de surfactante, os picos correspondentes às cadeias linkers, $\mathrm{L}_{1}{ }^{+}$e $\mathrm{L}_{2}{ }^{+}$, apresentam uma intensidade em torno de $13-15 \%$ em relação ao pico do monômero protonado, $\mathrm{d}^{+}$. De modo similar, os picos associados ao trímero têm intensidades em torno de $10 \%$ comparadas com o pico do monômero protonado sem surfactante. Podemos observar também que a presença do surfactante CTAC leva a um aumento na intensidade dos picos das cadeias linker e trímero, para $34 \%$ e $27 \%$, respectivamente, relacionado ao pico do monômero protonado, $d^{+}$(Fig. 46A). Esta observação sugere que o surfactante catiônico CTAC favorece o processo de ionização na técnica de MALDI-TOF-MS para esta proteína. Provavelmente, este processo de ionização é devido a presença de um número maior de sítios protéicos disponíveis na superfície da cadeia polipepitídica, em função da dissociação oligomérica e desnovelamento parcial da proteína, originado pela interação significante entre HbGp e CTAC em $\mathrm{pH} 7,0$. 
A figura 46C mostra a região do espectro correspondendo ao monômero duplamente protonado, $\mathrm{d}^{2+}$, e é observado que ocorre uma supressão do sinal do pico $\mathrm{d}^{2+}$, uma vez que a intensidade é bastante reduzida.

A segunda ionização pode ser suprimida devido a presença do surfactante catiônico em alguns sítios da proteína. Um desnovelamento parcial da HbGp originado pela presença do surfactante favorece a primeira protonação em função do aumento dos sítios disponíveis, mas na segunda ionização os cátions de $\mathrm{CTA}^{+}$competem com os prótons da matriz pelos sítios na superfície da proteína, impedindo a segunda protonação. Ambos os processos podem ocorrer como conseqüência da pronunciada interação do CTAC com HbGp, o que é evidente pelo aumento de massa dos picos relacionados às cadeias linkers e trímeros na presença de CTAC quando comparado com HbGp na ausência de surfactante [69].

Há evidências de que as cadeias linkers podem formar auto-agregados ou agregar-se com o trímero [62,74], o que também pode ser a razão da dificuldade no processo de ionização, destas subunidades. 


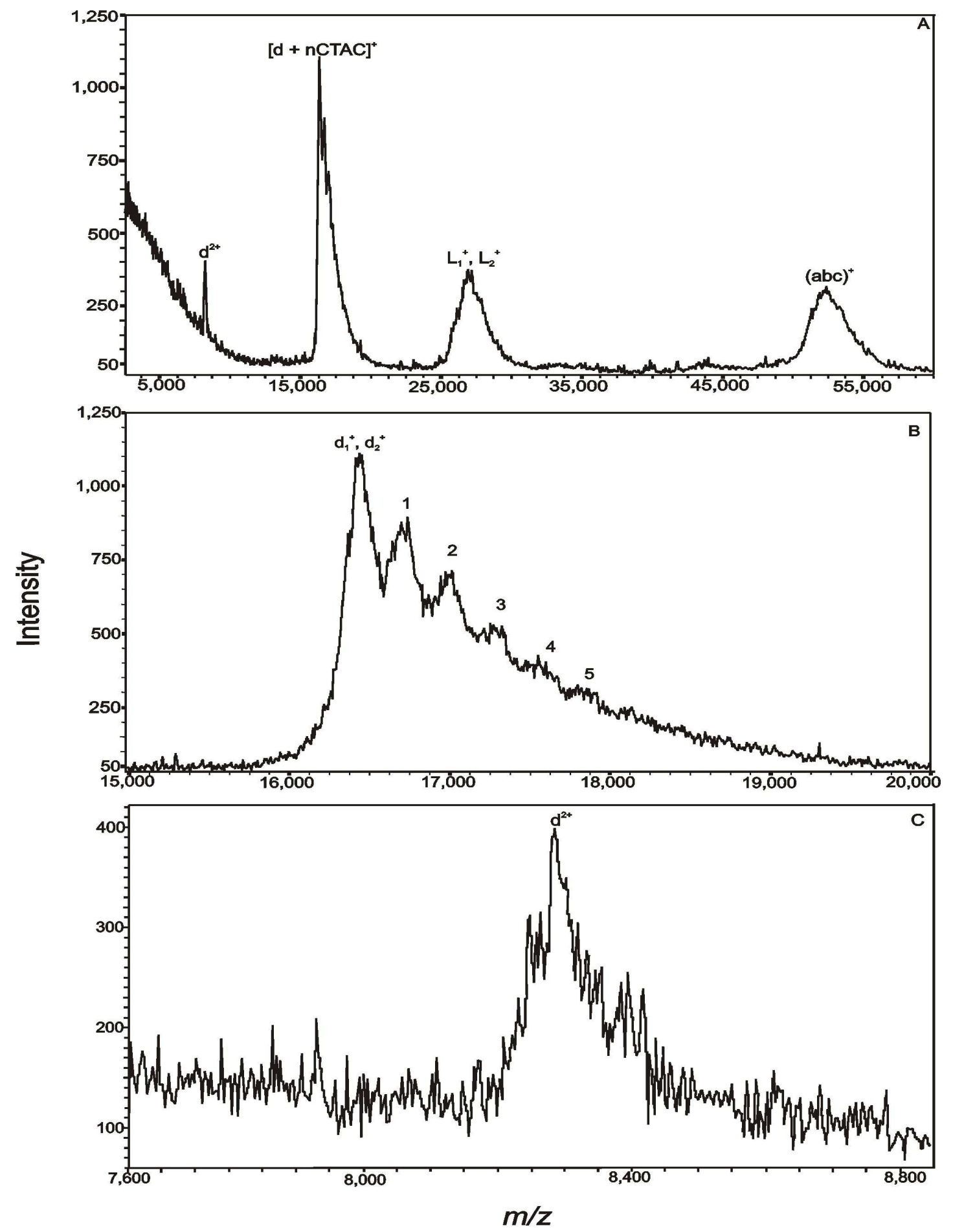

Figura 46: (A) Espectro de massas da HbGp íntegra com 1,0 mM de CTAC. (B) região expandida de 15.600 a $18.800 \mathrm{Da}$, correspondente ao monômero protonado $\mathrm{d}^{+}$com incremento de $\mathrm{n}$ moléculas de CTAC. (C) região expandida de 8.050 a $8.600 \mathrm{Da}$, correspondente ao monômero duplamente protonado. 
A figura 47 apresenta o espectro de massa para o monômero $d$ na forma pura com $0.2 \mathrm{mM}$ de SDS. Uma proporção de monômero d/matriz de 1:10 foi utilizada. Neste caso, observa-se um comportamento diferente quando comparado com o sistema CTAC-monomero $d$. Os picos relacionados ao monômero com uma e duas protonações, $\mathrm{d}^{+}$e $\mathrm{d}^{2+}$, são observados com massas de $16.364 \pm 25$ e $8.182 \pm 13 \mathrm{Da}$, respectivamente, com pobre resolução e são apresentados nas figuras $47 \mathrm{~B}$ e $47 \mathrm{C}$. As massas correspondendo ao $\mathbf{d}_{1}$ (16.364 $\pm 25 \mathrm{Da}), \mathbf{d}_{2}(16.446 \pm 26 \mathrm{Da}), \mathbf{d}_{3}(16.588 \pm 31 \mathrm{Da})$ e $\mathbf{d}_{4}(16.671 \pm 28 \mathrm{Da})$, são consistentes com os valores reportados para o monômero d sem surfactante (Tabela 3): $\mathbf{d}_{1}(16.355 \pm 25 \mathrm{Da}), \mathbf{d}_{2}(16.428 \pm 24 \mathrm{Da}), \mathbf{d}_{3}(16.580 \pm 24 \mathrm{Da})$ e $\mathbf{d}_{4}$ $(16.650 \pm 26 \mathrm{Da})$.

Observa-se no espectro de massas que o monômero d na presença de $0,2 \mathrm{mM}$ de SDS mostra picos com baixa intensidade quando comparado aos obtidos na ausência de surfactante.

Também foram realizados experimentos utilizando uma concentração de 0,4 mM de SDS, o espectro obtido mostrou uma difícil ionização da amostra e não houve uma boa resolução dos picos (dados não mostrados). Este fato pode estar associado a algum tipo de competição entre o SDS e as cadeias polipeptídicas pelos prótons da matriz. Um surfactante aniônico como o SDS pode originar atração eletrostática dos prótons do ácido sinápico inibindo a ionização da proteína, o que pode ser devido ao aumento da afinidade da matriz pelo próton.

Podemos mencionar também, que uma redução do pKa de alguns compostos orgânicos na presença de CTAC tem sido observada em estudos da interação destes compostos com micelas de CTAC [43,99].

Como o surfactante catiônico CTAC induz um deslocamento no pKa para valores menores em solventes orgânicos, o surfactante aniônico SDS induz o oposto, deslocando o pKa para valores maiores [43,99]. Este efeito pode explicar a inibição da ionização pelo SDS. 

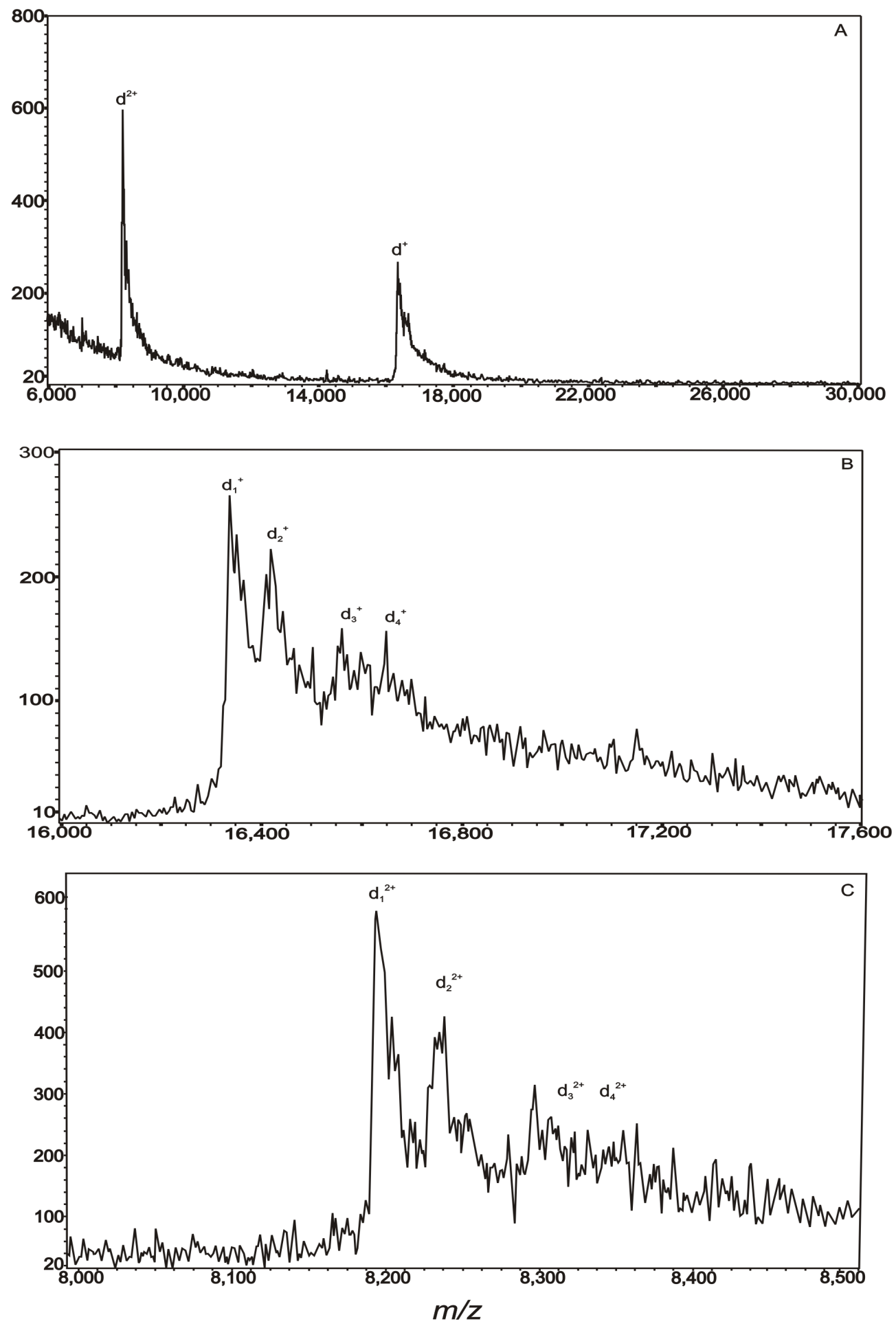

Figura 47: (A) Espectro de massas do monômero d com 0,2 mM de SDS. (B) região expandida de 16.000 a $17.600 \mathrm{Da}$, correspondente ao monômero protonado $\mathrm{d}^{+}$. (C) região expandida de 8.000 a $8.500 \mathrm{Da}$, correspondente ao monômero duplamente protonado. 
A figura 48 mostra o espectro de MALDI-TOF-MS para HbGp em pH 7,0 com adição de 1,0 mM de SDS, utilizando uma proporção amostra/matriz de $1: 10$.

Diferente do sistema CTAC-HbGp, na presença de surfactante SDS incrementos de massa ligados ao monômero d não foram observados. De fato os picos correspondentes ao monômero com uma e duas protonações, aparecem com maiores intensidades e massas de $16.436 \pm 28$ e $8.217 \pm 15 \mathrm{Da}$, respectivamente.

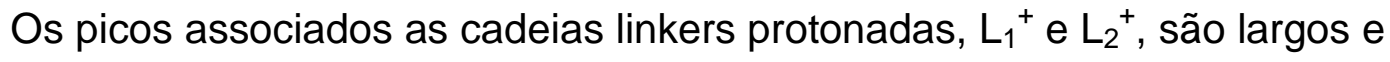
de baixa intensidade, apresentando massa em torno de $26.741 \pm 7 \mathrm{Da}$. Um pequeno pico aparece em $13.370 \pm 3 \mathrm{Da}$, correpondendo ao linker duplamente protonado, $\mathrm{L}^{2+}$. E por último o pico associado ao trímero $(\mathrm{abc})^{+}$, foi detectado com massa de $51.875 \mathrm{Da}$.

Comparando as massas dos Linkers e trímeros apresentados na Tabela 3, um aumento de massa de 452 e $353 \mathrm{Da}$, respectivamente, foi observado. Sabendo que a massa do SDS $^{-}$é de $265 \mathrm{Da}$, a diferença citada acima corresponde a $2(1,7)$ e $1(1,3)$ moléculas de SDS, respectivamente, ligadas às cadeias linkers e trímero.

A faixa de massa correspondente ao monômero $d$ foi expandida e é apresentada na figura 45B. Os picos relacionados as isoformas do monômero d, $d_{1}, d_{2}, d_{3}$ e $d_{4}$ com massas de 16.360 $\pm 27,16.436 \pm 28 \mathrm{Da}, 16.544 \pm 40$ e 16.631 $\pm 40 \mathrm{Da}$, respectivamente, foram observados, o que está de acordo com os valores reportados para a HbGp íntegra na ausência de surfactante (Tabela 3) [69].

Nossos resultados mostram que na presença de surfactante aniônico SDS não ocorre uma mudança significativa no espectro de massas, especialmente relacionada às mudanças no monômero como observadas para o CTAC. Estes resultados indicam fortemente que a interação SDS-HbGp é, provavelmente, mais fraca quando comparada com a interação CTAC-HbGp. Os incrementos de massa observados são associados à forte interação eletrostática entre as subunidades da $\mathrm{HbGp}$, especialmente o monômero d e o surfactante 
catiônico $\mathrm{CTA}^{+}$. De acordo com a discussão anterior, a influência do pl ácido da HbGp é bastante relevante, favorecendo o contacto iônico na interação surfactante-hemoglobina. Entretanto, o contacto iônico entre CTAC e HbGp é favorecido no $\mathrm{pH}$ fisiológico usado, quando comparado com SDS, devido ao maior número de sítios aniônicos na superfície da proteína.

Geralmente, a influência do surfactante na estrutura oligomérica das outras hemoglobinas é maior para o surfactente aniônico do que para o catiônico [25]. Este não é o caso da HbGp, devido ao seu pl ácido. 

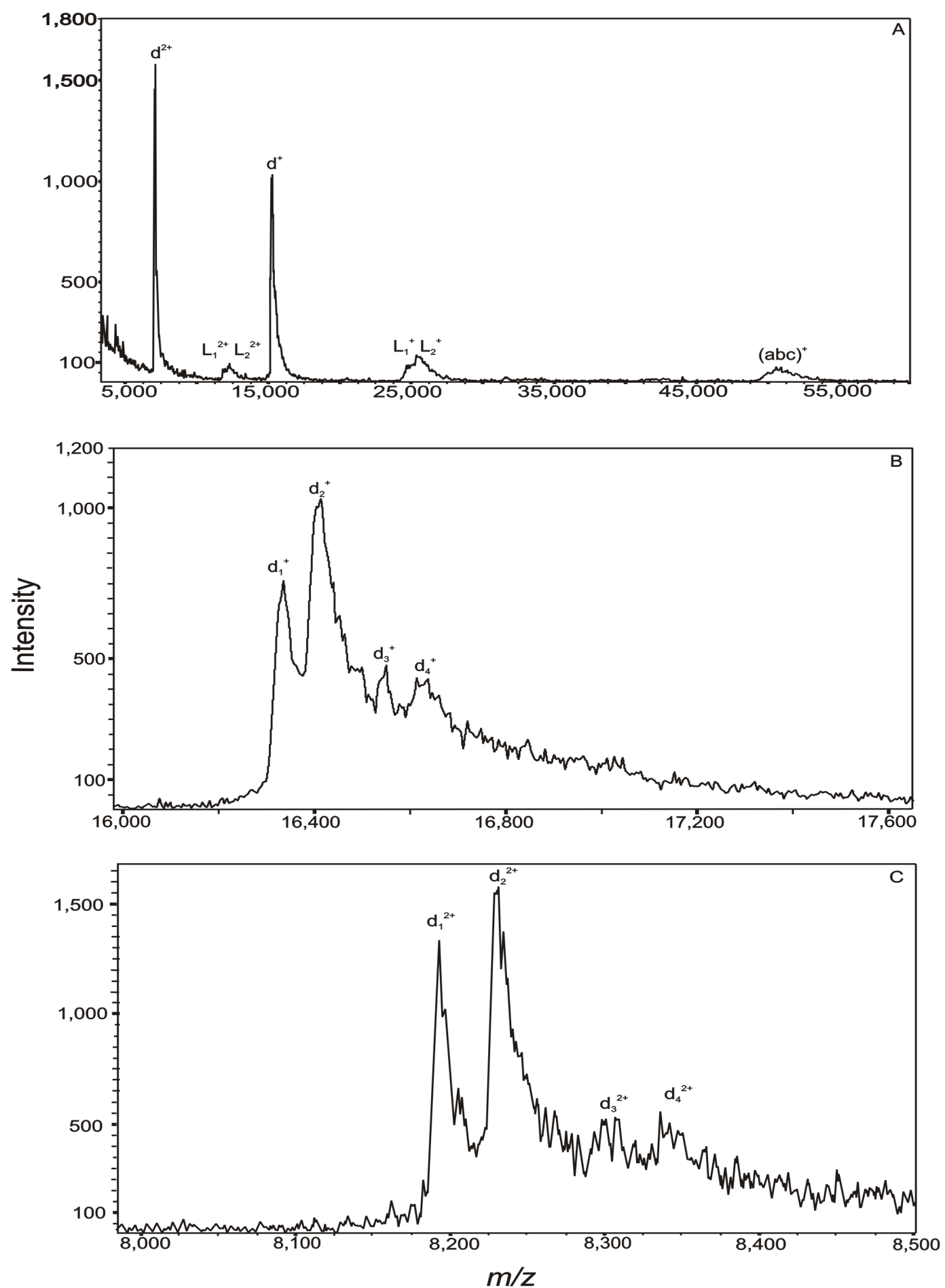

Figura 48: (A) Espectro de massas da HbGp íntegra com 1,0 mM de SDS. (B) região expandida de 16.000 a $17.600 \mathrm{Da}$, correspondente ao monômero protonado $\mathrm{d}^{+}$. (C) região expandida de 8.000 a $8.500 \mathrm{Da}$, correspondente ao monômero duplamente protonado. 


\section{Conclusões}

\section{Supressão de oxigênio singlete}

O estudo da supressão de oxigênio singlete pelo DIP, RA47 e RA25 mostra que o dipiridamol é um potente supressor de $\mathrm{O}_{2}\left({ }^{1} \Delta_{g}\right)$, uma das mais importantes espécies reativas de oxigênio. Em meio orgânico aprótico (ACN) a supressão pelo DIP e seus derivados é mais eficiente do que em meio ácido onde a constante de supressão de $\mathrm{O}_{2}\left({ }^{1} \Delta_{\mathrm{g}}\right)$ é cerca de 20 vezes menor. Este resultado está de acordo com os dados eletroquímicos, onde em meio aquoso ácido é necessário um potencial bem maior para oxidar os compostos. A constante de supressão química é muito pequena, $k_{q}>>k_{r}$, mostrando que a supressão é um processo físico. Cálculos do valor de $\Delta G_{\text {et }}$ mostram que o processo de supressão ocorre pela formação de um complexo de transferência de cargas.

\section{Fotooxidação}

Diante dos resultados descritos neste trabalho podemos concluir que DIP é fotoestável na presença e na ausência de oxigênio em acetonitrila, sendo que uma espécie radicalar é formada como intermediário da reação, observada através de EPR. Na presença de oxigênio, DIP reage rapidamente com o oxigênio molecular formando produtos oxidados. Três produtos da fotooxidação do DIP em acetonitrila são observados, dois isóbaros com $\mathrm{m} / \mathrm{z}$ de 269 e outro fotoproduto com $\mathrm{m} / \mathrm{z}$ de 519 . Em meio aquoso ácido a participação do oxigênio singlete, gerado pelo fotossensibilizador, é o fator principal para a fotooxidação do DIP, formando um produto majoritário com $\mathrm{m} / \mathrm{z}$ de 269 , o qual também é observado na incubação do DIP com $\mathrm{DHPNO}_{2}$. A presença do oxigênio no produto oxidado foi confirmada com experimentos na presença de oxigênio-18. Isto nos leva a concluir que a fotooxidação do DIP nos diferentes meios leva à formação de um produto majoritário oxidado. O DIP pode ainda reagir fotoquimicamente via mecanismos do tipo I e do tipo II, ou seja, via reação radicalar ou com oxigênio singlete, uma vez que o potencial eletroquímico 
favorece a reação. Desta forma, o presente estudo contribui para entender melhor a química desta classe de compostos e seu funcionamento como antioxidante nas aplicações e propriedades biomédicas.

\section{Caracterização parcial da Hemoglobina gigante de Glossoscolex paulistus.}

Nossos resultados de espectrometria de massas da HbGp apresentam uma similaridade grande com sua homóloga HbLt. Os dados obtidos neste trabalho são totalmente inéditos para as massas das subunidades da hemoglobina extracelular gigante de Glososcolex paulistus (HbGp). As diferentes isoformas do monômero $\mathbf{d}$ da $\mathrm{HbGp}$ foram caracterizadas por análises de MALDI-TOF-MS. Pelos espectros obtidos, o monômero d parece ter duas isoformas majoritárias com massas moleculares que correspondem a dois ou três resíduos a mais do que o valor de massa esperado baseado na sua seqüência primária. Duas isoformas minoritárias foram também detectadas. As massas do trímero abc e de duas cadeias linkers foram também estimadas, sendo similares às descritas para a HbLt. Os monômeros d são facilmente protonados produzindo picos intensos e bem resolvidos, correspondendo a molécula do monômero com uma e duas protonações. No entanto, o trímero bem como as cadeias linkers produzem picos de baixa intensidade, os quais são relativamente largos sugerindo a existência de uma heterogeneidade. Pela redução das pontes disulfeto do trímero, foi possível determinar as massas para as cadeias monoméricas associadas ao mesmo, as quais foram designadas com a, b e c. De forma similar à HbLt a cadeia a apresenta maior massa molecular quando comparado com as cadeias b e c, o que pode estar associado a presença de carboidratos associados ao monômero a. Estes resultados são um importante passo na caracterização da $\mathrm{HbGp}$, mas estudos posteriores ainda são necessários para a sua completa caracterização. 


\section{Interação da Hemoglobina gigante de Glossoscolex paulistus com surfactantes iônicos.}

As análises por MALDI-TOF-MS foram realizadas para obter dados espectrométricos de intensidade suficiente para avaliar o efeito do surfactante na HbGp, especialmente em 0,2 mM de SDS. Incrementos de massas nos picos associados ao monômero d-CTAC e no sistema HbGp íntegra-CTAC foram observados, o que denota a ocorrência de uma intensa interação eletrostática entre CTAC e HbGp, não encontrada para o sistema HbGp-SDS. É importante mencionar que condições pré-micelares impedem uma interação mais efetiva entre CTAC e HbGp, isto é observado quando as moléculas de $\mathrm{CTA}^{+}$estão mais livres em solução, ou seja, quando monômeros de surfactante não estão associados na micela. Deste modo, este trabalho enfatiza a influência peculiar do pl ácido da HbGp nas interações com os surfactantes iônicos. Em pH 7,0 os sítios aniônicos são mais numerosos favorecendo a interação entre CTAC e HbGp quando comparado com o sitema SDS-HbGp. Isto é notado nos dados de MALDI-TOF-MS, onde um total de 5-10 moléculas de surfactante são ligadas a monômero d. Além disso, para o SDS incrementos de massas moderados são observados somente para os linkers e o trímero. Trabalhos complementares serão necessários a esclarecer melhor a ligação dos surfactantes nas subunidades individuais desta proteína oligomérica. 


\section{Perspectivas futuras para o projeto}

1- Realização de experimentos de fotólise por pulso de laser para caracterização da espécie radicalar formada na fotooxidação em acetonitrila.

2- Caracterização do produto oxidado em acetonitrila e meio ácido por técnicas de RMN ${ }^{1} \mathrm{H} \mathrm{e}^{13} \mathrm{C}$.

3- Prosseguir na separação e caracterização das subunidades da Hemoglobina de Glossoscolex paulistus. 


\section{Artigos publicados em periódico}

1. OLIVEIRA, M. S., MOREIRA, L. M., TABAK, M.

Interaction of Giant extracellular Glossoscolex paulistus hemoglobin ( $\mathrm{HbGp}$ ) with ionic surfactants: a MALDI-TOF-MS study. International Journal of Biological Macromolecules. v.42, p. 111-119, 2007.

2. OLIVEIRA, M. S., MOREIRA, L. M., TABAK, M.

Partial characterization of giant extracellular hemoglobin of Glossoscolex paulistus: A MALDI-TOF-MS study. International Journal of Biological Macromolecules. , v.40, p.429 - 436, 2007.

3. OlIVEIRA, M. S., LIMA, M., SEVERINO, D., BAPTISTA, M. S., Di MASCIO, P., TABAK, M.

Quenching of singlet molecular oxygen, $\mathrm{O}_{2}\left({ }^{1} \Delta_{\mathrm{g}}\right)$, by dipyridamole and derivatives. Photochemistry and Photobiology. v.83, p.1 - 7, 2007. 


\section{6- Referências}

1- HALLIWELL, B.; GUTTERIDGE, J. M. C. Free radicals in Biology and Medicine, 3rd ed., Oxford University Press, Inc., New York.

2- DEGÁSPARI, C. H.; WASZCZYNSKYJ, N. Propriedades antioxidants de compostos fenólicos. Visão Acadêmica, Curitiba, v.5, n.1, p. 33-40.

3- SIES, H. Oxidative stress: from basic research to clinical application. Am. J. Med., v. 91: p. 31S-38S, 1991.

4- BIANCHI, M. L. P.; ANTUNES, L. M. G. Radicais livres e os principais antioxidantes da dieta. Rev. Nutr., Campinas, v. 12, n. 2, p. 123-130, 1999.

5- Cardoso, Daniel Rodrigues. Oxidantes e Antioxidantes em Alimentos e Bebidas: Fotooxidação do leite e atividade antioxidante de extratos alcoólicos de madeiras brasileiras. 2004. 107p. Tese (Doutorado) - Instituto de Química de São Carlos, Universidade de São Paulo, São Carlos, 2004.

6- LI, T.; KING, J. M.; MIN, D. B. Quenching mechanism and kinetics of carotenoids in riboflavin photosensitized singlet oxygen oxidation of vitamin $D_{2}$. J. Food Biochem., v.24, p.477-492, 2000.

7- JORGENSEN, L. V.; CORNETT, C.; JUSTESEN, U.; SKIBSTED, L. H. Twoelectron Electrochemical Oxidation of Quercetin and Kaempferol Changes Only the Flavonoid C-ring. Free Radical Res., v. 29, p. 339-350, 1998.

8- JORGENSEN, L. V.; MADSEN, H. L.; THOMSEN, M. K.; DRAGSTED, L. O.; SKIBSTED, L. H.; Regeneration of phenolic antioxidants from phenoxyl radicals: An ESR and Electrochemical Study of antioxidant hierarchy. Free Radical Res., v. 30, p. 207-220, 1999.

9- MORTENSEN, A.; SKIBSTED, L. H. Relative stability of carotenoid radical cations and homologue tocopheroxyl radicals. A real time kinetic study of antioxidant hierarchy. FEBS Letters. v. 417, p. 261-266, 1997.

10- MARTINEZ, G. R.; MEDEIROS, M. H. G.; DI MASCIO, P.; Utilização de endoperóxidos de derivados de naftaleno como fontes químicas de oxigênio singlete em sistemas biológicos. Química Nova. v. 23, n. 5, p. 686-689, 2000. 11- MIYAMOTO, Sayuri. Hidroperóxidos de lipídeos como fonte biológica de oxigênio singlete: estudos com marcação isotópica, espectrometria de massa e 
luminescência. 2005. 199p. Tese (doutorado) - Departamento de Bioquímica, Instituto de Química, Universidade de São Paulo, São Paulo, 2005.

12 - KAJIWARA, T.; KEARNS, D. R. Direct spectroscopic evidence for a deuterium solvent effect on the lifetime of singlet oxygen in water. J. Am. Chem. Soc., v.5, n.5886-5890, 1973.

13- POSADAZ, A.; BLASUTTI, A.; CASALE, C.; SANZ, J.; AMAT-GUERRI, F.; GARCIA, N. A. Rose Bengal-Sensitized Photooxidation of the Dipeptides LTryptophyl-LPhenylalanine, L-Tryptophyl-L-Tyrosine and L-Tryptophyl-LTryptophan: Kinetics, Mechanism and Photoproducts, Photochem. Photobiol., v.80, p.132-136, 2004.

14- STRAIGHT, R. C.; SPIKES J. D. Photosensitized oxidation of biomolecules. In Singlet O2, Vol. 4 (Edited by A. A. Frimer), p. 91. CRC Press, Boca Raton, FL, 1985.

15- LISSI, E. A.; ENCINAS, M. V.; LEMP, E.; RUBIO, M. A. Singlet Oxygen $\mathrm{O}_{2}\left({ }^{1} \Delta_{\mathrm{g}}\right)$ bimolecular process. Solvent and compartmentalization effects. Chem Rev., v. 93, p. 699-723, 1993.

16- DARMANYAN, A. P., JENKS, W. S. Charge-Transfer Quenching of Singlet Oxigen $\mathrm{O}_{2}\left({ }^{1} \Delta_{\mathrm{g}}\right)$ by Amines and Aromatic Hydrocarbons, J. Phys. Chem. A, v.102, p.7420-7426, 1998.

17- SCHWEITZER, C., SCHMIDT, R., Physical Mechanism of Geration and Deactivation of Singlet Oxygen, Chem. Rev., v.103, p.1685-1757, 2003.

18- ENCINAS, M.V.; LEMP. E.; LISSI, E. A. Interaction of singlet oxygen $\mathrm{O}_{2}\left({ }^{1} \Delta_{g}\right)$ with aliphatic amines ond hydroxylamines, J. Chem. Soc. Perkin Trans., v. 2, n. 8, p. 1125, 1987.

19- FOOTE, C. S.; Mechanisms of photosensitized oxidation. Science, v. 162, p. 963-970, 1968.

20- FOOTE, C. S.; DAKPASU, A. A.; LIN, J. W. P. Chemistry of Singlet Oxygen. 20. Mechanism the Sensitized Photooxidation of Enamines. Tetrahedron Lett., v. 14 , p. $1247-1250,1975$.

21- FOOTE, C. S. Definition of type I and Type II photosensitized oxidation.

Photochem. Photobiol., v. 54, p. 659,1991. 
22- TURRO, N. J. Modern Molecular Photochemistry. Sausalito CA, University Science Books, 1991.

23- MARTINEZ, Glaucia Regina. Geração química de oxigênio-18 molecular no estado singlete, ${ }^{18} \mathrm{O}_{2}\left({ }^{1} \Delta_{\mathrm{g}}\right)$, e estudos de lesões em DNA. 2003. 171p. Tese (doutorado) - Departamento de Bioquímica, Instituto de Química, Universidade de São Paulo São Paulo, 2003.

24- SCURLOCK, R. D.; WANG, B.; OGILBY, P. R. Chemical Reactivity of Singlet Sigma Oxygen $\left(\mathrm{b}^{1} \boldsymbol{\Sigma}_{\mathrm{g}}{ }^{+}\right)$in Solution. J. Am. Chem. Soc., v. 118, p. 388-392, 1996. 25- STEIMBERG, D. Antioxidants in the prevention of human artherosclerosis, Circulation, v.85, p.2338-2343, 1992.

26- FITZGERALD, G.A. Dipyridamole, N. Engl. J. Med., v. 316, p.1247-1257, 1987.

27- KLEM, I.; HEITNER, J.F.; SHAH, D.J. Improved detection of coronary artery disease by stress perfusion cardiovascular magnetic resonance with the use of delayed enhancement infarction imaging. Journal of American Cardiology, 47, p. 1630-1638, 2006.

28- UDELSON, J.E.; DILSIZIAN, V.; BONOW, R.O. Cardiologia nuclear - Tratado de doenças cardiovasculares. Revista de Radiologia Brasileira, 40(5), p. 287333, 2007.

29- CHAKRABARTI, S.; BLAIR, P.; WU, C.; FREEDMAN, J. E.; Redox State of Dipyridamole is a Critical Determinant for Its Beneficial Antioxidant and Antiinflammatory Effects. J. Cardiovasc. Pharmacol. v. 50, n. 4, p. 449-457, 2007.

30- I Diretriz da Sociedade Brasileira de Cardiologia Sobre Cardiologia Nuclear. Arquivo Brasileiro de Cardiologia, volume 78, (suplemento III), p. 5-42, 2002. 31- IULIANO, L. VIOLI, F.; GHISELLI, A.; ALESSANDRI, C.; BALSAMO, F. Dipyridamole inhibits lipid peroxidation and scavengers oxygen free radicals, Lipids, v. 24, p. 430-433, 1989.

32- PEDULLI, G.F., LUCARINI, M.; MARCHESI, E.; PAOLUCCI, F.; ROFFIA, S.; FIORENTINI, D.; LANDI, L. Medium effects on the antioxidant activity of dipyridamole. Free Radical Biol. \& Med. v.26, p. 3-4, p.295-302, 1999. 
33- ALMEIDA, L.E.; CASTILHO, M.; MAZO, L.H.; TABAK, M. Voltammetric and spectroscopic studies the oxidation of the antioxidant drug dipyridamole in acetonitrile and ethanol. Anal. Chim. Acta. v.375, p.223-231, 1998.

34- CASTILHO, M.; ALMEIDA, A. M. P.; ALMEIDA, L. E.; TABAK, M.; MAZO L. $\mathrm{H}$. The electrooxidation of dipyridamole derivatives in acetonitrile solution. J. Electroanal. Chem., v. 528, p. 175-183, 2002.

35- CASTILHO, M.; ALMEIDA, L.E.; TABAK, M.; MAZO, L.H. Voltammetric oxidation do dipyridamole in aqueous acid solutions. J. Braz. Chem. Soc. v.11, n.2, p.148-153, 2000.

36- Castilho, Marilza. Estudo da oxidação eletroquímica do dipiridamol em meio orgânico, aquoso e micelar. 2001. 174p. Tese (Doutorado) - Instituto de Química de São Carlos, Universidade de São Paulo, São Carlos, 2001.

37- MARCUS, R. A. On The Theory of Oxidation-Reduction Reactions Involving Electron Tranfer. II. Applications to Data on the Rates of Isotopic Exchange Reactions, J. Chem. Phys., v.26, p.867-871,1957.

38- Brasileiro, Adaíla M. P. Almeida. Contribuição ao estudo dos produtos de oxidação eletroquímica do vasodilatador coronário e antioxidante dipiridamol. 2001. 156p. Tese (Doutorado) - Instituto de Química de São Carlos, Universidade de São Paulo, São Carlos, 2001.

39- ALVES, C. N., CASTILHO, M.; MAZO, L. H.; TABAK, M.; DA SILVA, A. B. F. Theoretical calculations on dipyridamole structure allow to explain experimental properties associated to electrochemical oxidation and protonation. Chem. Phys. Letters, v. 349, p.146-152, 2001.

40- Borges, Christiane Philippini Ferreira. Estudos espectroscópicos da interação de derivados de dipiridamol com sistemas biofísicos. 1994. 144p. Tese (Doutorado) - Instituto de Química de São Carlos, Universidade de São Paulo, São Carlos, 1994.

41- BORISSEVITCH, I. E., BORGES, C. P. F.; BORISSEVITCH, G. P.; YUSHMANOV, V. E.; LOURO, S. R. W.; TABAK, M. Binding and location of dipyridamole Derivatives in micelles: The Role of Drug Molecular Structure and Charge. Z. Naturforsch., v. 51C, p. 578-590, 1996. 
42- NEPOMUCENO, M. F., ALONSO, A.; DA SILVA, L. P.; TABAK, M. Inhibitory effect of dipyridamole and its derivatives on lipid peroxidaion in mitochondria. Free Radical Biol. Med., v. 23, n.7, p.1046-1054, 1997.

43- BORGES, C. P. F.; BORISSEVITCH, I. E.; TABAK, M. Charge and pHdependent binding sites of dipyridamole in ionic micelles: A fluorescence study. J. Lumin., v.65, p.105-112, 1995.

44- BORGES, C. P. F.; HONDA, S.; BERLINCK, R. G. S.; IMASATO, H.; BERCI, P.; TABAK, M. Sinthesis, characterization and interaction with ionic micelles of tetraacetylated dipyridamole. Spectrochim. Acta Part A, v.51, p.2575-2584, 1995.

45- Almeida, Luis Eduardo. Estudos espectroscópicos da interação do dipiridamol e seus derivados com sistemas biológicos: membrana modelo e proteínas. 2000. 146p. Tese (Doutorado) - Instituto de Química de São Carlos, Universidade de São Paulo, São Carlos, 2004.

46- FILHO, E. R.; ALMEIDA, A.M. P.; TABAK, M. Fragmentation of dipyridamole and related dipyrimidines by electrospray ionization collisional activated decomposition mass spectrometry. J. Mass Spectrom., v.38, p.540-547, 2003. 47- VAN STEVENINCK, J.; TRANNOY, L. L.; BESSELINK, G. A. J.; DUBBELMAN, T. M. A. R.; BRAND, A.; KORTE, D.; VERHOEVEN, A. J.; LAGERBERG, J. W. M. Selective protection of RBCs against photodynamic damage by the band 3 ligand dipyridamole. Transfusion v. 40, p. 1330-1336, 2000.

48- VARGAS, F.; RIVAS, C.; FUENTES, A.; TSE CHENG, VELUTINI, A.; G. The photochemistry of dipyridamole. J. Photochem. Photobiol. A, v. 153, p. 237243, 2002.

49- BORISEVITCH, I. E., PASCUTTI, P.G., TABAK, M., Kinetic studies of photodecomposition of dipyridamole in solution: interaction with lysophosphatidylcholine and bovine serum albumin, Spectrochim. Acta, Parte A 48, n.10,1427-1436,1992.

50- MADURA, J. D.; SALTER, E. A.; WIERZBICKI, A.; DALAL, P.; HARRINGTON, J. P. Homology models for the tetrameric and dodecameric 
complexes of Lumbricus terrestris hemoglobin. J. Mol. Struct. (Theochem), v. 592, p. 173-181, 2002.

51- KREBS, A.; ZIPPER, P.; VINOGRADOV, S. N. Lack of size and shape alteration of oxygenated and deoxygenated Lumbricus terrestris hemoglobin? Biochim. Biophys. Acta, v.1297, p.115-118, 1996.

52- HIRSH, R.E.; JELICKS, L.A.; WITTENBERG, B.; KAUL, D. K.; SHEAR, H.L.; HARRINGTON, J.P. A first evaluation of the natural high molecular weight polymeric Lumbricus terrestris hemoglobin as an oxygen carrier. Artifical Cells, Blood Substitutes and Immobilization Biotechnology, v.25, n.5, p.429-444, 1997.

53- KUCHUMOV, A. R.; TAVEAU, J. C.; LAMY, J. N.; WALL, J. S.; WEBER, R. E.; VINOGRADOV, S. N. The role of Linkers in the reassembly of the $3.6 \mathrm{MDa}$ hexagonal bilayer hemoglobin from Lumbricus terrestris. J. Mol. Biol., v. 289, p. 1361-1374, 1998.

54- VINOGRADOV, S.N. The stoichiometry of the four linker subunits of Lumbricus terrestris hemoglobin suggests an asymmetric distribution. Micron, v.35, p. 127-129, 2004.

55- BAILLY, X.; VINOGRADOV, S. The sulfide binding function of annlelid hemoglobins: relic of in a old biosystem? J. Inorg. Biochem., v.99, p. 142-150, 2005.

56- ZAL, F.; GREEN, B. N.; MARTINEU, P.; MARTINEU, P., LALLIER, F. H.;TOULMOND, A.;VINOGRADOV, S. N.; CHILDRESS, J. J. Polypeptide chain composition diversity of hexagonal-bilayer haemoglobins within a single family of annelids, the Alvinellidae. Eur. J. Biochem., v.267, p.5227-5236, 2000.

57- WEBER, R.E.; VINOGRADOV, S.N. Nonvertebrate hemoglobins: Functions and molecular adaptations. Physiol. Rev. 81 (2001) 569-628.

58- ROUSSELOT, M., DELPY, E.; LA ROCHELLE, C.D.; LAGENTE, V.; PIROW, R.; REES, J.; HAGEGE, A.; GUEN, D.LE; HOURDEZ, S.; ZAL, F. Arenicola marina extracelular hemoglobin: a new promising blood substitute. Biotechnol. J., v.1, p.333-345, 2006. 
59- STRAND, K; KANAPP, J. E.; BHYRAVBHATIA, B.; ROYER Jr, W. E. Crystal structure of the hemoglobin dodecamer from Lumbricus Erythrocruorin: Allosteric core of giant annelid respiratory complexes. J. Mol. Biol., v.344, p.119-134, 2004.

60- DORMAN, S. C.; HARRINGTON, J. P.; MARTIN, M. S.; JOHNSON, T. V. Determinação of formal reduction potential of lumbricus terrestris hemoglobin using thin layer spectroelectrochemistry. J. Inorg. Biochem., v. 98, p. 185-188, 2004.

61- ROYER, W.E.; KNAPP, J.E.; STRAND, K.; HEASLET, H.A. Cooperative hemoglobins conserved fold, diverse quaternary assemblies and allosteric mechanism. Trends Biochem. Sci., v.26, n.5, p. 297-304, 2001.

62- ROYER, W.E.; SHARMA, H.; STRAND, K.; KNAPP, J.E.; BHTRAVBHATLA, B. Lumbricus Erythrocruorin at $3.5 \AA$ Resolution: Architecture of a Megadalton Respiratory Complex. Structure, v. 14, p. 1167-1177, 2006.

63- TINTO, M. H. Caracterização das subunidades da hemoglobina de Glossoscolex paulistus. 1994. 82p. Dissertação (Mestrado) - Instituto de Química de São Carlos, Universidade de São Paulo, São Carlos, 1994.

64- FERNANDES, S. P. Isolamento do trímero e suas subunidades a, b, c da hemoglobina de Glossoscolex paulistus e caracterização por análise de aminoácidos. 2001. 77p. Dissertação (Mestrado) - Instituto de Química de São Carlos, Universidade de São Paulo, São Carlos, 2001.

65- COSTA, M.C.P.; BONAFÉ, C.F.S.; MEIRELLES, N.C.; GALEMBECK, F.

Braz. J. Med. Res., v. 21, p. 115-118, 1998.

66- MEIRELLES, N.C.; OLIVEIRA, B.; OLIVEIRA, A.R.; DE PAULA, E.; MARANGONI, S.; RENNEBECK, G.M. Erythrocruorin of Glossoscolex paulistus (Oligochaeta, Glossoscolecidae) Dissociation at alkaline $\mathrm{pH}$ and its ligand properties as revealed by chemical, immunochemical and electron-microscopy. Comp. Biochem. Physiol., Part A: Mol. Integr. Physiol., v.88, n.2, p.377-379 1987.

67- STRUPAT, K.; KARAS, M.; HILLENKAMP, F.; ECKERSKORN, C.; LOTTSPEICH, F. Matrix-Assisted Desorption Ionization Mass Spectrometry of 
Proteins Electroblotted after Polyacrylamide Gel Electrophoresis. Anal. Chem., v. 66, p. 464-470, 1994.

68- OLIVEIRA, M.S.; MOREIRA, L.M; TABAK, M. Partial characterization of giant extracellular hemoglobin of Glossoscolex paulistus: a MALDI-TOF-MS study. Int. J. Biol. Macromol., v. 40, p. 429-436, 2007.

69- OLIVEIRA, M.S.; MOREIRA, L.M; TABAK, M. Interaction of Giant extracellular Glossoscolex paulistus hemoglobin ( $\mathrm{HbGp}$ ) with ionic surfactants: a MALDI-TOF-MS study. Int. J. Biol. Macromol., v.42, n.2, p. 111-119, 2008 70- SANTIAGO, P.S.; MOURA, F.; MOREIRA, L.M.; DOMINGUES, M.M.; SANTOS, N.C.; TABAK, M. Biochim. Biophys. Acta, v. 1770, p. 506-517, 2007. 71- BEAVIS, R. C.; CHAIT, B. T. Rapid, sensitive analysis of protein mixtures by mass spectrometry. Proc. Nati. Acad. Sci., v. 87, p. 6873-6877, 1990.

72- ZHANG, N.; DOUCETTE, A.; LI, L. Two-Layer Sample Preparation Method for MALDI Mass Spectrometric Analysis of Protein and Peptide Samples Containing Sodium Dodecyl Sulfate. Anal. Chem., v.73, p.2968-2975, 2001.

73- AMADO, F. M. L.; SANTANA-MARQUES, M. G.; FERRER-CORREIA, A. J.; TOMER, K. B. Analysis of Peptide and Protein Samples Containing Surfactants by MALDI-MS. Anal. Chem., v. 69, p. 1102-1106, 1997.

74- TUMMALA, R.; GREEN-CHURCH, K. B.; LIMBACH, P. A. Interactions Between Sodium Dodecyl Sulfate Micelles and Peptides During Matrix-Assisted Laser Desorption/Ionization Mass Spectrometry (MALDI-MS) of Proteolytic Digests. J Am Soc Mass Spectrom. v. 16, p.1438-1446,2005.

75 - SKOOG, D. A.; WEST, D. M.; HOLLER, F. J.; CROUCH, S. R.; GRASSI, M. T.; Fundamentos de Química Analítica. 8 ed. Pioneira Thomson learning, São Paulo, 2006.

76- ZENOBI, R.; KNOCHENMUSS, $R$. Ion formation in MALDI Mass Spectrometry, Mass Spectrom. Rev., v. 17, p. 337-366, 1998.

77- KARAS, M.; BAHR, U. Laser desorption ionization mass-spectrometry of large biomolecules. TRAC-Trends in Analyt. Chem., v. 9, p. 321-325, 1990.

78- WILKINSON, F., HELMAN, W. P., ROSS, A. B. Rates Constants for the Decay and Reactions of the Lowest Electronically Excited Singlet State of 
Molecular Oxigen in Solutions. An Expanded and Revised Compilation, J. Phys. Chem. Ref. Data. v. 24, n. 2, p. 779,1995.

79- SCULLY, F. E.; HOIGNE', J. Rate constants for reactions of singlet oxygen with phenols and other compouns in water. Chemosphere, v. 16, p. 694-698, 1987.

80- GORMAN, A. A., GOULD, I. R., HAMBLETT, I. STANDEN, M. C. Reversible Exciplex Formation between Singlet Oxygen, ${ }^{1} \Delta_{g}$, and Vitamin E. Solvent and Temperature Effects, J. Am. Chem., v. 106, p. 6956-6959, 1984.

81- JUNQUEIRA, H. C., SEVERINO, D.; DIAS, L. G.; GUGLIOTTI, M. S.; BAPTISTA, M. S. Modulation of methylene Blue photochemical properties based an adsorption at micelle interfaces. Phys. Chem. Chem. Phys., v. 4, p. 23202328, 2002.

82- FOOTE, C. S.; VALENTINE, J. S.; GREENBERG, A.; LIEBMAN, J. F. Active Oxygen in Chemistry. Blackie Academic \& Professional. New York. 1995.

83- MUKAI, K., DAIFUKU, K.; OKABE, K.; TANIGAKI, T.; INOUET, K. StructureActivity Relationship in the Quenching Reaction of Singlet Oxygen by Tocopherol (Vitamin E) Derivatives and Related Phenols. Finding of Linear Correlation between the Rates of Quenching of Singlet Oxygen and Scavenging of Peroxyl and Phenoxyl Radicals in Solution. J. Org. Chem., v. 56, p.4188-4192, 1991.

84- SCHWEITZER, C., SCHMIDT, R., Physical Mechanism of Geration and Deactivation of Singlet Oxygen, Chem. Rev., v. 103, p. 1685-1757, 2003.

85- REHM, D.; WELLER, A. Kinetics of fluorescence quenching by electron and H-Atom Transfer, Isr. J. Chem., v. 8, p. 259-271,1970.

86- KAISER, S.; DI MASCIO, P.; MURPHY, M. E.; SIES, H. Physical and Chemical Scavenging of Singlet Molecular Oxygen By Tocopherols. Arch. Biochem. Biophys., v. 277 n.1, p.101-108,1990.

87- FOOTE, C. S.; DENNY, R. W. Chemistry of singlet Oxygen. VII. Quenching by $\beta$-Carotene. J. Am. Chem. Soc., v. 90, p. 6233-6235,1968.

88- SUNDQUIST, A. R.; BRIVIBA, K.; SIES, H. Singlet Oxygen Quenching by Carotenoids. Antioxid. Characteriz. And Assay, v. 234, p. 384-388, 1994. 
89- DI MASCIO, P.; KAISER, S.; SIES, H. Lycopene as the most efficient biological carotenoid singlet oxygen quencher. Arch. Biochem. Biophys., v. 274 n. 1 , p. $532-538,1989$.

90- IQBAL, J.; HUSAN, A.; GUPTA, A.; Photooxidation of Acyclovir with Thermally Generated Triplet Excited Ketones. A Comparison with Type I and II Photosensitizers. Chem. Pharm. Bull. V. 54, n. 4, p. 519-521, 2006.

91- KAO, W.; QIN, J.; FUSHITANI, K.; SMITH, S.S.; GORR, T.A.; RIGGS, C.K.; KNAPP, J.E.; CHAIT, B.T.; RIGGS, A.F. Linker chains of the gigantic hemoglobin of the earthworm Lumbricus terrestris: Primary structures of linkers L2, L3, and L4 and Analysis of the connectivity of the disulfide bonds in linker L1. Proteins: Struct., Funct., Bioinf., v. 63 p. 174-187, 2006.

92- MARTIN, P.D.; KUCHUMOV, A.R.; GREEN, B.N.; OLIVER, R.W.A.; BRASWELL, E.H.; WALL, J.S.; VINOGRADOV, S.N. Mass spectrometry composition and molecular mass of Lumbricus terrestris hemoglobin: A refined model of its quaternary structure. J. Mol. Biol., v. 255, p. 154-169, 1996.

93- OWNBY, D.W.; ZHU, H.; SCHNEIDER, K.; BEAVIS, R.C.; CHAIT, B.T.; RIGGS, A.F. The extracelular hemoglobina of the earthworm, Lumbricus terrestris. J. Biol. Chem. 268 (1993) 13539-13547.

94- CABRAL, C.B.; IMASATO, H.; ROSA, J.C.; LAURE, H.J.; SILVA, C.H.T.P.; TABAK, M.; GARRAT, R.C.; GREENE, L. Fluorescence properties of tryptophan residues in the monomeric d-chain of Glossoscolex paulistus hemoglobin: an interpretation based on a comparative molecular model. J. Biophys. Chem., v. 97, p. 139-157, 2002.

95- SHLOM, J.M.; VINOGRADOV, S.N. A study of the subunit structure of the extracelular hemoglobin of Lumbricus terrestris. J. Biol. Chem., v. 248, p.79047912, 1973.

96- IMASATO, H.; TINTO, M.H.; PERUSSI, J.R.; TABAK, M. Fluorescence studies of extracelular hemoglobin of Glossoscolex paulistus obtained by gel filtration. Comp. Biochem. Physiol., Part B: Biochem. \& Mol. Biol. v.112B, p. 217-226, 1995. 
97- LAMY, J.N. GREEN, B.N.; TOULMOND, A.; WALL, J.S.; WEBER, R.E.; VINOGRADOV, S.N. Giant hexagonal bilayer hemoglobins. Chem. Rev., v.96 p. 3113-3124, 1996.

98- tUMmALA, R.; GREEN-CHURCH, K. B.; LIMBACH, P. A. Interactions Between Sodium Dodecyl Sulfate Micelles and Peptides During Matrix-Assisted Laser Desorption/Ionization Mass Spectrometry (MALDI-MS) of Proteolytic Digests. J. Am. Soc. Mass Spectrom., v. 16 p. 1438-1446, 2005.

99- BORISSEVITCH, I. E.; BORGES, C. P. F.; YUSHMANOV, V. E.; TABAK, M. Localization of dipyridamole molecules in ionic micelles: effect of micelle and drug charges. Biochim. Biophys. Acta., v. 1238, p. 57-62, 1995. 